2002

\title{
Genetic Services in Ontario: Mapping the Future
}

Roxanne Mykitiuk

Osgoode Hall Law School of York University, rmykitiuk@osgoode.yorku.ca

Follow this and additional works at: http://digitalcommons.osgoode.yorku.ca/reports

Part of the Other Law Commons

\section{Repository Citation}

Mykitiuk, Roxanne, "Genetic Services in Ontario: Mapping the Future" (Ottawa: Queen's Printer for Ontario, 2002). Commissioned Reports and Studies. Paper 101.

http://digitalcommons.osgoode.yorku.ca/reports/101 
Genetic Services in Ontario:

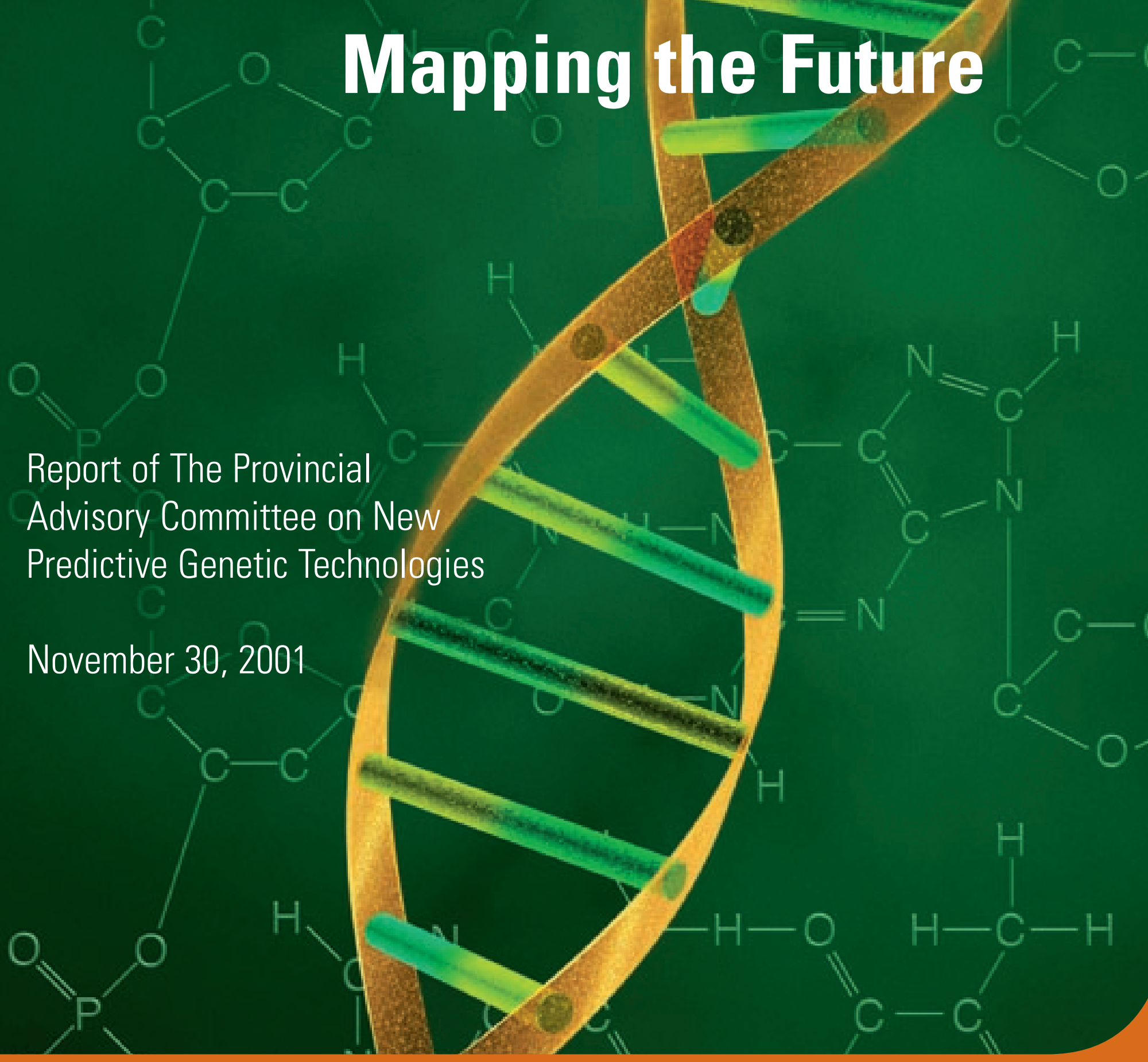

Working together for a healthier Ontario. 9 


\section{Acknowledgements}

The Provincial Advisory Committee on New Predictive Genetic Technologies wishes to gratefully acknowledge the assistance provided by countless volunteers, researchers and sources in the development of this report.

In addition, a number of experts in the area of integrating genetic medicine into mainstream clinical practice made invaluable contributions to the work of the Committee, including:

- Dr. Ed McCabe, Chair, Secretary's Advisory Committee on Genetic Testing (SACGT), Chair of UCLA Department of Pediatrics, President of the American College of Medical Genetics, and President Elect of the Western Society for Pediatric Research;

- Dr. Alan Guttmacher, Senior Clinical Advisor to the Director at the National Human Genome Research Institute (NHGRI);

- Dr. Robert Hegele, Director, Blackburn Cardiovascular Genetics Lab, John P. Robarts Research Institute, and Professor of Medicine and Biochemistry, University of Western Ontario,

- Dr. Neil Holtzman, Director, Department of Genetics and Public Policy Studies at the Johns Hopkins Medical Institutions, and

- Dr. Alex McKenzie.

All of these experts made major presentations to a scientific session organized by the Committee on September 19, 2001. The Committee also sought separate input from Dr. Ronald Carter, President of the Canadian College of Medical Geneticists. The Committee is grateful for the exceptional contributions from all of these sources.

The Committee and its voluntary members functioned through a series of subcommittees and research tasks. Sub-committee reports and the research papers written for the Committee are available on request from Helen Wright, 416-314-1431, Helen.Wright@moh.gov.on.ca

The complete report is also available on the web site of the Ministry of Health and Long-Term Care www.gov.on.ca/health

Sommaire, Aperçu, Recommandations du Comité provincial consultatif et Annexes A et B sont disponibles en français sur le site web ci-haut.

For a list of sub-committee reports and other documents produced for the Committee, see Appendix E. 


\section{Table of Contents}

\section{Executive Summary}

1 The Committee

2 The Report

2 Impacts of New Genetic Technology

6 Challenges of New Genetic Technology

6 Overview of the Recommendations

\section{Section 1: Overview}

\section{The Evolution of Genetic Medicine \\ 9 Genes for Adult Onset Disorders \\ 10 Environmental Factors}

11 Scientific Developments

11 The Human Genome Epidemiology Network

12 A Growing Number of Identified Genetic Disorders

12 A Growing Number of Predictive Genetic Tests

13 Advances in Genetic Technology

14 Next Stage Genomic Treatments and Cures

15 Genetic Reductionism

16 Effects on the Health System

16 The Ontario Public's Views about Genetics

17 Public Perceptions

17 Privacy a Concern

18 Far-Reaching Effects

18 Patenting of Human Genetic Materials and Genetic Testing

18 The Provincial Genetics Program

20 Personnel in Genetic Services

21 Training of Genetic Personnel

\section{Section 2: Sub-Committee Reports} and Recommendations

22 Report of The Legal and Ethical Issues Sub-Committee

22 Objectives

22 Findings

22 Ethical and Legal Considerations
23 Why Do Genetic Information and Genetic Testing Warrant Special Attention?

24 Recommendations

24 Discrimination and Stigmatization Issues

26 Insurance and Employment Issues

28 The Regulation of Research

30 Laboratory Testing

31 Allocation of Resources for Genetics

31 Patents, Commercialization and Direct Marketing of Genetic Testing

33 Regulation and Liability of Genetic Counsellors

34 Clinical Issues

37 Storing Genetic Information and Genetic Material and Protecting Privacy

38 Report of the Evaluation Sub-Committee

Objective

38 Findings

Decision Framework for Genetic Testing Evaluating Predictive Genetic Technologies

Guiding Assumptions

1 Assessing Analytical and Clinical Validity of Genetic Predictive Technologies and Systematic Review Methods

42 Elements of Decision Making - Explaining the Evaluation Template

46 Examples of Analytical Questions for Defining the Cutoffs for Evaluative Criteria

48 Defining the Characteristics of Predictive Genetic Tests: A Framework for Evaluation Decision-Making

50 Recommendation

50 Report of the Laboratory Sub-Committee

50 Objective

50 Findings

50 The Need for Quality Assurance and Confidentiality

52 Quality Assurance

52 New Technologies

53 Systemic Issues

53 Staff Resources

53 Evaluation of Future Therapies

54 Out-of-Province Testing

54 Stakeholders

54 Recommendations 


\begin{tabular}{ll}
$\mathbf{5 6}$ & Report of the Clinical Sub-Committee \\
56 & Objective \\
56 & Findings \\
57 & Key Steps for Genetic Counselling and Testing \\
58 & A Multi-Disciplinary Response \\
58 & Human Resource Shortage \\
59 & Recommendations \\
59 & Access to Care \\
59 & Quality Assurance and Outcome Evaluation \\
59 & Categories of Disease/Service \\
60 & Additional Recommendations \\
$\mathbf{6 1}$ & Report of the Psychosocial Sub-Committee \\
61 & Objectives \\
61 & Findings \\
61 & Psychosocial Impact on the Patient and Family \\
62 & Impact on Decision-Making Ability \\
63 & Familial Threat \\
65 & Recommendations \\
$\mathbf{6 6}$ & Report of the Education Sub-Committee \\
66 & Objectives \\
66 & Findings \\
67 & Both the Public and the Professions Need \\
67 & Education \\
68 & Educating Health Care Professionals \\
69 & Costs of Not Addressing Genetics Education \\
69 & Recommendations \\
\hline
\end{tabular}

\section{Section 3: Recommendations of The Provincial Advisory Committee on New Predictive Genetic Technologies}

70 An Ongoing Provincial Genetics Advisory Committee (1)

70 Approach to Introduction of New Genetic Tests and Services (2-8)

71 Programmatic Genetic Services (9-10)

72 Education and Information (11-12)

72 Quality Management and Guidelines (13-14)

72 Human Resources for Genetic Services (15)

73 Non-Discrimination (16-18)

73 Research Review (19)

73 Patents, Direct Marketing and Commercialization of Genetic Tests (20)

74 Informed Consent (21)

74 Genetic Testing of Minors (22-24)

74 Privacy and Confidentiality of Genetic Information (25-26)

\section{Section 4: Appendices}

76 Appendix A: Provincial Advisory Committee Terms of Reference

81 Appendix B: Provincial Advisory Committee Membership

87 Appendix C: Molecular Genetic Tests Offered in Ontario

89 Appendix D: Glossary of Terms for Genetic Disorders and Genetic Testing

93 Appendix E: List of Sub-Committee Reports and Other Documents Produced for the Committee

95 Appendix F: The Toolkit - The Evaluation Template 


\section{Report of The Provincial Advisory Committee on New Predictive Genetic Technologies}

\section{Executive Summary}

During the past decade, science has made enormous advances in understanding the human genome. Sophisticated technologies have permitted human gene mapping on an unprecedented level. The increasing ability to test for genetic predisposition to disease has resulted in optimism that genetic predictive testing will help improve treatments and health care delivery. An understanding of the genetic basis of disease is expected to help everyone better understand disease processes.

Public polls show that people in Ontario are interested in learning more about the new genetic sciences and what they will mean to them. Before embracing these new technologies, governments need to carefully examine their value and their consequences for patient outcomes, legal systems and society.

\section{The Committee}

In April 2000, the Ministry of Health and Long-Term Care (MOHLTC) established a Provincial Advisory Committee on New Predictive Genetic Technologies to help Ontario navigate the new frontier of human genetic medicine and science.

The mandate of the Advisory Committee was to develop a policy framework for introducing new genetic predictive testing and services into Ontario's health care system. This framework would help ensure that the provincial health system promotes wellness and improves health outcomes in advance of the appearance of disease.

The Committee would also develop guidelines, principles, broad criteria and advice to guide decisions on how new genetic services should be incorporated into the province's health care system. See Appendix A for Terms of Reference for the Committee.

The multidisciplinary Committee was made up of:

- geneticists,

- a genetic counsellor,

- family physicians,

- genetic researchers,

- laboratory directors,

- academics in law, ethics and medicine, educators,

- a clinical epidemiologist,

- an expert in psychosocial issues, and

- representatives from the Canadian Cancer Society, the Heart and Stroke Foundation, the Huntington Society of Canada, the Ontario Association of Medical Laboratories, the Ontario College of Family Physicians, the Ontario Hospital Association, and the Ministry of Health and Long-Term Care. 
The work of the Committee was divided among six areas:

- education,

- evaluation,

- clinical practice,

- psychosocial issues,

- laboratory practice, and

- legal and ethical issues

The sub-committees drew on a broad base of provincial expertise in each of these areas. Membership of the Provincial Advisory Committee and its sub-committees appear in Appendix B.

\section{The Report}

This report will help MOHLTC understand recent advances in genetic science. The report also examines the current state of genetic services in Ontario, and anticipates numerous impacts that genetic medicine and technology will have on patients, the physician-patient relationship, the health care system, and society.

Although the effects of genetic science on clinical practice, health services and individuals are still to be seen, the rapid increase in genetic technology requires responsive strategies and an objective assessment of the immediate and future scope of these advances.

The report directs its recommendations to the provincial and federal governments and to non-governmental bodies who can ensure that people in Ontario benefit from genetic science.

\section{Impacts of New Genetic Technology}

\section{On Health Systems}

Differences in the reliability, accuracy and predictive power of new genetic technologies, as well as clinical and psychosocial impacts, mean that each new technology must be evaluated for its usefulness and impact within a public health system.

The complex nature of each test procedure requires strict laboratory protocols to ensure the test results are accurate, meaningful and can be clearly communicated from physician to patient. 
John, James and Paul

John's older brother, James (28), is recently diagnosed with colon cancer. Their father died of colon cancer at the age of 39. John (23), concerned about his own risk, gets referred to a genetics clinic.

The genetics clinic counsellor tells John his family would be eligible for testing but they need James' medical records to verify the diagnosis. If testing were to be done, they would have to start with James. John is reluctant to ask his brother who has recently been through surgery and is undergoing chemotherapy. The counsellor tells John he is at high risk based on his family history and so he should start having annual colonoscopies. She refers him to a gastroenterologist.

Four years later, James is doing well. John and his new wife want to start a family so John talks to James about testing. James agrees to be tested and is found to have a mutation in the MSH2 gene, which is consistent with the family history of colon cancer. John is tested and does not have the mutation. His gastroenterologist tells him to stop his current level of surveillance and that he needs only to follow normal precautions.
Their younger brother, Paul, learns of James' result and requests testing. Prior to testing, he has always been healthy, had no surveillance and hasn't thought much about either colon cancer or his health in general. He is counselled about the potential medical and psychosocial effects of the testing, seems to understand and is eager to proceed.

Testing shows he carries the same mutation as James. He is told this mutation is associated with an $80 \%$ chance of developing colon cancer in his lifetime (as compared to the population risk of $6 \%$ ). $\mathrm{He}$ is referred to a gastroenterologist for colonoscopy. Although the result is normal, he becomes extremely anxious about developing cancer and requests a second opinion. The second normal colonoscopy doesn't seem to relieve his anxiety; his family also reports that he spends hours searching the Internet for possible ways to prevent colon cancer.

His family doctor refers him to a psychiatrist who treats him for about a year. Paul's anxiety slowly abates although it is heightened for the two weeks before each colonoscopy appointment.

\section{On Clinical Practice}

Genetic tests vary significantly in the degree of certainty of developing disease, the risk and reliability associated with the test, the type of treatment required, and the complexity of their management. As the number and type of genetic tests increases, family physicians will encounter increasing indications for these tests and then will need to interpret the results.

Increasing genetic tests will also increase the workload of medical geneticists, other medical specialists and genetic counsellors. New approaches to clinical practice will need to be developed and in order to be fully effective, physicians will need to acquire new knowledge and integrate skills from different fields. 


\section{David}

32-year-old David's father, John, has recently been diagnosed with hemochromatosis, a genetic disorder where iron accumulation in body tissues results in multiple problems including cirrhosis of the liver, diabetes, impotence, skin bronzing and heart failure. This disorder is easily treated by regularly bleeding the patient to remove iron from the body. David's father was diagnosed early enough to reverse the effects of the disease with this treatment.

John's genetic testing revealed he carries two copies of the C282Y mutation in the hemochromatosis gene. This mutation, when present in two copies, is known to be associated with the disease. David asks his doctor if he, David, should start treatment which in this case consists of removing blood on a regular basis.

David's doctor suggests that he have DNA testing before undergoing treatment. A blood test indicates that David has one copy of the C282Y gene and one copy of the normal form of the gene. Unfortunately, the laboratory erroneously interprets this result as predisposing David to hemochromatosis. David's doctor starts him on monthly blood letting.

Six months later, David has become anemic. The doctor, puzzled by this result, seeks the advice of a hematologist who explains that David's DNA result is, in fact, not consistent with a

predisposition to hemochromatosis; he is merely a carrier like $10 \%$ of the Caucasian population. Therefore, David's anemia is to be expected, given the amount of blood he has been giving over the past six months.

The hematologist also reminds David's doctor that a predisposition doesn't mean that a person has the disease, so further testing for signs of the disease should be done before treatment is begun.

\section{On the Patient}

The probabilities and risks of genetic information are difficult concepts to understand and to base decisions on. Careful attention must be paid not only to the clinical information provided to the patient but also to the psychosocial effects which the testing may have on the individual and their families.

Unlike other forms of medical diagnosis, genetic predictive testing spans generations. Testing individuals also tests other family members, including offspring and their offspring. The test for Huntington Disease, for example, is predictive for the individual tested and also for future generations. 


\section{Helen}

Helen is a 27-year-old married lawyer whose 60 -year-old mother is in the last stages of Huntington's Disease (HD). Helen understands she has a $50 \%$ chance of having inherited it and that there is no specific treatment or cure. She tells a geneticist that she wants to have testing so she and her husband can make reproductive choices. Secondarily, she has been offered a job with less benefits than she receives now and feels that the information about her HD status will help her plan her career.

Testing shows that Helen carries the HD gene but neurological assessment confirms she has no symptoms or signs of the disease. She is somewhat depressed by the DNA result but is encouraged by her normal neurological examination.
Helen returns to the clinic for a follow-up appointment a year later with her husband and newborn son. The couple proceeded to have a child having decided against prenatal testing since they hoped that advancing research would have something to offer Helen and by extension, their children if they inherit the gene.

Helen tells the geneticist that she is staying at her present job because she has a group life insurance policy plus a good pension plan and she doesn't want to lose these benefits even though she may earn more in the private sector. She also feels that staying in her current job will allow her more flexibility to spend time with her family.

Although saddened by the news that she carries the HD gene, Helen believes the knowledge has allowed her to plan her life in a very positive way and she is happy.

\section{On the Public}

Advances in biomedical science and new technologies offer an array of new health and reproductive choices. To make informed choices, the public needs reliable information about what is medically necessary and ethically appropriate.

\section{Karen}

Karen, a 35-year-old woman, has read about a new gene test for breast cancer. She has no family history of breast cancer but her best friend recently died of the disease at the age of 36 so she is worried. She visits her family doctor and demands the test. The doctor refers Karen to a genetic centre counsellor who explains the complexity of testing and the implications of both positive and negative results. The counsellor tells Karen that based on family history, she is not eligible for testing.

Karen is not totally satisfied with this answer and tells her family doctor that she has heard that, if she is willing to pay, she can send her blood out of province for testing. The family doctor agrees to facilitate this for her but advises against it. A month later, the testing laboratory result says Karen has a change in her gene that has never been seen before, so its significance is unknown.

The family doctor suggests that she return to the genetic centre where a geneticist tells her that the gene is not perfectly understood and that previously undescribed changes are frequently found. These changes are impossible to interpret and therefore, she cannot tell Karen whether her risk is increased or not. Karen gets the same answer from the genetic counsellor at the testing laboratory. She tells the counsellor that she regrets having the test. 


\section{Challenges of New Genetic Technology}

Because risk is often determined by complex interactions with other genes and with environmental factors, interpreting the risk or probability of conditions through genetic testing will require a unique educational strategy.

Weighing the costs of providing a test and all the consequent lifestyle changes, surveillance programs, potential psychological, family, ethical and legal impacts against reliance on other sources of information and traditional clinical practices for dealing with disease is a concern.

There is a need to guard against controlling disease through the new genetic technologies at the expense of other, known approaches to disease. Other

approaches to disease control will need to be considered, including lifestyle changes that apply to the entire population, irrespective of genetic predisposition.

New testing technologies where one small blood or tissue sample can be tested simultaneously for many different disorders will open up new possibilities not previously contemplated.

Predictive genetic testing opens legal and ethical dilemmas that require guidance and decisions based on shared social values in the context of a public debate. It also raises issues that go beyond the provincial realm to areas of federal and international regulation.

\section{Overview of the Recommendations}

The recommendations of the Advisory Committee appear in section 3 of this report.

\section{A Permanent Advisory Committee on Genetics}

The initial recommendation is that Ontario establish a permanent and more broadly mandated Advisory Committee on Genetics:

- to evaluate new genetic tests for service delivery,

- to determine resource needs and health care service approaches as genetic issues evolve,

- to facilitate the implementation of new genetic tests, and

- to provide advice on educational, legal, and ethical issues relating to genetic testing.

\section{The Need for Evaluation}

The recommendations reiterate the importance of developing an evaluation process that builds on the template presented in this report. Before becoming insured services, all new tests should be evaluated for:

- technical accuracy,

- clinical effectiveness,

- usefulness to tested individuals,

- adverse and additional effects,

- expansion potential and cost,

- ethical/legal implications, and

- resource implications. 


\section{Genetic Service Issues}

Since genetic testing often produces complex results, testing must be part of broader integrated multidisciplinary genetic services that incorporate genetic assessment and counselling, quality testing, psychosocial support and follow-up services, including surveillance, prevention and treatment. Every effort should be made to integrate genetic service into current health care.

Because of the potential growth in the number and volume of genetic tests and their accompanying costs and consequences over the coming decades, the Committee has also made recommendations to increase recruitment and training capacity for genetic service health care providers. Each aspect of genetic services should have quality management guidelines in place.

\section{Ethical and Legal Issues}

Ethical and legal issues permeate every phase of predictive genetic testing.

Recommendations emphasize the need:

- to ensure privacy and confidentiality and protect patients from discrimination and stigmatization,

- for fully informed consent for genetic testing,

- to ensure quality management in laboratory testing, and

- for governments and regulatory bodies to examine and take steps in the areas of patents, commercial use and direct marketing of genetic testing.

\section{Educational Program}

The Advisory Committee recommended developing and promoting a genetics educational program for everyone in Ontario including health professionals and decision-makers to meet public and professional needs. They also recommended developing a specific education program for each new predictive genetic test approved as an insured service.

Until recently, much of the practice of genetics involved diagnosing rare inherited disorders, estimating risk for family members, and providing prenatal diagnosis. There was little need for most health care providers to have any more than a rudimentary knowledge of genetics. Now, there is an urgent need for the Ministries of Education and of Colleges and Universities to review the curricula of secondary and post-secondary schools and incorporate core genetic issues.

\section{Moving Forward}

Governments, citizens and scientists are attempting to understand the benefits and the limitations of genetics. This report attempts to assist Ontario in that endeavour with confident caution. The monitoring of developments in genetics and the resulting genetic clinical practice is an ongoing task for all governments. 


\section{Section 1: Overview}

Science's success in mapping the human genome is an event of considerable magnitude. It is important, not just for its technological achievement, but for its potential in helping to alleviate human suffering and improve the quality and longevity of people's lives.

Scientific information acquired through the mapping of the human genome will accelerate the use and availability of genetic tests. This expansion will present substantial planning and financial challenges to Ontario's health care system, as well as legal and ethical challenges to society.

Currently, according to MOHLTC statistics, molecular genetic testing is performed on one in 700 Ontario residents each year. This number is expected to grow substantially in the coming years with the possibility that one in two Ontarians may seek genetic testing in the near future ${ }^{1}$

More opportunities will soon be developed to prevent or treat diseases that have a genetic predisposition through:

- conventional therapies,

- protein/enzyme replacement therapy,

- gene therapies aimed at correcting the genetic abnormality, and

- pharmacogenetics (drugs tailored to a person's genetic make-up).

This anticipated rapid increase in genetic technology requires response strategies.

\section{The Evolution of Genetic Medicine}

Genetic disorders result from alterations in full chromosomes, in chromosomal segments, or in one or more of the approximately 40,000 genes which make up the human genome. These disorders can be passed on to future generations during reproduction.

Predictive genetic testing has focused increasing attention on gene changes (mutations) rather than chromosomal disorders. A mutation usually changes a gene's ability to produce an essential protein or enzyme required for the body's function. The lack of this protein or enzyme results in disease.

About 2-3\% of children are born with a significant birth abnormality ${ }^{2}$, approximately $0.6 \%$ of these are due to chromosomal anomalies, $1.4 \%$ to single gene disorders and the remainder are multifactorial - due to genetic and environmental factors.

\footnotetext{
${ }^{1}$ The Genetics of Common Diseases. A Second Report to the National Health Service Central Research and Development Committee on the New Genetics, 1995.

${ }^{2}$ Harper, Peter S (1998) Practical Genetic Counselling, Butterworth and Heineman, Oxford, P.11.
} 
Single gene disorders, where a single gene or pair of genes result in disease development, would include:

- Tay-Sachs disease (1 in 960 Ashkenazi Jews),

- cystic fibrosis ( 1 in 2,500 Caucasians), and

- Huntington Disease ( 1 in 10,000 - 1 in 20,000).

There are more than 6,000 single gene disorders and about 870 of these can be detected through molecular genetic tests ${ }^{3}$. For most of these disorders, the finding of mutations in the gene or gene pair indicates a high probability of having the disease.

In the past, geneticists tended to deal with rare disorders mainly seen in the prenatal or paediatric populations. While this aspect of genetic medicine continues, the practice has expanded to include genes for adult onset disorders.

\begin{tabular}{lll}
\hline Type of tests & 'Old' Genetics & 'New' Genetics \\
\hline Type of disorders & Mainly diagnostic & Mainly predictive \\
& $\begin{array}{l}\text { Rare genetic disorders } \\
\text { Predominantly paediatric } \\
\text { Usually a high chance of having or } \\
\text { developing the disorder }\end{array}$ & $\begin{array}{l}\text { Common disorders with a genetic } \\
\text { component }\end{array}$ \\
& $\begin{array}{l}\text { Predominantly adult-onset } \\
\text { Low to high chance of developing } \\
\text { the disorder }\end{array}$ \\
\hline Type of results & $\begin{array}{l}\text { Usually confirm or predict presence } \\
\text { of disease but not severity }\end{array}$ & $\begin{array}{l}\text { More complex risk predictions } \\
\text { which may involve gene(s) and } \\
\text { environmental factors }\end{array}$ \\
\hline
\end{tabular}

\section{Genes for Adult Onset Disorders}

This group of genes when tested before symptoms appear may predict disease with certainty as in Huntington's Disease, or may merely provide an estimate of risk for developing the disease as with testing for breast cancer genes.

The strength of the risk prediction may vary. For example, a woman carrying a change in the BrCal gene may have an $80 \%$ chance of developing breast cancer ${ }^{4}$ while someone carrying a particular predisposition gene for coronary artery disease may have a minimal increase in risk ${ }^{5}$.

\footnotetext{
${ }^{3}$ GeneTests-Gene Clinics: Human Genetics Information Resource, 2001; Also Dr. R. Pagon in correspondence with the Ministry of Health and Long-Term Care.

${ }^{4}$ Easton DF, Bishop DT, et al. for the Breast Cancer Linkage Consortium. Genetic linkage analysis in familial breast and ovarian cancer: results from 214 families. American Journal of Human Genetics 52(4): 678-701, 1993.

${ }^{5}$ Winkelmann BR; Hager J (2000) Genetic variation in coronary heart disease and myocardial infarction: methodological overview and clinical evidence. Pharmacogenomics; $1(1): 73-94$
} 
As biomedical science advances, more research is being directed at genetic susceptibility to common adult onset disorders such as:

- breast cancer which affects 1 in 9 women,

- coronary artery disease which affects 1 in 4 people,

- Type II diabetes mellitus which affects 1 in 20 people, and

- Alzheimer Disease which affects $\geq 1$ in $20^{6}$.

In these disorders, susceptibility genes play a smaller role in the development of the disease. Having one of these gene mutations does not guarantee that a person will get the disease, but it does imply a susceptibility or predisposition.

The ten leading causes of death in Canada in 1997 were:

- Cancers (58,703 deaths)

- Heart disease $(57,417)$

- Cerebrovascual diseases $(16,051)$

- Chronic Obstructive Pulmonary Disease (COPD) $(9,618)$

- Injury $(8,626)$

- Pneumonia/influenza $(8,032)$

- Diabetes $(5,699)$

- Neurogenerative diseases $(5,049)$

- Diseases of blood vessels $(4,767)$

- Psychoses $(4,645)$.

With the exception of injury, at least a small percentage of nine of the leading causes of death have a genetic component. For example, about $5 \%$ of people with cancer have a genetic predisposition ${ }^{7}$. In infectious diseases such as influenza, pneumonia or HIV/AIDS, genetic makeup plays a role in the immune system's ability to fight infection. For example, people who have one copy of the CCR5 mutant gene are less susceptible to AIDS, and those with two copies are immune ${ }^{8}$.

It is important to remember that among the diseases listed above are chronic illnesses with a genetic component such as diabetes and chronic obstructive pulmonary disease. Such illnesses take a long-term toll on human health and have related social and health care costs.

\section{Environmental Factors}

Environmental factors such as diet, exercise, and exposure to chemicals influence many single or multiple gene disorders. Such disorders are called multifactorial. Although the interaction between genetic and environmental factors is not well understood, environmental factors may influence the age of onset, severity and progression of the disorder.

\footnotetext{
${ }^{6}$ Genetics: Basis for Medicine in the $21{ }^{\text {St }}$ Century, Dr. Achim Regenaur, Munich Reinsurance Company, Dr. Jorg Schmidtke Medical University Hanover

${ }^{7}$ Harper, Peter S (1998). Practical Genetic Counselling, Butterworth and Heineman, Oxford, P.295

${ }^{8}$ Dean M. et al (1996) Genetic restriction of HIV-1 infection and progression to AIDS by a deletion allele of the CKR5 structural gene. Science $\underline{273}$, 1856-186
} 
Environmental factors and interactions with other genes also play a role in disease development. As a result, these multifactorial disorders tend to have lower genetic risk and tend to be variable in their severity, age of onset and progression.

For example, mutations in genes such as those that control cholesterol metabolism, transportation and its effect on cells will impact on the risk for coronary artery disease (CAD). However, CAD also has a number of well-known environmental risk factors including hypertension, obesity, diabetes, smoking and lack of exercise ${ }^{9}$. Personal lifestyle choices play a crucial role in whether someone with a predisposition to a disease will actually develop its symptoms.

Tests for disorders such as CAD or diabetes will need to be incorporated into complex risk calculations involving both genetic and environmental factors.

A few of the disorders being studied for their genetic origins/risk factors include:

- Alzheimer's Disease $e^{10}$

- obesity $^{11}$

- prostate cancer ${ }^{12}$

- cerebrovascular disease (stroke $)^{13}$

- osteoporosis ${ }^{14}$ and

- pre-eclampsia in pregnancy (affects 3-7\% of pregnancies) ${ }^{15}$.

\section{Scientific Developments}

\section{The Human Genome Epidemiology Network}

Genetic predisposition to disease represents only one cause of disease. Other areas of research and population-based studies of the incidence and distribution of disease are also needed to better target medical, behavioural and environmental interventions.

To meet this need, the American Centre for Disease Control set up the Human Genome Epidemiology Network (HuGE) ${ }^{16}$ to assess the validity and determinants of use of genetic tests in different populations ${ }^{17}$.

HuGE analysis will not only help evaluate predictive genetic technologies but will also help policy-makers identify the appropriate mix between genetic interventions, disease prevention, health promotion and treatment.

\footnotetext{
${ }^{9}$ Classical risk factors and emerging elements in the risk profile for coronary artery disease. Gensini GF; Comeglio M; Colella A (1998). Eur Heart J 1998 Feb;19 Suppl A:A53-61

${ }^{10}$ Nature Genetics vol 27 March 2001; 245

${ }^{11}$ Nature Genetics vol 28 June 2001: 188

${ }^{12}$ Nature Genetics vol 27 Februray 2001; 134

${ }^{13}$ Roche and deCode, May 22, 2001

${ }^{14}$ Roche and deCode, November 14, 2000

${ }^{15}$ DeCode, September 19, 1999

${ }^{16} \mathrm{HuGE}$ Net, www.cdc/genetics/hugenet

${ }^{17}$ Muin J. Khoury and Janice S. Dorman, The Human Genome Epidemiology Network (HuGE Net), American Journal of Epidemiology, 1998;148:1-3, www.cdc/genetics/hugenet/about/editorial.htm
} 


\section{Number of Gene-Disease Relationships}



\section{Growth in Molecular} Genetic Tests

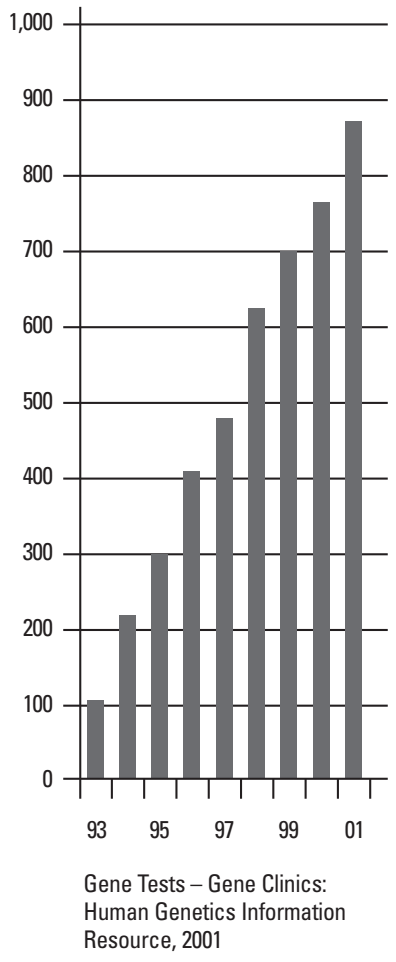

\section{A Growing Number of Identified Genetic Disorders}

As of May 2001, approximately 93\% of the human genome had been defined with the remainder to be completed by 2003. This is no small feat given the 3.1 billion base pairs that make up the human genome.

To date, the achievements of genetic technology have been in their use as a descriptive science - describing, mapping, sequencing and testing. Once the 3.1 billion DNA base pairs of the human genome have been mapped, the next set of goals for genetic technologies is to determine the function of various genes and to find ways to intervene in the biological basis of disease and develop more effective ways to diagnose, treat and prevent illness.

As the accompanying graph indicates, molecular genetic tests have been developed based on knowledge of the relationship between gene function and disease. As of October 2001, the Online Mendelian Inheritance in Man identified 13,060 gene loci that have been made public (www. ncbi.nlm.nih.gov). The final number to be described is expected to approximate 40,000.

Once a gene-disease relationship has been discovered, the stage is set for developing a molecular genetic test. Currently, approximately 877 molecular genetic tests are available internationally ${ }^{18}$. In Ontario, about 107 molecular genetic tests ${ }^{19}$ are being performed. (Appendix $C$ identifies the laboratories and the molecular genetic tests performed in Ontario.)

With genetic research expanding from the relatively rare monogenic disorders to the more common multifactorial diseases, a significant increase in the number of people seeking genetic testing is expected. Based on the prevalence of the more common multifactorial diseases, one in two people in Ontario could eventually be eligible for testing ${ }^{20}$.

One of the most significant benefits of genomic research is that it provides an opportunity to study the biology of all diseases. As research continues into tests, treatments and the biology of these diseases, researchers will gain a better understanding of the genetic mechanisms and the resulting production of proteins responsible for changes in cell behaviour that give rise to disease. This understanding may help researchers develop new treatments or prevention strategies for all patients affected by a disease, not just those with a genetic predisposition.

\section{A Growing Number of Predictive Genetic Tests}

While it is not possible to predict with any certainty the number of new genetic tests for adult onset diseases over the next decade, it is likely that it will represent an ongoing pressure. The variety and volume of the new predictive genetic technologies

\footnotetext{
${ }^{18}$ GeneTests world wide web at genetests.org

${ }^{19}$ GeneTests world wide web at genetests.org

${ }^{20}$ The Genetics of Common Diseases. A Second Report to the National Health Service Central Research and Development Committee on the New Genetics, 1995
} 
that provide risk-based information about future health status is potentially quite large. In addition, the risk determination for genetic changes in multifactorial diseases will become extremely complex.

Although most of the new discoveries in genomic medicine involve finding a genetic cause for a medical disorder, some researchers are exploring the genetic link to certain behavioural traits such as intelligence, criminality, sexual orientation, aggressiveness and hostility ${ }^{21,22,23}$.

Not only are ethical issues raised by the existence of these tests, they also raise fundamental questions about what does and does not fall within the realm of medicine and insured services. These tests also may result in the medicalisation of the trait with the risk that the underlying difficult social issues such as poverty are ignored.

\section{Advances in Genetic Technology}

The rapid evolution in our knowledge of the genome and advances in "molecular" techniques has been accompanied by rapid expansion of the use of these techniques in genomic medicine. Advances in automating molecular genetic techniques, as well as in the storage and handling of genetic data by supercomputers, continue to emerge.

One of the most significant advances will be achieved through the use of microchip arrays of molecular probes where it may soon be possible to test 400,000 gene samples in 5 minutes $^{24}$. Over the next decades, this will significantly increase the speed and number of test results, as well as lower the cost per sample. Both are essential to the use of this technology.

With this technology it will be possible to provide people with a personalized genetic profile that outlines not only their predisposition to a variety of diseases, but also the carrier and character traits they may pass on to future generations.

This technology also generates major questions about informed consent in medicine:

- Can patients fully consent to all of the tests being performed?

- How will the risk for each genetic test in the microarray be determined?

- How will lifestyle changes and surveillance programs for each patient be determined?

- How will broad-based genetic testing impact on follow-up care of healthy people?

\footnotetext{
${ }^{21}$ Abbar M, Molecular Psychiatry Volume 6:268 -273; Suicide Attempts and the Trptophan Hydroxlyase gene

${ }^{22}$ Hamer DH, Hu S, Magnuson VL, Hu N. and Pattatucci AML. A linkage between DNA markers on the X chromosome and male sexual orientation, Science 1993; 261:320-326; See also Dean Hamer's work into other traits - http://rex.nci.nih.gov/RESEARCH/basic/biochem/hamer.htm.

${ }^{23}$ Glenn McGee, The Perfect Baby: Parenthood in the New World of Cloning and Genetics, Rowman $\&$ Littlefield Pub. Inc., 2000, 36

${ }^{24}$ Nature Genetics v. 27 February 2001, www.nanogen.com/natgen
} 
The latter will impact on the health system for single genetic tests as well.

Although advances in genetic technology make it possible to detect a broader range of diseases, it poses the dilemma of being able to diagnose diseases for which there is no known cure or treatment. In the experience with Huntington Disease testing, families who wish to know their status benefit from the knowledge in terms of life planning and for the relief from "not knowing" 25 . When this kind of testing is done, the health care system must include necessary supports to individuals and families, as well as legal protection from misuse of the information provided.

\section{Next Stage Genomic Treatments and Cures}

The first phase of the human genome project - gene mapping - will lead to more intensive efforts for developing new treatments and cures for many of today's common diseases. It is conceivable that over the coming decades, predictive genetic tests will be accompanied by an array of genetic treatments including:

- conventional therapies;

- pharmacogenetics - genetically tailored drugs to maximize effective response while reducing unwanted side-effects;

- protein replacement therapy to provide missing hormones, enzymes, antigens or other proteins that the body fails to provide (e.g. genetic engineering of bacteria to make human insulin);

- new biologic material for invasive therapies (e.g. treating brain tumours with modified herpes virus);

- genetic engineering of a person's genetic structure by modifying the genes within the somatic cells (body cells other than egg or sperm cells);

- modifying the germline (egg or sperm cells) of a patient to pass on altered traits ${ }^{26}$.

\section{Pharmacogenetics}

Pharmacogenetics is a central focus of the pharmaceutical industry and on the near horizon of clinical practice. Since differences in drug response are often genetically determined, genetic testing will be used to fit medicines to individual genetic profiles. This strategy is expected to avert problems such as adverse reactions. This form of genetic testing will add a pressure to laboratories.

Pharmacogenetics could lead to the development of medications to treat specific diseases based on a person's particular genetic make-up, as well as presymptomatic preventive therapies. If pharmacogenetics is to become an effective tool in clinical practice, it will require genetic testing of individuals to identify the disease-related mutations, as well as variants related to drug efficacy ${ }^{27}$.

\footnotetext{
${ }^{25}$ Hayden, 1992

${ }^{26}$ Note that in the U.S. a moratorium has been placed on this type of intervention by the Human Genome Project.

${ }^{27}$ Nature 405, p. 857-865 (2000)
} 
A review of recent pharmacogenetic research shows that a number of common pre-disease or disease conditions are undergoing study, including:

- high cholesterol,

- depression,

- asthma,

- hypertension,

- breast cancer,

- schizophrenia and migraine ${ }^{28}$,

- heart disease ${ }^{29}$,

- vascular disorders such as peripheral arterial occlusive disease and atherosclerosis (hardening of the arteries) ${ }^{30}$, and

- rheumatoid arthritis ${ }^{31}$.

While none of these has yet been proven in a clinical setting, they give an indication of areas where genetic technology may impact on medical practice.

\section{Gene Therapy}

Once causal links have been established between gene(s) and disease, gene therapies offer another approach to treating genetic disorders. These therapies fall into the four categories of:

- protein replacement therapy,

- new biologic material,

- genetic engineering of somatic cells, and

- germline modification.

Currently, a number of gene therapy protocols are being tested worldwide. Should a therapy find its way into clinical practice, biochemical and molecular genetic tests will be required to identify the gene mutation and the outcome of the therapy.

\section{Genetic Reductionism}

With rapid and exciting developments in genetic technology, there may be a tendency to exaggerate the role this technology will have in changing health care outcomes for people.

The Advisory Committee recommends a cautious approach to embracing and implementing genetic technologies. This approach recognizes the complex interactions of genes and the environment and is mindful of the uncertainties of

\footnotetext{
${ }^{28}$ DeCode and Affymetrix, July 24, 2001

${ }^{29}$ Myriad Genetics and Roche, January 5, 2000

${ }^{30}$ Roche and DeCode, February 14, 2001

${ }^{31}$ DeCode and Genmab, June 12, 2001
} 
genetic testing. It also recognizes that, depending on the disorder, other approaches to disease control, such as population-based health promotion, could be more appropriate and effective than an approach based on genetic testing.

For example, most hereditary breast and ovarian cancers are due to mutations in the BRCA 1 and BRCA 2 genes. It is also possible to detect individuals at risk for hereditary colon cancer syndromes. But only $10 \%$ of people diagnosed with breast, ovarian or colon cancer has a hereditary disposition to these diseases. Genetic testing by itself is not an absolute predictor of these common illnesses. Other factors including environmental influences play a vital role.

In common diseases such as coronary artery disease, genetic changes may reveal predisposition, but the strategy for dealing with the disease may be populationbased health promotion and prevention programs.

Governments delivering health care must determine what proportion of health care resources should be devoted to detecting genetic predictors when these predictors are not absolute and other known, sometimes preventable, influences remain in the development of diseases.

\section{Effects On The Health System}

Advances in the biomedical science of human genetics, as well as in the technology, will affect the health system in a variety of ways:

- the volume and variety of the new predictive genetic technologies that provide risk-based information is potentially quite large. This means that the number of people seeking genetic tests and patients seeking health care will increase;

- genetic testing for traits rather than diseases, raises serious questions about the definitions of medicine and medical necessity;

- advances in microarray chip technology may not only increase public demand for the technology, but raise issues about the content and use of genetic information;

- the need for trained geneticists, genetic counsellors, and laboratory staff with new expertise will increase;

- predictive genetic medicine will result in greater emphasis on health promotion rather than medical treatment;

- the ordering of a test must not be divorced from the education, interpretation and counselling which must accompany the testing for patient well-being.

\section{The Ontario Public's Views About Genetics}

In September 2001, the province commissioned Ipsos-Reid to conduct a telephone survey of the public's level of knowledge and views on human genetic testing. One thousand adults were surveyed ${ }^{32}$.

\footnotetext{
${ }^{32}$ Accuracy of $+/-3.1 \%, 95 \%$ of the time.
} 
$89 \%$ of those surveyed stated that they were personally interested in this important subject.

The survey found that $89 \%$ of Ontarians are favourable in their overall opinion of human genetic testing. They are willing to admit that they know little about the issue, but they are interested in finding out more about it. They are aware that genetic predictions are not definitive pre-determinants, but rather that genetics may play a role in some health conditions and diseases.

The public's favourable views stem from optimistic perceptions of the direct, health related benefits that could stem from human genetic testing - that genetic testing can be used for detecting/curing/preventing diseases and so are beneficial to humans for the future. Genetic testing is perceived as potentially helping doctors diagnose disease, helping medical researchers develop new medical innovations, and helping governments plan and develop health care programs.

\section{Public Perceptions}

The public has positive views about informing people of their likelihood of developing disease to permit preventive actions, as well as helping parents advise their children about an inherited family disease.

- $78 \%$ felt that new genetic developments will mean children are healthier and free from inherited disabilities.

- 79\% felt it was appropriate for couples planning a family to use genetic information if their children are likely to have an inherited disability or lifelimiting illness.

- $40 \%$ were concerned that research in human genetics may be tampering with nature and is potentially unethical.

\section{Privacy a Concern}

People surveyed emphasized the need to ensure that genetic testing does not result in discrimination in employment, insurance, or access to services.

- $86 \%$ of those surveyed strongly felt that people should always be asked for their permission for their blood or tissues to be used in a genetic test, or for genetic research.

- $97 \%$ agreed that information should only be included in a database if an individual has given consent.

- $87 \%$ believed that consent must be given for each specific new research initiative for which a sample is to be used.

- $79 \%$ agreed that genetic databases and information should only be stored in Canada.

- $66 \%$ agreed that Canadian genetic databases should be publicly owned or controlled. 


\section{Far-Reaching Effects}

- 38\% are confident that rules and regulations are keeping pace with developments and research in genetic testing.

- 54\% of respondents believe the federal government should be making guidelines, rules and regulations that will guide the use of human genetic testing.

- 34\% believe that international organizations have a role.

They believe that the provincial government has a role in paying for genetic services but acknowledge that there may be instances where payments for tests should be left with individuals. For example, if the testing is for character traits or behaviours rather than for medical conditions. They recognize that the funding of genetic testing research and regulation may be national and/or international responsibilities.

\section{Patenting of Human Genetic Materials and Genetic Testing}

While they saw a strong role for the private sector in genetic research to develop treatments, respondents also recognized the dilemma in genetic patenting.

- $64 \%$ felt that if a private company invested large amounts of time and money to develop a new way to use human genetic information for genetic testing, they should have the right to charge for its use.

- Only $51 \%$ expressed a favourable view of a company's ability to patent genetic material identified to develop the tests.

\section{The Provincial Genetics Program}

Ontario has developed an international profile in genetics research. Significant funding for genetics research continues to foster new discoveries at several Ontario Research Laboratories including:

- the Hospital for Sick Children,

- the Samuel Lunenfeld Research Institute,

- the Ontario Cancer Institute,

- John P. Robarts Research Institute, and

- the Children's Hospital of Eastern Ontario.

Ontario's scientists have been responsible for identifying genes for cystic fibrosis, retinoblastoma and myotonic dystrophy and are at the forefront of proteomic research that explores proteins made by genes that are responsible for diseases. Providing a sound clinical infrastructure should improve opportunities for translational research and continue to mirror the excellence that clinicians and scientists in the province have achieved in this area.

While genetics research was not in the terms of reference for the Advisory Committee, it is important for the province to appreciate the outstanding contributions that Ontario's scientists and clinicians continue to make in this area. 
For the past 25 years, Ontario has provided genetic services as a priority program through a cooperative interlinked series of services in hospitals and public health units across Ontario.

Ontario's genetics program is believed to be the most comprehensive and coordinated in Canada. It consists of initiatives in:

- genetic diagnosis,

- genetic counselling,

- genetic testing,

- prenatal genetics, and

- metabolic services.

It operates under practice guidelines developed by:

- the Canadian College of Medical Genetics,

- the Canadian Association of Genetic Counsellors,

- the American Society of Human Genetics,

- the Society of Genetic Counsellors in the United States, and

- the American College of Medical Genetics.

Professional bodies in other areas of medicine have set guidelines and policies for a variety of conditions and situations that directly relate to the practice of genetics. For example, the American College of Obstetrics and Gynecology has guidelines on cystic fibrosis screening, and the Canadian College of Medical Geneticists and the Society of Obstetrics and Gynecology of Canada have created guidelines for prenatal diagnosis.

While medical geneticists order most genetic tests, some are ordered by family physicians and other specialists who may also provide counselling without referral to a genetics centre.

The current regional genetics network consists of nine linked regional genetics centres made up of:

- 19 clinical genetic clinics,

- 11 cytogenetic laboratories,

- 10 biochemical genetic testing and maternal serum screening laboratories, and

- 8 molecular/DNA genetics laboratories.

Regional genetic centres are located in:

- Hamilton - Hamilton Health Sciences Corporation,

- Kingston - Kingston General Hospital,

- London - London Health Sciences Centre,

- Mississauga - Credit Valley Hospital,

- North York - North York General Hospital,

- Northern Ontario - Sudbury Regional Hospital,

- Oshawa - Lakeridge Health Corporation ,

- Ottawa - Children's Hospital of Eastern Ontario, and

- Toronto - Mount Sinai Hospital and the Hospital for Sick Children. 
All centres offer coordinated clinical and laboratory services. Each has various genetic service components. Along with 10 clinical outreach centres, these centres serve the province on a regional basis.

Current base funding for the Provincial Regional Genetics Program is approximately $\$ 39$ million. Genetic testing done in the course of physician care outside of the program is not included in this amount. In 2000/2001, OHIP payments of $\$ 1.460$ million were made for individual and family counselling and for laboratory testing for common genetic disorders.

To date, genetically based testing has been introduced into medical practice as new testing became available - without a consistent policy framework and with varying levels of scrutiny. The complexity of the results and their implications means that interpreting them in a meaningful way can be enormously difficult.

While any physician may order genetic tests, the interpretation of results can be complicated and ambiguous results are possible. Test results that predict risk can be difficult for patients to translate into decisions about their care and reproductive behaviour. As a result, certain genetic tests, such as those for breast and ovarian cancer, Huntington Disease and early onset Alzheimer disease, are usually provided through genetic centres or specialty clinics where counselling and support are available.

\section{Personnel in Genetic Services}

The Provincial Regional Genetics Program currently employs 28 MD and 22 PhD geneticists. Ontario currently has over 100 genetic counsellors spread throughout a network of hospitals, cancer centres and public health unit clinics. The program currently employs close to 200 laboratory personnel. Family physicians and specialists have always provided some genetic services in their offices without referral to a genetic centre and it is expected that this role will increase over time.

Clinical geneticists are physicians who practice medical genetics. They provide diagnosis and management of genetic conditions, usually in consultation with primary care physicians or other specialists. They supervise services provided by genetic counsellors and nurses.

Genetic counselors counsel and support individuals and families seeking genetic advice. Genetic counsellors may be trained to a Masters level through a university program, or they may be registered nurses who have learned genetics in the course of their work.

Each genetic centre has a Head of Genetic Services. Several have associated psychosocial staff to provide supportive counselling and treatment to their patients. Unfortunately, there are few mental health personnel at this time with knowledge of genetics, making referrals to mental health professionals difficult.

Some centres have other support personnel such as the dieticians at the Hospital for Sick Children who provide preventive care advice to children and adults with inborn errors of metabolism. 


\section{Training of Genetic Personnel}

The Canadian College of Medical Genetics has an accreditation program for training medical and biochemical geneticists. It also certifies PhD geneticists in cytogenetics and molecular genetics. Physicians must complete at least three years of postgraduate training in an accredited residency program before completing a twoyear fellowship in clinical genetics at an accredited centre. Fellowship in the college follows successful completion of an examination. Every two years, there are seven to eight new fellows in each of clinical genetics, molecular genetics and cytogenetics, and zero to one in biochemical.genetics.

The Royal College of Physicians and Surgeons (RCPS) now offers a specialtytraining program in medical genetics for physicians. Up until 1996, physicians with established credentials in medical genetics could take the exam for the Royal College. Since then, the exams can only be taken after a five-year residency in medical genetics. There are one to five graduates across Canada each year. 1992 was the first year that the Royal College qualified candidates as specialists in medical genetics.

Laboratory physicians may have completed training programs in anatomical pathology, general pathology, hematopathology, hematology and clinical chemistry accredited by the RCPS. Laboratory scientists who do not have a medical degree are not eligible for recognition by the RCPS.

McGill University, the University of Toronto and the University of British Columbia offer a two-year Masters Degree in Genetic Counselling following the completion of an undergraduate degree. Approximately 12 genetic counsellors graduate from these programs each year. Some Canadians train in American programs, where there are about 125 graduates a year.

Family physicians receive their training in genetics through the study of the biological sciences. However, training in genetics is not a core part of the curriculum in Ontario's Faculties of Medicine.

Technologists who work in Ontario genetics laboratories must be licensed by the Ontario College of Medical Laboratory Technologists. Two facilities in Canada, the Michener Institute in Toronto and the BC Institute of Technology, currently offer training in genetics technology. The Michener Institute trains eight individuals from Ontario per year in a combined cytogenetics and molecular genetics program. 


\section{Section 2: Sub-Committee Reports and Recommendations}

The Provincial Advisory Committee on New Predictive Genetic Technologies set up six sub-committees to assemble the framework for introducing new genetic predictive technologies. In developing the framework, the sub-committees considered:

- criteria to assess the validity and utility of a new technology,

- guidelines for implementation,

- guidelines for ongoing monitoring and evaluation,

- human and capital resource requirements for the short term and over five years,

- translation of research into service in the short term and over five years,

- approaches taken by other jurisdictions,

- commercialization and the role of the private sector, and

- data management.

\section{Report of The Legal and Ethical Issues Sub-Committee}

\section{Objectives}

To identify social, legal and ethical issues that require regulatory and professional intervention.

- To specify options for new regulatory structures and interventions.

- To identify areas where further analysis and debate is needed.

Findings

\section{Ethical and Legal Considerations}

Ethical and legal issues permeate every phase of the development of new forms of genetic testing - from the development of genetic knowledge through research, the development of quality standards for laboratory testing and decisions regarding health care coverage for genetic testing, to the provision of clinical care in genetics and the development of a regulatory structure for the professions providing genetic services.

Though many of the issues raised in the context of genetic testing are not entirely new and unique, the specific characteristics of genetic testing and genetic information do raise particular social and ethical issues that require a variety of regulatory and professional interventions and warrant the development of new regulatory structures and interventions.

In the coming years, legislative changes may also be warranted to address the ethical, legal and social issues of genetics. As important is adapting existing or newly proposed regulatory structures to enable them to address these issues in an accountable and transparent manner. 


\section{Why Do Genetic Information and Genetic Testing Warrant Special Attention?}

Genetic information brings the ethical, legal and social issues involved in the use of health information to a different level. Genetic tests provide more detailed risk information than most other tests, generating new grounds for potential discrimination and stigmatization.

Because one's genetic information reveals information about one's family, genetic testing increases dilemmas surrounding the duty to inform third parties, such as family members, of particular health risks.

Genetic information impacts in particular ways on communities, for example by opening the door to the verification of historical and cultural knowledge and by potentially increasing risks for stigmatization and discrimination.

Genetics also gives us a greater volume of information, which can be extracted from one sample and then kept indefinitely. At the same time, the nature of the information is such that it generally only reveals a person's risk for disease, and not his or her current health status. However, risk information has become a powerful tool in the current social and cultural environment. Genetic information will be particularly attractive because of its potential to provide more detailed data. As a result, the 'not yet ill' may be increasingly vulnerable in various areas of social life.

These "exacerbated problems" also increasingly play out in a specific commercial and international health care context. Commercial interests may impact on the development of genetic research, the promotion of genetic technologies, the provision of genetic and other health care, and the use of genetic information by third parties. Patent rights over genetic research may have a significant impact on the conduct of research and on the availability of genetic testing within a health care setting.

The international context has also changed. Genetic information does not respect borders, nor does it answer to customs officers, particularly in the context of a globalizing economy.

Genetic developments have not only been enabled by, but also take place in a new technological environment. Computer and other information technologies, for example, are crucial components of discoveries in genetics. They have simplified the storage and transfer of genetic information, accelerated the research and testing process, and made testing less invasive and less burdensome.

People can easily provide the necessary samples and send them in for testing, regardless of state or provincial borders. This is bound to have repercussions on the demand for health care services as people will try to access health services in the province based on genetic test results accessed elsewhere. 


\section{Recommendations}

The Legal and Ethical Sub-Committee offers recommendations in the areas of:

- discrimination and stigmatization,

- insurance and employment,

- the regulation of research,

- laboratory testing,

- allocation of resources for genetics,

- patents, commercialization and direct marketing of genetic testing,

- regulation and liability of genetic counsellors,

- clinical issues,

- storing genetic information and genetic material, and

- privacy and confidentiality.

\section{Discrimination and Stigmatization Issues}

Because genetic tests can reveal information about the future health risks of an individual, and potentially, information about personality traits and other personal characteristics, its use opens the door to discrimination and stigmatization.

Insurance companies could use, and to some extent already do use, genetic information to increase premiums or to deny coverage on the basis of risk status. At the same time, genetic test results could benefit people with family histories of disease to obtain better coverage. The interests of the insurance industry in avoiding adverse selection have to be balanced against society's interest to avoid discrimination.

Employers could use genetic information to identify at-risk employees or applicants, and deny them employment opportunities based on this information. At the same time, some genetic tests might also be used as an occupational health and safety tool.

Genetic information could also be used in immigration, education, and by financial institutions and adoption agencies. Genetic discrimination and the financial and social consequences of being affected by a 'genetic risk' could create pressure towards subtle, passive eugenics, if the potential social and financial costs of a genetic risk status become unbearable.

\section{Recommendations}

Human rights legislation should be amended to make sure that people with a genetic predisposition or susceptibility are adequately protected against discrimination. Such an amendment may need to include a specific prohibited ground of discrimination, covering the perception of future illness or disability.

The Legislature should consider amending the Human Rights Code to prevent discrimination on the basis of genetic traits. This could be done by explicitly 
including "genetic trait" as a prohibited ground of discrimination in Part 1, or, as the Ontario Law Reform Commission recommended, by amending the definition of "because of handicap" in section $10(1)$ so that it provides as follows:

10.-(I) In Part I and in this Part.

"because of handicap" means for the reason that the person has or has had, or is believed to have or have had, or for the reason that it is believed that the person will have

(a) any degree of physical disability, infirmity, malformation or disfigurement that is caused by bodily injury, birth defect or illness and without limiting the generality of the foregoing, including diabetes mellitus, epilepsy, any degree of paralysis, amputation, lack of physical coordination, blindness or visual impediment, deafness or hearing impediment, muteness or speech impediment, or physical reliance on a guide dog or on a wheelchair or other remedial appliance or device,

(b) a condition of mental retardation or impairment,

(c) a learning disability, or a dysfunction in one or more of the processes involved in understanding or using symbols or spoken language,

(d) a mental disorder, or

(e) an injury or disability for which benefits were claimed or received under the Workers' Compensation Act.

If the Legislature adopts the latter course of action, the Human Rights Commission should issue an interpretive rule providing that genetic conditions, both present and future, fall within the scope of its legislative protection.

In addition, the government should consider establishing measures that are proactive in avoiding discriminatory uses of genetic information. Human rights commissions and specialized commissions dealing with insurance and employment should be involved in determining what types of testing can be introduced and what types of genetic information can be used in the context of insurance, employment and any other area where discrimination could occur on the basis of genetics.

The government should establish an approval system for using genetic testing and genetic information in insurance, employment, adoption, education and any other areas outside of health care, where using genetic testing and genetic information could have negative or undesirable social consequences. If genetic testing and information were to be used in these contexts, it would have to be with the approval of a governmentally approved decision-making body which is interdisciplinary in nature and represents the various interests at stake.

If a Provincial Advisory Committee on Genetics is re-established, addressing all issues of discrimination and stigmatization through liaison with other relevant partners should be one of the first tasks undertaken. 


\section{Insurance and Employment Issues}

Many Canadians have identified the issue of insurance and genetic information as an immediate concern. Internationally, several jurisdictions have taken regulatory or legislative measures to curb genetic discrimination in the context of genetics. In other jurisdictions, official reports have urged governments to take action.

Many American states have enacted specific genetic discrimination statutes. But these focus mainly on health insurance and are enacted in a different health care environment. The absence of universal health care in most states makes it an immediate concern for them to protect people's access to health care insurance. Many health care specialists suggest that the further development of genetic testing will make it crucial for the United States to move towards publicly funded health care, accessible to all regardless of their risk status.

In Ontario, many health care products are currently being provided through private insurance. Many drugs, for example, are not covered by OHIP. Drug coverage will increase in importance with the further development of pharmaco-genomics increasing the risk that discrimination in private insurance will affect access to health care.

In Europe, several countries (including Austria, Belgium, France, Denmark, Luxemburg, the Netherlands and Norway) have prohibited or restricted the use of genetic information for insurance purposes. Some of these countries also prohibit applicants from submitting the results of potentially favourable genetic tests to insurance companies. This avoids positive selection where individual applicants submit a good risk-profile to obtain insurance - circumventing the prohibition against asking for test results.

Genetic discrimination in employment has not been as extensively dealt with by other jurisdictions but has been identified as a serious potential concern. In February 2001, the U.S. Equal Employment Opportunity Commission filed its first challenge under the Americans with Disabilities Act against a railway company that conducted genetic tests of its employees for Carpal Tunnel Syndrome. Because the pressure to introduce genetic testing in employment will likely increase in the coming years, this issue needs to be addressed now.

The 1996 European Convention on Human Rights and Biomedicine will be a driving force behind further legislative action in this area in Europe. It explicitly prohibits, in article 11, "any form of discrimination against a person on grounds of his or her genetic heritage." Article 12 prescribes that genetic tests can only be performed for health care or scientific purposes. It also specifies that appropriate genetic counselling should be provided.

Its explanatory report specifies that even a person's consent cannot be used to justify a genetic test conducted for other than health or research related purposes. In Europe, there is a clear development towards introducing legal tools to address the issue of discrimination. Signatories to the Convention have to introduce legislation for the state to respect the provisions of the Convention.

The Committee concluded that the issue of discrimination is one of the most serious and pressing issues raised by new genetic technologies, to be addressed. 


\section{Human Rights Issues}

The Committee felt that the magnitude of the issue of discrimination was so great that government should expand the power of the Human Rights Commission or establish a special commission to evaluate specific genetic tests and types of genetic information before their use for insurance or employment purposes.

The commission should include geneticists, actuarial specialists, members of the public and lay organizations, lawyers and ethicists, with no financial interests in, or contractual relations with, the industries potentially affected by its decisions. Industry and labour organizations would also be represented.

The commission's decisions would be informed by standards of accuracy, validity, and predictive value for the use of genetic information in insurance and employment. Any request would have to be supported by credible scientific and actuarial data that would be assessed by the commission in light of the potential social, ethical and legal consequences of using the test or information.

The task of the commission would be similar to that of the evaluation committee charged with the general evaluation of proposed genetic tests, but it would focus on the specific use of genetic testing and genetic information in insurance or employment.

As an interim measure, the government should urge the insurance industry to set up a commission of experts, with representatives of industry, lay organizations and the public, as well as specialists in actuarial sciences, law and ethics, who are independent from and have no financial interests in the insurance industry. This commission could make specific recommendations on using genetic information for insurance purposes.

The government should consider implementing a moratorium that would prevent insurance companies and employers from using genetic information to determine eligibility for insurance or employment.

A moratorium would provide time for the government to consult and work with interested stakeholders to develop policies and practices for employers and the insurance industry using genetic information. The moratorium should remain in effect until proper policies and processes for the use of genetic information in these contexts are implemented.

Since some tests for employment-related susceptibilities have already been developed which could benefit employees, employers could discuss with the Provincial Committee the appropriateness of offering genetic tests that could protect employees against workplace related harms. Such tests should not be a condition for employment but should be offered for employees who test positive to obtain reasonable accommodation.

In the insurance context, the terms of the moratorium should be discussed with the insurance industry. It may be appropriate to allow people with a family history of disease to use genetic test results to show that that their risk is low. It would also be appropriate to link the moratorium to a maximum amount of coverage. The moratorium could apply to most life and additional health insurance policies, but not to those of overly high value. 
In addition, the government could urge the insurance industry to immediately introduce a policy that no genetic test results obtained in research will be used for determining insurance premiums. This would avoid criticism that valuable research is being affected by people's concern about potential insurance implications.

\section{The Regulation of Research}

Canada currently has no clear statutory regime for reviewing research involving humans. In 1997, the three major federal funding agencies issued the Tri-Council Policy Statement on Ethical Conduct for Research Involving Humans, a set of guidelines that sets out acceptable practices and ethical standards for research involving humans. Health Canada has also declared that research supporting an application for drug approval has to respect this Statement, as well as the International Conference on Harmonization Tripartite Guideline for Good Clinical Practice (ICH guidelines).

These guidelines are the latest initiatives within a gradual development of research review and research ethics standards in Canada.

\section{Research Ethics Boards}

Many Research Ethics Boards (REBs) have developed significant expertise in reviewing research protocols for adherence to ethical standards. Many REBs and institutions have also been involved in teaching programs and workshops to educate researcher and REB members.

The duties of REBs and the expectations towards them have increased over time, with the result that many are overburdened and suffer from strained resources.

More importantly, no statutory regime regulates the establishment, membership, decision-making process, administrative structure, and regulatory powers of these REBs. There is also no system of registration of REBs and no information on how many REBs function in the province or in the country.

Funding agencies and Health Canada recognize REBs as playing a crucial role in the review process but no clear structure or enforcement mechanisms are in place to ensure that REBs function appropriately and that they, the researchers and the institutions in which they operate, respect the guidelines.

Until recently, the National Council on Ethics in Human Research (NCEHR) was the main national body with a mandate to promote research ethics standards across the country. However, the NCEHR has no clear regulatory power and has never been significantly funded so as to enable it to play a very active role.

\section{Publicly Funded Research}

The Tri-Council Policy Statement only binds institutions and researchers with respect to funded research. It does not have force of law.

If researchers and research institutes do not respect the Statement, they could be sanctioned by the withdrawal of funding by the funding agencies. However, the funding agencies have little control on how REBs in Canada apply the Statement. In the absence of a clear process and reporting structure, it is unclear how and when the funding agencies would be informed of violations of the Statement. 


\section{Privately Funded Research}

The ICH guidelines do not cover all forms of private research, but only private research that aims at an application for drug approval.

Health Canada requires that those who are seeking approval of a new drug obtain prior REB approval for the clinical trial that supports their application. But applicants only have to answer in the affirmative that they obtained such approval. The system relies entirely on self-reporting and there is little or no control on the actual review process.

There seems to be no legally enforceable obligation to obtain an external REB approval before engaging in non-funded, private research that will not result in drug approval.

\section{Research Funded by the National Institutes of Health}

Institutions conducting research funded by the U.S. National Institutes of Health are subject to more rigorous control of the REBs by the Office of Human Research Protection. Although more detailed regulations exist in the U.S., several official reports have pointed out that the overseeing of research ethics review is weak and has several loopholes.

\section{Lack of Regulatory Supervision}

The potential consequences of the lack of regulatory overseeing of research ethics review should not be underestimated. The regulatory and funding agencies recognize that REBs have as their primary duty the protection of the rights and well-being of research participants. Health Canada has recognized that REBs have a crucial role to play in, for example, assessing the risks and benefits of a study, preventing the potential impact of conflicts of interests and in monitoring ongoing studies.

In the review process and in the monitoring of studies, REBs have to take into consideration adverse event reports that relate to the drugs or therapies being tested. Recent reports have indicated that adverse events are underreported and that it is unclear how many adverse events in research really occur.

Research mishaps in the United States, including the deaths of healthy or only mildly ill research participants who died as the result of research participation, have forced regulatory agencies to suspend the research activities in some of its most prestigious institutions $^{33}$. While Canada has not been confronted with the same public controversies involving deaths of research participants, it is not clear that the research context is so different that it could not happen here.

Recent controversies related to conflict of interests in research indicate that similar pressures do exist in the research context as in the U.S. There is also less regulatory supervision which might make it more difficult to have public knowledge about mishaps in Canada.

\footnotetext{
${ }^{33}$ For a discussion of a recent U.S. case and an analysis of whether Canadian rules and procedures for conducting clinical trials on voluntary research subjects would have been any better, see: Richard Ian Ogilvie (Nov. 13, 2001) "The death of a volunteer research subject: lessons to be learned" CMAJ 165(10) 1335-1337).
} 
At this time, REBs are operating differently across the province and the country and there is little control on their functioning, decision-making, membership and training. As well, many REBs are struggling with issues around conflicts of interest within their boards.

Formal regulation of research review is of interest to everyone who would be protected by this regulation, including the public, research subjects, researchers and the many members of REBs in Ontario and Canada. The regulatory vacuum creates uncertainty and harms the efficient, solid and coherent review of research protocols and may hamper research. It also may impact on how Ontario researchers can collaborate internationally.

The lack of clear regulatory structure and supervision is of significant importance in the area of genetics. Many genetic programs are first introduced in the research setting. Potentially harmful genetic information becomes available in these research projects but there is no clear standard of review. Expertise and knowledge in genetics and in the ethical and legal issues raised by genetics are often lacking on REBs. A central review board may be required for certain types of high-risk research and for research invoking significant social concerns.

Health Canada's Ethics Division is currently looking into the need for regulation and Ontario's efforts should be harmonized with these efforts. Other provinces (including Newfoundland and Quebec) are also implementing, or considering, stricter regulation in this area. Internationally, there is a clear move towards the development of regulatory structures around research.

\section{Recommendation}

While the Committee did not have consensus on how to deal with this issue, it agreed that the growing prevalence of genetic testing in research makes the need even more pressing to examine what research is approved and the conditions for that approval.

At a minimum, the government should ensure that no genetic testing is undertaken for research in Ontario without adequate research ethics review by an independent and accountable REB. In looking into the development of an adequate research review system, Ontario should coordinate its efforts with those of the federal government and other provinces. The current regulatory structure or lack of structure is a cause for concern.

\section{Laboratory Testing}

In Ontario, the present evaluation process for approval of new laboratory testing focuses on ensuring the quality and scientific validity of tests. The evaluation process does not necessarily address the informational and social risks associated with a particular test, or the ethical and legal issues.

Few would question the value of a genetic test that would enable us to identify an increased risk of developing a particular form of treatable cancer, or a preventable disease. The notion of disease is however expandable. Genetic research could lead to 
the development of a test that would reveal an increased chance of having a particular personality or behavioral trait, such as aggressiveness. Parents could use such a test and decide to abort their "affected" foetus.

The determination of how to weigh potential benefits and harms of introducing a new test is not something that ought to be done only by those having technical expertise. It involves a weighing of social and ethical issues which requires that the public be represented within the decision-making process, as is proposed in this report.

It would be wise to have societal debate about these issues even before allowing the introduction of such tests, whether insured or not. An evaluation of the social and ethical impacts of a proposed genetic test should be conducted before the test is approved for use. The review structure for genetic laboratory testing should be adapted to include an appropriate and solid review of the ethical, legal and social issues.

The sub-committee recommends that no genetic test should be introduced in Ontario unless a thorough evaluation of the ethical, legal and social impacts of the proposed test has been conducted. The committee responsible for this evaluation should include people who are knowledgeable about the scientific, ethical, legal and social issues, as well as members of the public and lay organizations.

\section{Allocation of Resources for Genetics}

Although genetic testing has the potential to improve human health, the costs of genetic testing and genetic services can be very high.

An appropriate balance must be struck between investing public financial resources in genetic testing and services and in other health services and technologies including those related to the social determinants of health. When evaluating a service that will be beneficial, determinations must also be made to ensure that all individuals will have equitable access to this service, regardless of socio-economic status or place of residence.

\section{Patents, Commercialization and Direct Marketing of Genetic Testing}

\section{Patenting genes and genetic tests}

Increasingly, patent protection is sought for genetic tests, as well as for the genes that are the subject matter of genetic tests. While products of nature are unpatentable, courts have held that genes that have been isolated, purified or modified are patentable. To be patented, these "inventions" would still have to fulfill the patent requirements of disclosure, novelty, non-obviousness and utility.

Once an invention is patented, the patent holder has the exclusive right to make, use or sell it for 20 years. Given this monopoly, it is imperative that patents on genes and genetic tests are validly granted and that there is no deviation from the traditional requirements of patentability. 
Another major concern is that patents not restrict the availability of genetic testing by facilitating monopolistic pricing and restrictive licensing agreements. It is important to determine whether the Patent Act should be amended to ensure some control over the price of patented tests and access.

Ontario has already been confronted with the impact that gene patents may have on the costs of health care in the province, in the controversy around BRCAl+2 testing. With the further development of genetic testing, this may create a significant financial burden to the health care system or may make it harder for the provincial governments to decide to cover new genetic tests.

Depending upon the type of regulatory regime that is desirable for genetic tests, it may be important to enable domestic labs to obtain licenses to provide the tests in Canada instead of having samples sent for testing abroad.

Although statutory changes would require careful study, they would not necessarily require a rethinking of our basic patent system. Analogies can be made to existing provisions about the abuse of patents, government use of patents, and the patented medicines regime.

Gene patents also raise more fundamental questions about our patent system. Patents provide incentives for innovation by allowing the patent holder to recoup the cost of research and development, as well as to realize a return on this investment. This monopoly is granted to the patent holder in exchange for the full disclosure of the invention so that this knowledge can become a part of the public sphere and contribute to further innovations. In this way, patent rights promote the public interest and can be vital to our research industry.

However, some people question whether patents on genes and gene fragments impede rather than facilitate innovation by providing monopolistic rights over the basic building blocks of research. There are many other related questions about whether patent law provides the correct incentives in the area of genetics or whether it overcompensates patent holders.

But private companies are not the only ones providing financial and other support for the research that leads to patents. In many cases, research takes place in public institutions, partly funded by federal and provincial governments. Other costs of research, for example when research subjects are treated in hospital for adverse events, are carried by the publicly funded health care system. By participating as research subjects, individual Ontario citizens also contribute to the development of patents.

It is important to determine to what extent all of these public contributions are recognized and rewarded in the current system. The government could stimulate an open debate among interested parties about this issue.

Fundamental questions have also been raised about the nature of genes and gene sequences. Commentators have objected to the idea that individuals or companies would be able to have patent rights over these 'fundamental building blocks of life'. 
These complex economic issues are beyond the competence of the subcommittee but it is important that this area receive serious attention. Overprotection means that the tests will cost more than they should; underprotection means that fewer tests may be developed.

While it may be legally difficult to distinguish patents on isolated genes from existing patents on chemical compounds, it is important that this widely expressed concern be addressed in public debate. The government of Ontario has already taken initiative in this area and should continue to take part in this debate.

Countries throughout the world have, or are undertaking, a variety of options to address the problems currently raised by genetic testing. The sub-committee supports the Ontario government in urging that these options be considered by the Canadian government through a public debate.

\section{Commercialization and Direct Marketing}

Direct patient access to commercial genetic testing raises important issues about the adequacy of pre-test information and counselling, which are essential for informed consent, and for post-test counselling and support especially where the test is positive for carrier status or susceptibility to a disorder.

This testing will likely have spillover effects on the publicly funded health care service within the province, particularly in the areas of genetic counselling and follow-up care. The commercial availability of genetic testing could result in aggressive marketing strategies, potentially promoting over-use of genetic testing, determining which tests are available irrespective of their utility for health care, and inhibiting planning.

As a first step, the government of Ontario should engage in discussions with the government of Canada regarding patents, direct to consumer marketing and other areas of federal jurisdiction related to the commercialization of genetic tests, which also have direct and pressing implications for the delivery of health care in Ontario.

\section{Regulation and Liability of Genetic Counsellors}

The significant role that genetic counsellors play in genetic testing services is gradually being reflected through policy. The Canadian Association of Genetic Counsellors has developed guidelines on the scope of practice of genetic counsellors, as well as a certification procedure for its members. Genetic centres also have developed their own policies and standards of practice.

However, there is currently no statutory regime for the regulation of the practice of genetic counselling in Canada. Ontario's Regulated Health Professions Act does not apply to genetic counsellors, nor is there any licensing procedure for them comparable to the provincial colleges of physicians and surgeons' licensing of physician-geneticists to practice medicine. 
In contrast to other health professionals, genetic counsellors do not have their own malpractice insurance. Institutions and physician-geneticists who employ genetic counsellors bear legal responsibility for their actions, provided they are acting within the scope of their employment.

The legal status of other non-regulated health personnel who are directly involved in genetic laboratory testing is equally uncertain.

Liability could become a greater concern in the future as predictive genetic testing becomes more common and the role of genetic counsellors and other nonregulated health personnel expands and gains importance. Genetic counsellors will likely bear increasing responsibility for their role as communicators, and more liability could be placed on them. As testing becomes more widespread, other nonregulated health personnel could also see their responsibilities increase.

The regulation of genetic counsellors and other personnel who are directly involved in genetic testing is likely to become necessary. Regulation would: recognize the importance of the services provided by these professionals, increase their profession's status, and establish more rigorous norms with regard to qualification, responsibility and liability.

Genetic counsellors and other personnel who are directly involved in genetic services should be covered by the Regulated Health Professions Act. This could be achieved by including new professions in the list of "Self Governing Health Professions" in Schedule 1 of the Regulated Health Professions Act or by including non-regulated personnel into existing Self Governing Health Professions.

\section{Clinical Issues}

Genetic testing raises specific issues about:

- informed consent,

- patient confidentiality, and

- the testing of minors and incapable persons.

\section{Informed Consent}

In Ontario, consent to health care treatment may be express or implied, verbal or written. In general, implied consent is reserved for common, simple, low-risk interventions in which the benefits greatly outweigh the risks. In the context of genetic testing, express consent is required, due to the complexity of the information obtained and its uncertain risk-benefit ratio.

The consent must also be voluntary, relate to the proposed treatment and be adequately informed. This means providing a patient with the information necessary to understand the purpose and implications of a proposed test, and to make a choice based on his or her values. 
Given the complexity of the information that the patient must receive, the possible consequences of undergoing testing, the probabilistic nature of the results, and the uncertain risk-benefit ratio, some bodies recommend that consent to testing should be written. This would further confirm the voluntary nature of genetic testing and the right of the individual to withdraw his or her consent.

The committee did not reach consensus on how to address this issue. The legal and ethical issues sub-committee recommended that informed consent be written. Other members of the committee expressed concern about the implications of a written consent requirement for current clinical practice. The legal and ethical issues sub-committee therefore recommends that the issue of written consent be further reviewed. It encourages consultation with lay organizations who have drafted model informed consent forms for genetic testing (e.g. The International Huntington Association).

Technological advancements also raise particular concerns about informed consent. For example, multiplex testing such as microarray allows testing of a single biological sample for multiple genetic disorders simultaneously. The potential cost savings and the apparent efficiency of this technique make it an attractive option. Because multiplex testing potentially involves testing for hundreds of conditions and diseases at once, each significantly different from the others, it poses a particular challenge for informed consent.

The basis of informed consent is that the patient receives and understands enough information about the testing process and the condition being tested for, to make an informed decision about whether to undergo testing. With multiplex testing, this decision would involve hundreds of conditions. Should informed consent be required for each test in a microarray panel, or would a generic consent to all tests included be sufficient?

Requiring health professionals to discuss each condition in advance of testing would entail practical difficulties. This could be problematic in the current context of limited resources. A generic consent would likely not be considered adequately informed and would undermine the concept of informed consent and respect for autonomy.

Various approaches could be taken to address these issues. The use of multiplex testing could be strictly limited to exceptional situations in which important health reasons can justify using this technology. If multiplex testing were deemed necessary, tests could be grouped on different panels by related types of disorders, such as those with similar availability of effective treatment, or similar severity or nature of condition. This could make obtaining informed consent for each condition manageable.

If a Provincial Advisory Committee on Genetics is re-established, the committee should follow technological developments in this area and continue to investigate this issue. At this stage, there is no clear situation where multiplex testing seems appropriate. 


\section{Testing of Minors}

It is expected that in the coming years, the most frequent form of genetic testing will be newborn screening. Newborn screening programs are generally used to detect diseases that are treatable but would not be detected by simple physical examination before their effects have manifested and become irreversible.

To be included in a universal screening program, a disease should have the following characteristics:

- the disease will result in severe morbidity (mental and physical) and/or mortality if it is not diagnosed in the neonatal period;

- clinical screening by simple physical examination is not effective and will not identify the disease;

- an effective treatment is available;

- there is a significantly improved prognosis with early treatment;

- the disease has a relatively high incidence (greater than 1 in 15,000 infants); and

- there is a simple, rapid, reliable, inexpensive screening test.

Some jurisdictions have introduced mandatory screening programs under which no parental consent is required. In these cases, the benefits of testing are considered to strongly outweigh the possible risks.

In Ontario, parental consent is required for any form of genetic testing or screening of children and newborns. There are currently no exceptions to the requirement for informed consent for newborn screening.

The new Provincial Advisory Committee on Genetics, if appointed, should examine how newborn screening is currently being conducted and whether health care providers and parents are correctly informed about this issue. This research should examine if there is a need for further education about the current ethical and legal standards in this area and for changes to the system of newborn screening.

The practice in Ontario of banking samples obtained from newborn screening, and the process of informed consent for banking and the future use of samples, require further review.

Genetic testing of children raises serious ethical issues when the proposed tests are not likely to provide timely medical or psychosocial benefits, or when the benefits of testing will not accrue until adulthood, as in the case of adult-onset disorders. Such testing could cause serious psychological harm, could expose children to stigmatization and discrimination, and could deny their future autonomy.

For these reasons, the sub-committee recommends that newborns and children should not be tested for genetic conditions where there are no timely medical or psychosocial benefits, or where these benefits will not accrue until adulthood. 


\section{Confidentiality}

A patient's genetic test results generally reveal information about the risk status of family members. If the patient's results are relevant to family members, the patient should be encouraged to share that information with them. If the patient refuses to share this information with them, should the physician breach confidentiality to the patient in order to inform the family members that they are at increased risk of developing a particular genetic disorder? Doing so could damage the patient's trust in the physician but if the disorder is preventable or treatable, it could have a significant impact on the health of family members.

Further research should be undertaken to determine whether disclosing genetic information to high-risk relatives against an individual's wishes should be allowed. Any criteria to allow this disclosure should include the following conditions:

- the interest in informing relatives strongly outweighs the interest in maintaining confidentiality;

- reasonable attempts to elicit voluntary disclosure are unsuccessful;

- there is a high probability of serious and irreparable harm to an identifiable person;

- the disclosure of the information will enable that person to prevent the harm, and there is a high probability that the harm will occur if the information is withheld; and

- the disclosure is limited to the information necessary for the diagnosis or treatment of the third party

\section{Storing Genetic Information and Genetic Material and Protecting Privacy}

Because DNA samples and genetic information have the potential to be stored indefinitely, special consideration needs to be given to issues of:

- ownership of samples and test results,

- consent to storage,

- time limits for storage,

- use of samples in research,

- recall of tested individuals, and

- privacy and confidentiality of patient information.

Stored genetic information and genetic material may be of interest to third parties such as family members, insurance companies and employers. Legislation is needed to:

- protect the privacy of all health information including genetic information,

- establish norms for the collection and storage of such information, and

- determine who should have access to stored genetic information and genetic samples under various circumstances. 


\section{Report of The Evaluation Sub-Committee}

\section{Objective}

- To develop an evaluation framework that would guide decision-makers' and the public's priorities in making genetic predictive tests available through the publicly funded health system.

\section{Findings}

The Evaluation Sub-Committee proposes an evaluation framework for making predictive genetic tests available through public financing. The Sub-Committee:

- defines the elements of decision-making,

- makes recommendations about the structure of the evaluation process, and

- introduces an evaluation template to be used by evaluators ${ }^{34}$. (See Appendix F). Because the use of innovative decision frameworks improves as decision-makers learn about their utility through experience, the evaluation template is presented as a starting point.

\section{Decision Framework for Genetic Testing}

Predictive tests differ from diagnostic genetic tests by suggesting future rather than present disease. The predictive power of these tests varies by disease and by test. Tests for genetic diseases where mutation status implies the certainty of disease in the future (e.g. Huntington Disease) have near-100\% predictive power. Tests for genetic diseases where mutation status creates an increased risk (susceptibility) of disease (e.g. BRCA1/2) have lower predictive power.

Like any new and evolving technology, predictive genetic tests can constitute a major pressure on health services (Stevens ${ }^{35}$, Newhouse ${ }^{36}$ ) prompting policy-makers to engage in priority setting and rational evaluations of effectiveness. In addition, predictive genetic tests have some particular characteristics that warrant specialized attention ${ }^{37}$.

To date, few evaluation frameworks for predictive genetic tests are available to guide both technology assessment and priority setting. Large public policy agencies have conducted most of the available evaluation efforts. They have concentrated on evaluating technologies for their safety and effectiveness in order to secure approval as marketable health products. These evaluations do not generally address questions of service coverage and issues related to medical, personal or economic effectiveness.

\footnotetext{
${ }^{34}$ Appendix E contains a list of papers produced for the Advisory Committee, including those produced by the Sub-committee on Evaluation

${ }^{35}$ Stevens, A, R Milne, R Lilford, and J Gabbay. 1999. Keeping pace with new technologies: systems needed to identify and evaluate them. British Medical Journal 319:1291.

${ }^{36}$ Newhouse J P. 1992. Medical care costs: how much welfare loss? Journal of Economic Perspectives 6 (3): 3-21.

${ }^{37}$ For a fuller discussion, see the Sub-committee Discussion Paper 7.5, listed in Appendix E
} 
In Ontario however, evaluation frameworks must grapple with a full spectrum of evaluation criteria ${ }^{38}$.

The sub-committee proposes an evaluation framework for making predictive genetic tests available through public financing. The framework:

- proposes criteria for these evaluations,

- defines the elements of decision-making,

- makes recommendations about the structure of the evaluation process, and

- introduces an evaluation template ${ }^{39}$.

Any evaluation process should include a rigorous analysis of the evidence and respond to the social and cultural context in which the evidence is being interpreted and applied.

Many factors will enter into funding decisions about predictive genetic technologies, including clinical and economic issues, and the opportunity and magnitude for benefit and harm that can result from the service. Because different interests will weigh factors differently, evaluation must include input from a variety of stakeholder and expert groups, and ensure that the process remains flexible.

\section{Evaluating Predictive Genetic Technologies}

In a recent talk, Dr. Ed McCabe, Chair of the U.S. Secretary's Advisory Committee on Genetic Testing (SACGT), raised the issue of "an unresolved dichotomy" between the role of the Food and Drug Administration (FDA) in reviewing the safety and effectiveness of genetic tests and the role of the Centers for Medicare $\&$ Medicaid Services (CMS) in determining which tests are necessary and reasonable, and therefore warrant public coverage ${ }^{40}$.

This dichotomy is apparent in Canada where the federal government makes decisions about the approval of new health products but provincial governments are responsible for providing public coverage for necessary and appropriate medical services.

To date, most efforts to develop systematic criteria for evaluating genetic tests have focused on issues relevant to federal review, rather than provincial resource allocation $^{41}$. Exceptions include current initiatives in the UK that address the National Health Service provision of genetic services, and the sophisticated model developed by the Crossroads 99 group ${ }^{42}$. Both are incomplete.

\footnotetext{
${ }^{38}$ See Discussion Paper 7.4 listed in Appendix E.

${ }^{39}$ Appendix F contains the proposed evaluation template produced by the Evaluation Committee.

${ }^{40}$ Dr. Ed McCabe, 2001

${ }^{41}$ See the background paper of this title by Fiona Miller, Ph.D. and Mita Giacomini, Ph.D. both of the Centre for Health Economics and Policy Analysis and Department of Clinical Epidemiology and Biostatistics, McMaster University, 7.4 of the Subcommittee on Evaluation.

${ }^{42}$ Goel, V (for Crossroads 99 Group), Appraising organised screening programmes for testing for genetic susceptibility to cancer. British Medical Journal 322:1174-1178 (2001)
} 
In the absence of developed models, the Evaluation Sub-Committee developed a new approach to the evaluation of predictive genetic tests. It is informed by the work of other groups including the SACGT.

\section{Guiding Assumptions}

The evaluation of predictive genetic technologies as a health service should consider more than simply the technology itself.

\section{Unit of Analysis}

The sub-committee adopted as the unit of analysis, the genetic test service - a package of three elements: test technology, target population, and clinical condition. Each of these elements must be specified and must be taken together for the evaluation and coverage decision to be meaningful.

\section{Multiple Criteria}

The evaluation of predictive genetic tests must take many criteria into consideration, including:

- technical accuracy (analytical validity),

- clinical effectiveness (clinical validity),

- usefulness to tested individuals (clinical utility),

- adverse and additional effects, and

- expansion potential and cost (social utility).

Many of these criteria are not traditionally considered by the clinical evaluative sciences. Adequate assessment of these criteria may require the use of different forms of expertise and evidence, including quantitative studies, case studies and other types of qualitative research designs.

\section{Complex Decision Sequence}

The multiple criteria to be considered in the evaluation of predictive genetic tests are not amenable to a linear, hierarchical decision process where criterion $\mathrm{A}$ is met before criterion B is considered. While some decision criteria can be determined in a linear and hierarchical fashion (e.g. technical accuracy), many other criteria must be assessed as a whole.

\section{Jagged Cutoffs and Grey Zones}

Many criteria for assessing predictive genetic tests have poorly defined cutoffs or cutoffs may differ for different circumstances. There is limited evidence to support decision-making in particular cases. The recommended approach explicitly recognizes these jagged cutoffs and grey zones.

Jagged cutoffs are value-laden criteria for deciding what is "good enough" in any given category for a particular circumstance. Establishing the cutoffs requires answering questions such as "How worthwhile is worthwhile enough?" and "How effective is effective enough?" 
Grey zones are indeterminate evaluations. Although cutoffs have been established, it is not clear where a particular test should fall because of uncertainty or a lack of information. If a case falls in the grey zone, conditions on practice

(e.g. practice guidelines, regulation of practice, priority setting, pilot studies, phased introduction, etc.) are required to supplement "yes/no" coverage decisions. The "Grey Zones" concept is illustrated on page 54.

\section{Assessing Analytical and Clinical Validity of Genetic Predictive Technologies and Systematic Review Methods}

For a clinical diagnostic or predictive test, validity refers to the extent to which the test measures what it is intended to measure. The analytical validity of a genetic test refers to the ability of the test to accurately measure the gene/mutation or gene product of interest in the laboratory.

Accuracy is a function of the sensitivity of the test (its ability to detect the gene/mutation or product when it is present), and its specificity (the ability of a negative test to correctly identify an unaffected individual). These parameters define the performance of the test in the laboratory, and are routinely assessed as part of usual laboratory quality control programs. These programs also specify the conditions under which the test is performed, and the reliability of the estimates.

A more complex assessment of a test's performance is its clinical validity. Clinical validity of a predictive test is assessed according to its ability to correctly predict the clinical condition of interest based on the test result. Like analytical validity, the clinical validity of a test can also be defined in terms of the test's performance in correctly predicting a future clinical condition when the condition is destined to occur (sensitivity), and correctly predicting that the condition will not occur (specificity). The clinical accuracy of the test is a function of its sensitivity and specificity.

But, for genetic predictive tests, clinical sensitivity and specificity are rarely useful performance measures because of the low predictive power of these tests in many conditions.

For conditions where a positive test will almost always be associated with the development of a clinical condition (e.g. Huntington's Disease), sensitivity and specificity are useful concepts to describe clinical validity. But, where a test is predicting, for example, the risk of disease compared to a control group, or an absolute risk for the individual with a positive test compared to more people with a positive test likely not to develop the disease (low predictive power), sensitivity and specificity become less meaningful as performance measures of the test. In these cases, clinical validity is evaluated according to how close the claims for the predictive power of the test come to actually predicting the risk of the condition occurring. 
To assess the validity and precision of such clinical risk estimates, evaluators must examine the quality of the evidence upon which such claims are made, and the specific circumstances under which the data were generated. Criteria do exist to help evaluators determine the quality of the evidence upon which validity claims of this type are made $e^{43}$.

In examining the data that supports claims for analytical or clinical validity, evaluators should ensure that the studies used are not based on a biased sampling of the literature and that the populations from which the estimates are made are relevant to those who will be considered eligible to receive the service. Evaluators must understand the generalizability of a test's performance from one population to another. They should also undertake a comprehensive sampling of the relevant literature and be aware of publication bias that can provide optimistic assessments of the performance of genetic predictive tests.

\section{Elements of Decision-Making - Explaining the Evaluation Template}

The main decisions required are whether a particular genetic predictive test or service warrants approval for public financing and under what conditions. Two subdecisions are relevant:

- the appropriateness of making a predictive genetic testing service available in a particular case, and

- the specific genetic technology that should be used to detect the gene(s)/mutations in question.

The proposed evaluation template (see Appendix F) addresses seven main decision steps.

1. Does the intended purpose of this service justify continuing with the evaluation? The intended purpose should be stated clearly by individuals or groups who recommend the service before an evaluation is permitted to proceed. The purpose must apply to the fully-defined service comprising the technology, the target population and the clinical condition.

This first decision step asks the evaluators to determine whether the intended purpose justifies continuing with the evaluation. In effect, the evaluators are asked to make a value judgement about how compelling or non-compelling the intended purpose is from the perspective of the individual who will be tested, or society as a whole, irrespective of whether the purpose can be achieved technically.

\footnotetext{
${ }^{43}$ See Background paper 7.2 of full Evaluation Subcommittee Report
} 
2. Does the performance of the test in the laboratory justify further evaluation?

The analytical validity establishes whether the test measures or detects what it is intended to measure, and includes consideration of the reliability of the measurement of the test. Evaluators will want to assess the adequacy of available evidence for validity and reliability. This criterion is measured by the laboratory performance of the test as expressed through sensitivity, specificity and accuracy and is part of usual laboratory quality control processes.

\section{Does the clinical performance of the test justify further evaluation?}

Clinical validity ascertains:

- how accurately the test predicts the probability/occurrence of a future clinical state for a specified circumstance,

- reliability of the test. Technically, this is assessed differently but is related to validity, and

- the adequacy of available evidence upon which the clinical test performance data are based.

\section{Considering alternatives to the proposed service.}

The availability of alternatives determines how the proposed test compares with other resources for the same or similar predictive purposes. Evaluators should assess whether the proposed test will complement, replace or be replaced by alternatives and what additional information the proposed test provides.

Often, the proper evaluation of a particular test or service requires that it be evaluated in the context of a cluster of other complementary tests, frequently according to a prescribed sequence. Evaluators will need to determine where in the sequence of tests the one being evaluated belongs to achieve optimal effectiveness and efficiency.

\section{Expected outcomes of service use.}

This step examines what clinicians and individuals can do with the test results. For example, will the test result alter the clinical (medical, psychosocial) management of the tested individual? How will the test result prove useful to tested individuals for personal or family management?

Evaluators are asked to determine any potentially negative outcomes, such as for clinical management or labelling effects for tested individuals and family members. Labelling effects refer to unanticipated health consequences that can be triggered when otherwise healthy people are given a diagnosis of disease, irrespective of whether the disease itself causes symptoms. There might also be unanticipated or secondary positive outcomes, such as reduced utilization of health services for those with a negative test that is confirmed not to be associated with increased susceptibility to disease.

Relevant information will come primarily from clinical trials and other studies of effectiveness. 
6. Are the known and potential additional effects of the proposed service acceptable? Additional effects extend beyond expected or intended outcomes for the tested individual to other individuals, including the family and the community. Labelling effects and stigmatization of the individual or family members might also apply here.

Clinical, personal, social and cultural effects need to be determined. Social effects may be described as legal, ethical, and economic. Once additional effects of interest are identified, evaluative research (i.e. studies of effectiveness) can offer information about the magnitude and causes of these effects.

\section{Are the known and potential costs of providing the proposed service acceptable?} Data on the economic implications of predictive genetic tests are hard to develop and are often not readily available. Discussion Document 7.3 listed in Appendix E outlines the principles for conducting cost effectiveness evaluations of emerging predictive genetic tests.

Often economic evaluations are restricted to the direct costs of the test or service. Direct costs refer to the immediate funding required to provide the service and include unit price and projected service volumes. These reflect the test algorithm used, human resource, operational and capital costs ${ }^{44}$.

Using only direct costs can give a false impression of the true economic consequences of introducing a test or service. Such evaluations should include an estimation of indirect costs. For example, a test or service that has high acquisition or infrastructure costs may offset other higher costs later on, if disease or intensive investigations can be avoided because of the test.

Indirect costs can also include such things as lost wages resulting from a test service or the disease for which it predicts, which can then affect taxation revenues and reduce productivity. For example, labelling effects have been shown to lead to increased absenteeism from work where people were falsely diagnosed (i.e. labelled) with hypertension.

Ultimately, both unit cost and demand affect the cost of providing a genetic service. The demand depends upon the prevalence of the associated disease and the likely population of candidates who will use the service.

Expansion potential is the likelihood that the genetic service may, in time, become redefined in the course of clinical practice or product marketing to include broader populations, clinical contexts or indications. This will be determined not only by the prevalence of associated diseases, but also by popular beliefs about the relevance of information about risk status, and the availability of product marketing. Expansion potential could be initiated immediately, or over a period of time. The potential economic consequences of an expanded service should be considered ${ }^{45}$.

\footnotetext{
${ }^{44}$ See Discussion Document 7.3

${ }^{45}$ See But What Will They Really Cost? Economic Considerations for The Public Funding of Emerging Genetic Tests, Decision document 7.3 of the Sub-committee Report.
} 
Further decision steps occur within each of these seven steps. The decision to continue with the evaluation may be made with certainty, or it may be uncertain lying within a grey zone (see figure 1). In either case, the final decision about whether or not to recommend a potential predictive genetic service for provincial coverage will await the results from each step of the evaluation.

Where the decision falls in a grey zone, there are likely to be conditions attached, such as the requirement for more research, limited introduction, or the need for clinical or ethical protocols to guard against certain adverse or additional effects.

Evaluators and policy-makers will have to develop the cutoffs for each decision as they proceed and this task should be tackled explicitly.

Because the use of innovative decision frameworks improves as decision-makers learn about their utility through experience, the Evaluation Sub-Committee presents the Evaluation Template as a starting point. 


\section{Figure 1}

\section{Grey Areas in the Evaluation and Coverage of Genetic Testing Services The General Model ${ }^{46}$}

\begin{tabular}{|c|c|c|c|c|}
\hline \multirow{2}{*}{$\frac{\text { Evaluation criteria }}{\text { Intended purpose }}$} & \multicolumn{3}{|c|}{ Assessment of this test } & \multirow{2}{*}{$\begin{array}{l}\text { Conditions on } \\
\text { funding coverage } \\
\text { (if in grey cells) } \\
\begin{array}{l}\text { Clarify before further } \\
\text { evaluation. }\end{array}\end{array}$} \\
\hline & Worthwhile & Not worthwhile & Unclear & \\
\hline Effectiveness & Effective & Ineffective & Unknown & Research protocols. \\
\hline Additional effects & Acceptable & Unacceptable & $\begin{array}{l}\text { Worrisome } \\
\text { or unknown }\end{array}$ & $\begin{array}{l}\text { Interventions, additional } \\
\text { effects. } \\
\text { Ethical protocols? } \\
\text { Regulation? } \\
\text { Research protocols? } \\
\text { Clinical practice protocols? }\end{array}$ \\
\hline Unit price & Low & High & & $\begin{array}{l}\text { Priority setting under } \\
\text { defined envelope. }\end{array}$ \\
\hline Expected demand & Low & High & & $\begin{array}{l}\text { Priority setting under } \\
\text { defined envelope. }\end{array}$ \\
\hline Expansion potential & Low & High & & $\begin{array}{l}\text { Clinical practice protocols. } \\
\text { Priority setting under } \\
\text { defined envelope. } \\
\text { Periodic re-evaluation. }\end{array}$ \\
\hline
\end{tabular}

\section{Examples of Analytical Questions for Defining the Cutoffs for Evaluative Criteria}

What constitutes a worthwhile purpose for a new health service?

- Are alleviation of anxiety, reduction of uncertainty, clarification of paternity, information for family or life planning, worthwhile goals in themselves? Should they be valued strictly in terms of their longevity or quality of life effects?

- Is generating intermediate clinical or biological information worthwhile in itself, or must testing results play a definitive role in diagnosis or treatment?

- If reduction of uncertainty is a worthwhile goal, how much must a test reduce uncertainty to make it worthwhile?

\footnotetext{
${ }^{46}$ See Section 5.0 of the Evaluation Committee Report
} 
- If life saving is a worthwhile goal, how much life should be gained for a test to be worthwhile?

- If quality of life improvement is a worthwhile goal, how much improvement would be worthwhile, and according to what scale?

What would constitute an effective health service?

- What would constitute scientifically adequate evidence of effectiveness?

- How should effects on others be measured and assessed?

- How should harms offset benefits in the calculation of effectiveness? Are there any harms that would trump all benefits, or is the judgement entirely a question of ratios and degrees (e.g. very harmful tests may be tolerated to achieve significant gains in life)?

Which additional effects would be considered acceptable?

- Do genetic tests as a class present harms to societies or to groups within society?

- Might certain genetic tests present any categorically unacceptable harms to societies or communities?

- If the benefits and burdens introduced by the service are not distributed equally through a population, what kinds of distributions would be inequitable?

What is an acceptable level of costs for providing a new service?

- Considering the interactions between unit price, demand, and the potential for expanded demand after coverage, how expensive is too expensive for providing any one service?

What is an acceptable level of cost effectiveness for a new service?

- How many units of effectiveness (e.g. life years gained) per dollar of cost are required to qualify any new service as worth the investment of funds?

- What interests should determine the parameters of cost effectiveness estimation? For example: time period (long-term, short-term), perspective (governmental, societal), and outcomes (health, well-being). 


\section{Defining the Characteristics of Predictive Genetic Tests: A Framework for Evaluation Decision-Making}

The sub-committee developed a framework for analysing the characteristics of predictive genetic tests that are relevant to the evaluation process. The approach compares predictive genetic tests to two related health technologies (diagnostic genetic tests and non-genetic predictive tests) across four dimensions, and also distinguishes three types of predictive genetic tests. The analysis of predictive genetic tests demonstrates three things:

1. Predictive genetic tests share many characteristics with diagnostic genetic tests. For example, both have characteristics with respect to the information they provide that distinguishes them from other medical tests. Molecular genetic tests permit more information to be gleaned from more kinds of biological samples, and much of this information has relevance for individuals other than the one tested, including future generations.

There are other characteristics shared by predictive and diagnostic genetic tests that are less obvious. In particular, there is the high potential for the commercially driven expansion of these health services. This can create challenges for policymakers with respect to timely and efficient technology assessment, and the need for an effective gatekeeping function.

Predictive genetic tests also share important characteristics with other medical tests, specifically non-genetic predictive, or screening tests. Both types of predictive tests have the potential to create "protodiseases" - to generate disease states in otherwise healthy but at risk individuals.

The recognition of this parallel should encourage policy-makers to draw on the accumulated knowledge of the merits and demerits of disease screening programs when developing new programs for predictive genetic tests. Many of the evaluation criteria that are relevant to disease screening are also relevant to predictive genetic testing

\section{Despite the existence of shared characteristics, the analysis demonstrates that} predictive genetic tests have a unique characteristic of "disease malleability." This refers to the complex relationship between diseases and genetic status. It can be difficult to attribute certain disease states to single mutations and mutations may manifest to produce more than a single state disease. Traditional ways of organizing and evaluating disease screening or diagnostic testing do not accommodate this unique situation. 


\section{A Comparison of Genetic and Predictive Test Technologies}

\begin{tabular}{|c|c|c|c|c|}
\hline & & $\begin{array}{l}\text { Predictive } \\
\text { Genetic Tests }\end{array}$ & $\begin{array}{l}\text { Diagnostic } \\
\text { Genetic Tests }\end{array}$ & $\begin{array}{l}\text { Non-Genetic } \\
\text { Predictive Tests }\end{array}$ \\
\hline Technical Scope & $\begin{array}{l}\text { Test Capacity } \\
\text { Significance } \\
\text { for biological } \\
\text { family members }\end{array}$ & $\begin{array}{l}\text { - Enhanced } \\
\text { - High } \\
\text { - Moderate }\end{array}$ & $\begin{array}{l}\text { - Enhanced } \\
\text { - High }\end{array}$ & $\begin{array}{l}\text { - Standard } \\
\text { - Low }\end{array}$ \\
\hline Clinical Impact & Utility & $\begin{array}{l}\text { - Medical } \\
\text { - Information }\end{array}$ & - Medical & - Medical \\
\hline Additional Effects & $\begin{array}{l}\text { Creating } \\
\text { proto-disease } \\
\text { (identifying the } \\
\text { potentially-ill } \\
\text { well }\end{array}$ & - Yes & - No & - Yes \\
\hline Expansion Potential & $\begin{array}{l}\text { Opportunity for } \\
\text { commercial } \\
\text { exploitation }\end{array}$ & - High & - High & - High \\
\hline Disease Malleability & $\begin{array}{l}\text { Clarity and } \\
\text { consistency of } \\
\text { disease identity }\end{array}$ & - High & - High & - Low \\
\hline
\end{tabular}

3. Predictive genetic tests can be distinguished by three types - presymptomatic, familial susceptibility, and risk-factor. These analytic distinctions have policy relevance for assessing the utility of testing programs (see Table below). 
Three Provisional Types of Predictive Genetic Tests ${ }^{47}$

\begin{tabular}{|c|c|c|c|}
\hline & $\begin{array}{l}\text { Presymptomatic } \\
\text { Predictive Genetic Tests }\end{array}$ & $\begin{array}{l}\text { Familial Susceptibility } \\
\text { Predictive Genetic Tests }\end{array}$ & $\begin{array}{l}\text { Non-Genetic } \\
\text { Predictive Tests }\end{array}$ \\
\hline Disease & $\begin{array}{l}\text { - Rare genetic } \\
\text { diseases }\end{array}$ & $\begin{array}{l}\text { - Less rare diseases } \\
\text { (often hereditary forms } \\
\text { of common conditions) }\end{array}$ & $\begin{array}{l}\text { - Common or relatively } \\
\text { common conditions }\end{array}$ \\
\hline Genetic Involvement & $\begin{array}{l}\text { - Single gene disease } \\
\text { - } 100 \% \text { penetrance } \\
\text { - Clear familial } \\
\text { transmission }\end{array}$ & $\begin{array}{l}\text { - Single gene has } \\
\text { major impact on disease } \\
\text { - Significant penetrance } \\
\text { - Familial transmission, } \\
\text { but less clear because } \\
\text { of reduced penetrance }\end{array}$ & $\begin{array}{l}\text { - Complex genetic } \\
\text { causation } \\
\text { - Low penetrance } \\
\text { - Non-obvious patterns } \\
\text { of familial transmission }\end{array}$ \\
\hline Predictive Power & $\begin{array}{l}\text { Virtually all people } \\
\text { testing positive will } \\
\text { develop the disease } \\
\text { if they live long enough }\end{array}$ & $\begin{array}{l}\text { Many people testing } \\
\text { positive will never } \\
\text { develop the disease }\end{array}$ & $\begin{array}{l}\text { Most people testing } \\
\text { positive will never } \\
\text { develop the disease }\end{array}$ \\
\hline Client Populations & $\begin{array}{l}\text { - Very small client } \\
\text { population } \\
\text { - Family history provides } \\
\text { a clear indication of } \\
\text { the client population } \\
\text { - Pre-screening to identify } \\
\text { appropriate candidates }\end{array}$ & $\begin{array}{l}\text { - Small client population } \\
\text { major impact on disease } \\
\text { - Family history provides } \\
\text { a reasonable indication } \\
\text { of the client population } \\
\text { - Pre-screening needed } \\
\text { to identify candidates }\end{array}$ & $\begin{array}{l}\text { - Potentially relevant to } \\
\text { the population-at-large, } \\
\text { or major sub-populations } \\
\text { - Family history not } \\
\text { decisive in identifying } \\
\text { candidates }\end{array}$ \\
\hline Practitioner & - Genetics specialists & $\begin{array}{l}\text { - Disease specialists } \\
\text { - Primary care }\end{array}$ & - Disease specialists \\
\hline Utility of Testing & $\begin{array}{l}\text { - Informational utility } \\
\text { alone or combined } \\
\text { with medical utility }\end{array}$ & $\begin{array}{l}\text { - Medical utility alone } \\
\text { or combined with } \\
\text { informational utility }\end{array}$ & - Medical utility alone \\
\hline
\end{tabular}

\section{Recommendations}

The Evaluation Template and accompanying Toolkit developed by the subcommittee be adopted as the basis for the evaluation of new predictive genetic services in Ontario.

\footnotetext{
${ }^{47}$ From: Miller F and Giacomini M. Defining the characteristics of predictive genetic tests: A framework for evaluation decision-making, Table 2. Evaluation Committee background paper 7.5. Submitted for publication
} 


\section{Report Of The Laboratory Sub-Committee}

Objective

- To examine all issues on laboratory predictive genetic testing. This included:

- best practices,

- the availability of trained personnel,

- the number and type of training programs for laboratory personnel, and

v the ability to implement an effective quality assurance program.

\section{Findings}

Three systemic laboratory issues are critical in designing a responsible lab system to deal with genetic issues:

1. Genetics testing must be integrated into the existing lab medicine system as much as possible. Every effort should be made to integrate genetic service into the Ontario health care system and not to isolate genetic lab testing.

2. The use of similar technology in labs means that many tests can be used as either a unique diagnostic test or to provide family information. Any system of accountability must not interfere with providing a well functioning lab service that also properly services the need of acute medical care. Genetic testing must be integrated into existing general test review processes.

3. A systemic shortage of resources in laboratory services in Ontario must be addressed as genetic-based technology expands in laboratories.

\section{The Need for Quality Assurance and Confidentiality}

Ontario's health care system is built on the confidential relationship between the physician as the main provider of health care services and the patient as the consumer of health care services. Tests and services requested by the physician are an integral part of that relationship.

To protect the integrity of the relationship, ensure patient confidentiality, and minimize inaccurate test results, the three components of a genetic test - pre-test preparation, laboratory analysis and interpretation and support consultation of test results - must be integrated into clinical practice.

During the pre-test phase, physicians must have access to accurate information to inform the patient about the test, the disease or condition under consideration, and the benefits and risks associated with a genetic test. To maximize the value of the informed consent process, the physician must have access to readily available and reliable information about the genetic test. 
The laboratory analysis must be valid, accurate, efficient and ethical. Neither the patient nor the health care system can afford the emotional distress or financial expense of inaccurate test results. At all times, care must be taken to protect patient confidentiality.

The laboratory has become a useful resource for family physicians and other health care providers by providing analysis and interpretation of test results and support about referral for clinical management assistance and communication with other family members.

\section{Quality Assurance}

Standards for lab services are established through professional societies and regulated through the College of Physicians and Surgeons of Ontario and the College of Medical Laboratory Technologists. In Ontario, the Quality Management Program in Laboratory Services (QMPLS) monitors compliance with those standards.

All genetic tests performed in Ontario must be subject to a quality assurance program that meets professional, technical and ethical standards. Standards for genetic testing should include an informed consent process, full disclosure of available options for the patient and the option of follow-up consultation. As with all laboratory testing, an ongoing mechanism of consultation between the laboratory and the health care provider who requested the tests should be established.

\section{New Technologies}

Laboratory testing in genetics is changing quickly. With the rapid evolution in our knowledge of the genome and advances in "molecular" techniques, techniques in genetics have swiftly expanded. Advances in the automation of several molecular genetic techniques, such as sequencing, polymerase-chain reaction, and nucleic acid extraction continue to emerge.

Perhaps the most significant advance in molecular genetic testing will be achieved through the use of microchip arrays of molecular probes. This technology will allow for the fast, high volume screening of mutations within large genes, as well as the simultaneous genetic typing of individuals for mutations in many different genes.

It is likely that tests for multiple diseases may be done on a single specimen sample, such as microarray testing for numerous genes or gene products, or multiple tests on a newborn screening specimen as part of provincial screening initiatives. Multiple tests on single samples add additional complexity to the informed consent process and increase the difficulties in producing clear and understandable lab reports.

No single methodology for performing genetic testing will be sufficient. To date, the numbers of samples and diseases being analyzed in labs have been limited by methodology and staff resources. 
Despite its advances, molecular genetic testing is still in its infancy and will require new types of equipment not present in today's medical laboratories. The system should also be prepared to handle a vastly increased workload in molecular genetics. This will require investment in the new technologies to deal with the volume and maintain the quality of genetic services.

\section{Systemic Issues}

A number of systemic issues impact on the operation of laboratory medicine in Ontario including:

- shortages of trained personnel,

- strong commercialization pressures,

- the prospect of pharmacogenetic lab testing to individualize drug therapy to patients, and

- the use of laboratories in jurisdictions outside the province.

It is critical that the new genomic technologies and these systemic laboratory issues be addressed as part of the revitalizing and reorganizing of laboratory services in Ontario.

\section{Staff Resources}

There is a shortage of trained personnel at all levels in the field of genetics including:

- laboratory physicians,

- cytogeneticists,

- molecular and biochemical geneticists,

- technologists, and

- technicians.

While the lack of trained health personnel is not unique to genetics, the anticipated growth in demand for genetic services compounds the problem.

\section{Evaluation of Future Therapies}

In addition to laboratory-based diagnosis, there is the prospect of pharmacogenetic drugs, protein/enzyme replacement therapy and gene therapy.

All of these potential options will draw new, as yet undefined, lab technology and services into health care. Each will require laboratory professionals to participate in some components of the therapy. For example, the identification of the location and type of mutations in a gene may dictate the type and efficacy of a particular gene therapy that can be used in an individual case.

Measuring the effect of the new drugs and therapies used to treat genetic disease will likely involve examining patient outcomes in relation to the results of the genetic tests. The impact of these new treatment options needs to be reviewed before they are introduced. With the potential development of these new services, coupling of lab testing with clinical outcomes becomes a pressing need. 


\section{Out-of-Province Testing}

In some cases, the rarity of some genetic disorders requires that specimen samples be sent out of the province. Meanwhile other jurisdictions will send specimens for other rare tests to Ontario.

Consideration should be given to the development of a policy that permits the use of laboratories in other jurisdictions. Since laboratories in Ontario are beginning to function as part of a global system, they should comply with the rules and regulations of other jurisdictions. The Province's Quality Management Program in Laboratory Services participates directly in international development of these standards.

Any testing done by an out-of-province laboratory must meet the professional, technical and ethical standards established and monitored by Ontario's QMP-LS.

\section{Stakeholders}

Genetic testing has been performed in Ontario for many years in various settings, including commercial laboratories, hospital laboratories, and physicians' private laboratories. Funded predictive genetic testing has only been carried out by hospitalbased genetics laboratories because of concerns about the need for a coordinated system for Ontario residents.

The Sub-Committee's recommendation of standards for genetic tests begins to formally address some of the concerns about the lack of a coordinated system of genetic testing involving public and private facilities.

\section{Recommendations}

Since the Laboratory Sub-Committee produced its final report, changes continue to occur in the test review process currently being proposed for Ontario. This transition has allowed the sub-committee to modify its original recommendations to accommodate this apparent change in the Test Review Process. The original report and the full recommendations should be read to fully review the issues in laboratory genetics.

In light of these apparent changes, the Laboratory Sub-Committee offers modified and abridged recommendations in the following areas:

- Genetic testing should be coordinated as a program of medical services that must address:

- the pre-test component,

- the laboratory analysis component, and

- the clinical outcome of the service.

- A prerequisite for an effective genetic testing program in the province is an effective education process for all health care professionals who may order these tests. 
- All laboratories providing genetic test results need standard provincial genetic testing requisition and agreement on nomenclature and report format.

- External quality assessment must monitor all genetic testing.

- Laboratories providing genetic test services must be linked in an effective way to share information about rules and regulations for patient confidentiality.

- The current process for test introduction is in transition and needs to be harmonized to provide an effective system for timely review of tests. Genetic testing must be integrated into the general test review process, and not dealt with separately and in isolation. This test review process should be well publicized and open to review. Reasons for the rejection of a new genetic test and the implications associated with this rejection must be transparent.

- All genetic tests linked to any identified patient must be processed according to standard published provincial regulations.

- All laboratory professionals involved in patient testing should be subject to regulatory control.

- The Royal College of Physicians and Surgeons should review the potential for incorporating formal training in human genetics into specialty training programs in laboratory medicine. The training programs for $\mathrm{MD} / \mathrm{PhD}$ professionals and laboratory technologists should be coordinated to provide uniform and consistent training that facilitates communication between laboratory personnel and the performance of laboratory functions.

- There is need for support and funding for training site infrastructure. The appropriate accredited training programs should be encouraged to develop a coordinated training program for laboratory genetics staff in Ontario.

- All personnel directly involved in genetic testing should be members of regulated health professions.

- The Advisory Committee should establish a mechanism to monitor the implementation of its report. 


\section{Report Of The Clinical Sub-Committee}

\section{Objective}

- To develop a clinical framework for the referral, testing, counselling, treatment, and follow-up of patients with genetic concerns, particularly in regard to new predictive genetic tests.

\section{Findings}

As knowledge of the genetics of common multifactorial disorders (e.g. heart disease) increases, genetic issues will move further into the mainstream of medical care. All health care providers will need the knowledge, framework and supports to deal with these issues.

The Clinical Sub-Committee's report provides guidelines for how this can be done. It also highlights issues of concern, where input from experts in education, law, ethics, and psychosocial fields is essential.

Advances in genetic knowledge and technology are increasing the information that physicians can provide to patients. The technology allows for the diagnosis of some genetic disorders before the patient develops overt symptoms (predictive genetic tests). It also allows for the identification of genetic mutations or variations that may be risk factors for disease. These "susceptibility genes" can be added to other known risk factors (e.g. diet, environment) when assessing and treating patients.

Predictive genetic tests deal with the chance that a disorder will develop in the future. In many cases, the information derived from the test is useful to help prevent or delay the onset of disease. It also facilitates the transition from presymptomatic to affected status, even if there is no preventive measure possible. The information is useful to patients and their families in life planning and reproductive choices.

Because of the complexity and ambiguity of the results of genetic testing, and its tendency to heighten psychosocial problems, providers of genetic information will require new ways of communicating potential risk to patients. Education for health care providers and for the public is essential to help them understand the purpose and limitations of the tests, and how the results can best be used to improve quality of life.

In the clinical context, legal and ethical issues constantly arise. These include informed consent, patient confidentiality, testing of minors and incapable persons, as well as issues involving reproductive choices. For example, if a patient refuses to share genetic test results, should the family physician breach the duty of confidentiality to inform family members that they are at risk of developing a particular disorder? This could damage a patient's trust in his or her physician, but to the extent that the disease is preventable or treatable, it could have impact on the health of family members. 
These issues are described in detail in the Legal and Ethics Sub-Committee's report.

In Ontario, guidelines and education will assist in the proper utilization of genetic tests and services. The availability of private commercial genetic testing in other countries or jurisdictions is a concern. The downstream costs of privately purchased, inappropriate genetic tests are difficult to assess, but would have an impact on our health care system. Educating the public about genetics would help with this issue.

\section{Key Steps for Genetic Counselling and Testing}

The components of genetic counselling and testing are the same whether provided by a family physician, geneticist, or other specialist. Assessing the patient by history and physical examination is part of standard medical care. Part of the assessment of a genetics patient involves an analysis of the patient's risk of developing a genetic disease, and whether genetic testing may be of value.

The process of genetic testing involves informed choice and consent. The physician or genetic counsellor will review basic genetic principles, as well as information about the disorder, details regarding the purpose and limitations of the test, and the advantages and disadvantages of testing. The issues of possible discrimination in employment and insurance, as well as the chance of uncovering information about relatives need to be discussed explicitly. The alternatives to testing should also be presented in detail.

The decision for testing remains with the patient. The patient may require time for reflection and to review all the information.

If testing is undertaken, the physician should discuss when results will be available, how they will be conveyed, and to whom. Issues of confidentiality, and the possible need to inform relatives at risk should be discussed before the test. If testing is declined, there will still be the need for surveillance and follow-up of the at-risk individual.

Psychosocial assessment is an important part of the initial counselling for people at risk for genetic conditions. Patients at risk of crisis need to be identified, and referral to the appropriate support person made. Physicians also need to be aware of the possible development of psychological stress at any time following genetic testing.

In the future, genetic testing for multiple susceptibility genes for common disorders will become available. Genetic tests of this kind may be part of a general risk assessment for any patient, regardless of family history. It may be unreasonable and inappropriate to expect the same degree of detailed counselling for each part of such an assessment. The components of genetic counselling in these circumstances will need to be worked out by health care providers and experts in other fields. 


\section{A Multi-Disciplinary Response}

Genetic services are often provided in a multi-disciplinary environment to address multiple factors such as:

- the lack of certainty in risk assessment and test results,

- the variety of treatment options, and

- the complexity of disease management.

This multi-disciplinary response may involve numerous professionals including geneticists, genetic counsellors, laboratory physicians and technologists, psychologists, social workers and other allied health professionals.

Gene testing varies in complexity, psychosocial impact, and treatment options. The need for pre- and post-test counselling and determining who should provide advice varies with each genetic test and each patient. In some cases, the entire genetic service will be offered in the setting of primary health care. In other circumstances, the patient will benefit from referral to a specialized centre.

Factors that influence where and how a genetic service is offered are:

- gene prevalence,

- complexity of management,

- certainty of risk assessment and test results, and

- the urgency of the case.

\section{Human Resource Shortage}

There is a shortage of human resources in the area of genetics in particular, and in medicine in general with:

- not enough trained laboratory technologists to perform necessary tests in a timely manner;

- not enough geneticists and genetic counsellors for the current clinical load,

- not enough psychologists and social workers with expertise in the special issues relating to genetics and the ability to provide the necessary support for patients; and

- difficulty in accessing the necessary supports for follow-up of at-risk patients (e.g. colonoscopy, mammogram) in a timely manner.

A variety of institutions provide training and regulation of personnel in genetics. Medical genetics is a recognized specialty of the Royal College of Physicians and Surgeons of Canada. The Canadian College of Medical Genetics is involved in the accreditation of training centres and the certification of laboratory scientists and some physicians. Laboratory technologists receive training in cytogenetics and molecular techniques at the Michener Institute.

Physicians, nurses, and technologists are regulated by their colleges. Laboratory scientists and genetic counsellors are not members of a regulated health profession but work in a regulated environment. 
Recommendations

The Clinical Sub-Committee's recommendations are based on the assumption that the genetic test or service offered has clinical validity and utility.

\section{Access to Care}

All patients are entitled to genetic counselling if they have concerns about their genetic risks, even if they do not meet criteria for genetic testing. The counselling will help to educate patients about their risks, with the aim of decreasing anxiety, and avoiding the misuse of inappropriate genetic testing.

People at increased risk for developing a disease may be offered additional surveillance tests, or may need support to effect a lifestyle change. The expected downstream impact of new genetic services should be reviewed at the outset. The necessary supports and downstream services must be identified and in place before a genetic test is made available.

Equivalent services should be available across the province. Innovative ways of delivering services may be needed, such as telemedicine and web-based resources.

\section{Quality Assurance and Outcome Evaluation}

There should be a quality assurance system for all aspects of genetic services, not just for laboratories. A provincial organization such as QMPLS could provide the quality assurance program.

Outcome analysis should be part of the genetic service. The impact of the service on patients, their families, and the community, in terms of disease prevented, quality of life, and overall acceptance of the program should be evaluated.

All personnel involved in genetics should become members of a regulated health profession even though this is a lengthy process.

\section{Categories of Disease/Service}

A categorization of disease should be used to assist in planning for the implementation of new genetic services. This would help determine resource needs and funding requirements. The categories are based on who will provide the pre- and post-test counselling, and test interpretation. It is not intended that any family physician or specialist be excluded or restricted from performing any genetic service.

Category 1: Disorders for which the majority of counselling and testing will be carried out by the primary care physician or other specialists. These would include common disorders for which there is straightforward testing (e.g. factor $\mathrm{V}$ leiden). If the testing is straightforward for a rare disorder, the primary care physician may choose to provide the counselling, or make a referral to the genetics centre. 
Category 2: Disorders for which selection of patients and pre-test counselling are straightforward but interpretation of results is complex (e.g. cystic fibrosis). The primary care physician or specialist would identify the risk, provide the pretest counselling and initiate testing. The genetic centre would provide interpretation of the results and post-test counselling (e.g.cystic fibrosis).

Category 3: Rare disorders or conditions of such complexity that the best care is provided through a multi-disciplinary program offered by a genetic centre with appropriate referrals for prevention and/or surveillance. The primary care physician or specialist would identify the possible genetic risk (e.g. breast cancer, Huntington Disease).

\section{Additional Recommendations}

The Clinical Sub-Committee also offered recommendations in the following areas:

Development of Guidelines for Facilitating:

- mechanisms for referrals

- the flow of information to the extended family

- access to testing

- access to additional services such as psychosocial support and counselling

- management of people changing from at risk to affected status.

Guidelines for Service Standards and Requirements:

- referral waiting time

- personnel at a genetics clinic/centre

- what should occur at a genetic appointment

- aspects of the laboratory test

- communications with patient and with other professionals

- accessibility and time to contact

- storage of genetic records

- outcome measures for predictive testing.

Pre- and Post-Test/Counselling and Patient Follow-Up.

Regulatory Requirements for:

- genetic counsellors

- out-of-province laboratories

- laboratories/clinics

- release of genetic information. 


\section{Report Of The Psychosocial Sub-Committee}

\section{Objectives}

- To identify the needs for psychosocial counselling in an integrated genetic service.

- To develop strategies for addressing the psychosocial implications of genetic testing on patients and family members.

- To develop recommendations for screening people at risk who require psychosocial counselling including managing people changing from at risk to affected status.

\section{Findings}

\section{Psychosocial Impact on the Patient and Family}

The diagnosis of any disease can cause anxiety. Knowledge resulting from new and evolving genetic information has the potential to provide many benefits, but it can also increase emotional distress, increase misperceptions of illness, lead to stigmatization and other negative health outcomes.

Genetic knowledge does not translate directly into desired health behaviour changes. Psychosocial, emotional, and family factors play an important role in the understanding of genetic information, health behaviour change, under or over utilization of the health care system, and quality of life.

The diagnosis of genetic disease has a number of unique risks because of its complexity, ambiguity and tendency to heighten the psychosocial problems associated with effective disease treatment, family relationships and adjustments to quality of life.

While the results of genetic tests can be explained rationally, genetic information deals with probabilities and doubts that can evoke irrational thoughts, images and expectations for patients. It forces people to face their mortality, as well as raising concerns about their children's future. These concerns can be unsettling, so careful attention needs be paid to the psychosocial impact of the technology on the patient.

Simply being informed about a genetic disease does not mean that individuals will seek treatment or adhere to a treatment regime. People's perceptions about the new technology can influence their attitude about seeking a physician's help or complying with their advice. Efforts to persuade someone to accept a prevention, surveillance or treatment strategy may go unheeded if that person is not motivated to change behaviour.

In many cases, no treatment options will be available. Patients may perceive that if there is no cure, the disease is uncontrollable and threatening. This may result in a sense of fatalism undermining their motivation to address the issue.

The way people deal with genetic information is influenced by a variety of psychosocial factors. First is a person's perception of the risk. People who feel particularly vulnerable to disease tend to overestimate the risk. For example, women who have had a relative diagnosed with breast cancer and who may not be at high risk for developing breast cancer but feel that they are at very high risk. 
They may not be reassured by a negative test result and may adopt a denial coping strategy that keeps them from either seeking treatment or complying with a treatment regime. These women require educational counselling services that include methods to address their worry about their cancer risk and gain optimal understanding.

Studies have shown that while perceived risk and anxiety play an important role in an individual's willingness to undergo testing, excessive anxiety can affect a person's:

- willingness to be screened,

- adherence to surveillance programs,

- adoption of lifestyle changes, and

- willingness to seek additional information or services to alleviate concerns about risk.

Other factors that impact on patients' reactions include:

- pre-morbid psychological conditions,

- perception of the illness as having few or no treatments,

- nature of the disease and associated stigma,

- loss in the family,

- recent diagnosis in the family,

- coping style,

- perceived social support,

- age,

- gender,

- socio-economic status,

- culture, and

- pre-test expectations.

\section{Impact on Decision-Making Ability}

The knowledge of genetic risk can have a lasting and lifelong effect on the ability of individuals and families to make future health decisions. Many people who test positive for genetic diseases experience a reduced sense of control and feelings of isolation, particularly when confronted by other unanticipated decisions after receiving their test result.

Any test result that brings forward serious and difficult decisions, can pose a psychological burden that may limit a person's ability to make decisions about:

- prevention and treatment options,

- notifying extended family members and offspring, and

- relationship issues involving marriage and children. 
For example, women who test positive to the BRCA1/2 mutation, which is associated with a higher risk of ovarian as well as breast cancer, are confronted with the grim decision of surgery to remove their breasts or ovaries. They may also struggle with the dilemma of whether or not to have children "knowing" they may pass their genetic mutation on to them. It may also interfere with family relationships and even radically change their perception and attitude toward themselves and life generally.

\section{Familial Threat}

Another unique aspect of genetic diseases is that they pose a threat to both the individual and family members. This can arouse not only fears about developing the disease, but feelings of anger towards those who transmitted the disease, as well as guilt or worry about potentially transmitting the genes to children ${ }^{4849}$.

Such emotional reactions have the potential to influence a person's well-being and relationships with other family members. These dynamics could also interfere with the process of notifying family members who may be at risk of the disease and require treatment.

While genetic counsellors may be equipped to deal with individuals who have typical concerns, some individuals and families will require more specialized help to deal with:

- difficult decisions,

- family dynamic challenges, or

- serious psychological concerns, such as guilt about transmitting a risk to offpsring.

Studies indicate that about $20-25 \%$ of people undergoing genetic testing experience anxiety or depression levels requiring additional psychological services. Identifying these individuals early in the process of genetic testing allows the genetics health care provider to plan ahead for potential difficulties in their adjustment at later stages.

Many individuals will not suffer from a psychiatric disorder, but will have a variety of thoughts, feelings and behaviours that need to be understood in the context of a person's history. These individuals are often described as the "worried well". They tend to experience better adjustment to a test result if they have the opportunity to have psychosocial counselling in conjunction with the genetic testing process.

In order to provide psychosocial counselling to individuals undergoing genetic testing, it will be important for providers to have skill and knowledge in identifying individuals who may be at psychological risk.

\footnotetext{
${ }^{48}$ Kash KM., \& Lerman C. (1998) Psychological, Social, and Ethical Issues in Gene Testing. PsychoOncology, Chapter 18, 196-207.

${ }^{49}$ Lerman C., Peshkin BN., Hughes C., \& Isaacs C. (1998) Family Disclosure in Genetic Testing for Cancer Susceptibility: Determinants and Consequences. Journal of Health Care Law E Policy, 1, 352-371.
} 
Although genetic testing creates anxiety and distress for some individuals, others perceive the benefits of testing. In general, individuals who perceive more benefits associated with genetic testing are more likely to want the test. The types of benefits vary among diseases but may include the ability to use risk information to make decisions on:

- career choices,

- plans for retirement,

- life insurance,

- relationships,

- treatment options, and

- lifestyle.

\section{Resource Implications}

The Psychosocial Sub-Committee conducted a survey on eight regions in Ontario to determine the level of psychosocial service in current genetic services.

The most consistent concerns about the psychosocial impact associated with genetic testing were that:

- genetic counsellors/geneticists believed they needed further education and skill in identifying those at psychological risk, and

- when psychosocial issues were identified, there was no, or limited, access to a mental health professional in their area.

This finding was reported both in rural and urban settings.

The committee identified the needs for psychosocial counselling in an integrated genetic service. Currently, there is great variability in integrating mental health personnel into genetic service teams. Often in developing new health services, the psychosocial component is considered separate to the service. Prior experience and the literature suggest that a bio-psychosocial model that integrates a psychosocial component as an integral part of the service will best serve to identify those at particular psychological risk, lead to the opportunity to address the psychosocial impact, and result in more optimal health outcomes.

Integrating a psychosocial component can potentially reduce health care costs. It is frequently unaddressed psychosocial concerns or worry that result in patterns of unnecessary or inappropriate use of health care treatments or surveillance measures to alleviate concern or worries. Studies indicate that by proactively addressing psychosocial issues early on in the testing process, the potential for harm and further psychological or behavioural difficulties can be decreased. 
Current general mental health services in Ontario are stretched beyond capacity. The development of any further medical service requiring psychosocial support will need to carefully consider resource implications. The unique features of genetic knowledge, its potential impact on the family, and the limited capacity for the current mental health resources to address the psychosocial needs of emerging populations undergoing genetic testing, suggest that careful planning will be required.

Given the current limitations on mental health resources in Ontario, innovative models of mental health care provision, such as the "Shared Care Model " $(3)^{50}$, as well as new funding paradigms may be needed to ensure that mental health personnel and resources will be available.

\section{Recommendations}

The Psychosocial Sub-Committee recommends:

- integration of psychosocial and emotional support services into genetics service;

- mandatory access throughout the province;

- ongoing quality assurance to ensure adequacy and access to psychosocial services;

- commitment of resources for psychosocial services;

- commitment to training and support of health care professionals;

- commitment of funds for psychosocial services.

${ }^{50}$ Kates, N. Craven, M., Bishop, J., Clinton, T., Kraftcheck, D., LeClair, K., Leverette, J., Nash, L., Turner, T (1997). Shared Mental Health Care in Canada, The Canadian Journal of Psychiatry ,42 (8). 


\section{Report Of The Education Sub-Committee}

\section{Objectives}

- To review educational methods currently available provincially, nationally and internationally.

- To develop recommended approaches to public, patient and provider education requirements.

\section{Findings}

Health care is changing rapidly as a result of new advances in our knowledge of genetics. The issue facing society and the health care professions is how to integrate new genetic information and testing into health care practice. As the public's knowledge and need for information regarding genetics and genetic testing will inevitably accelerate, it is essential to develop programs appropriate for a smooth and efficient integration of this field into the health care mainstream.

The introduction of predictive genetic technologies requires the public and health care providers to interact and communicate more effectively about:

- the purpose of testing,

- eligibility for testing,

- risk,

- the accuracy of tests,

- the meaning of test results,

- the psychosocial effects of testing,

- possible further interventions, and

- impact on family members.

Studies have shown that access to high quality, timely information:

- enhances people's knowledge and empowerment,

- facilitates their interaction with their health care providers and the health care system, and

- enables them to participate in decision-making at the level they desire ${ }^{51} 52$.

For informed decision-making, it is essential to identify the most effective strategies and resources to educate the public and health care providers in this rapidly developing area.

\footnotetext{
${ }^{51}$ Ashbury FD, Cameron C. Principles and Lessons Learned to Develop and Disseminate Genetic Testing Educational Information to the Public, Patients and Primary Care Providers for Late Onset Diseases - A Review of the Literature. Prepared for Health Systems Division, Health Promotion \& Programs Branch, Health Canada; 2000:1-39.

${ }^{52}$ Degner LF, Kristjanson LJ, Bowman D, Sloan JA, Carriere KC, O’Neil J, Bilodeau B, Watson P, Mueller B. Information needs and decisional preferences in women with breast cancer.
} 


\section{Both the Public and the Professions Need Education}

The public has shown considerable interest in this area (Ipsos-Reid poll - September 2001) but lacks adequate knowledge about genetics and genetic testing. Similarly, health care providers are already dealing with genetic issues in their practices. They see a role for themselves in providing genetic services but they lack adequate knowledge about genetics and genetic testing ${ }^{53}$.

An informal survey of genetics courses in the undergraduate medical curricula of Canadian medical schools, identified only five out of a total of 16 medical schools in Canada as having explicitly designated curriculum time for genetics. However, it is likely that genetics is integrated with other courses, rather than existing as a specific course ${ }^{54}$.

Genetics is a rapidly expanding field and the media and commercial enterprises will likely play a role in educating the public. Both the public and the health professions want access to high quality educational materials.

As interest in genetics grows, there is an urgent need to develop and evaluate credible educational materials and strategies for health care providers and the public. Public access to credible sources of information may minimize misperceptions of genetics and facilitate informed choice around genetic testing.

Our education system often emphasizes the technical perspective, sometimes to the exclusion of related and relevant social, political, economic and moral issues, which can lead to people choosing simple and often radical solutions to complex problems $^{55}$. Ideally, public and provider education will clarify the broader ethical, social, and legal issues involved with genetics and reduce the stigmatization associated with genetically determined diseases. In some cases, people may even be able to adopt a more individualized preventive approach to their health by making positive lifestyle choices.

\section{Educating the Public}

To make informed choices about genetic testing, the public needs a basic understanding of genetic issues. Core genetic issues for the public include:

- a basic understanding of genetics and heredity,

- an understanding of "risk" or probability of disease,

- the risks, benefits, limitations and meaning of genetic test results,

- implications for the individual and family, and

- availability and access to genetic services.

\footnotetext{
${ }^{53}$ Emery J, Watson E, Rose P, Andermann A. A systematic review of the literature exploring the role of primary care in genetic services. Family Practice 1999;16:426-445.

${ }^{54}$ Data derived from the Association of American Medical Colleges (2000/2001) Curriculum Directory, Washington D.C.

${ }^{55}$ Peter Fingold, Nature Biotechnology 19(3), March 2001, p. 197.
} 
Strategies for educating the public include:

- media campaigns,

- social marketing strategies,

- credible genetic web sites,

- public health genetic initiatives,

- community-based educational symposia, and

- partnerships with volunteer disease-based organizations.

\section{Educating Health Care Professionals}

Many health care disciplines will be involved in delivering genetics services. Each health care discipline will need to modify its genetics curriculum and competencies to meet its specific involvement in genetics service delivery.

Health care professionals should understand:

- the core issues of genetics,

- the social and psychological implications of genetic information, and

- when and how to make a genetics referral.

Physicians will need to know about:

- the difference between the clinical diagnosis of disease and the genetic predisposition to disease in healthy people;

- the impact that behavioural, social, and environmental factors have on risk and coping;

- the importance of family history, risk assessment, and the communication of risk information;

- informed choice and its implications for the individual and family;

- availability and access to genetic services;

- the range of interventions available including prevention, surveillance and treatment options, psychosocial support and genetic counselling;

- physical and psychosocial benefits, limitations and risks of genetic testing and information;

- the sensitivity of genetic information and the need for confidentiality; and

- the importance of tailoring information and services to clients' culture, knowledge and language level.

Strategies for educating health professionals in genetics include:

- the development, evaluation and dissemination of family history and risk assessment tools,

- referral guidelines,

- communication strategies,

- management protocols,

- decision support tools, and

- genetic web sites. 
As new genetic tests become available and approved, strategies will need to be developed to educate health care professionals about disease-specific tests.

Communication strategies need to be developed, as well as innovative educational approaches such as problem-based learning modules and train-the-trainer initiatives.

\section{Costs of Not Addressing Genetics Education}

The consequences of not addressing education about genetics and genetic testing could result in inappropriate genetic testing which could lead to:

- unnecessary and potentially harmful tests or treatments,

- people at increased risk not being identified,

- psychological distress in patients,

- inadequate counselling regarding risks and benefits and the meaning and limitations of genetic testing,

- breaches of confidentiality,

- ethical dilemmas,

- family conflict, and

- overuse of health care resources and increased health care costs.

\section{Recommendations}

The Education Sub-Committee recommends:

- infrastructure support for the educational needs of the genetic testing program;

- the development, implementation and evaluation of a multi-faceted public education strategy;

- the Ministry of Education review and revise curricula for educating students in elementary and secondary schools to ensure that applied, relevant, and appropriate genetics and related topics are incorporated into courses;

- a strategy to educate current health care professionals about core genetic issues with special emphasis on knowledge translation and management;

- the Ministry of Colleges and Universities review and revise genetics components of curricula of post-secondary schools, especially for health profession training programs, but also in all science programs ${ }^{55}$;

- the development of a framework for implementation of education for new disease-specific genetic tests;

- partnering with volunteer organizations, Deans of health professional schools in Ontario and other appropriate educational organizations to develop educational materials, curricula and strategies for the public and health professions;

- evaluating educational materials and strategies and continually improving genetics educational programs;

- tailoring genetics educational programs, information and services to culture, knowledge and language level.

\footnotetext{
${ }^{56}$ Suggested genetics competencies are in the Education Subcommittee Report available from MOHLTC.
} 


\section{Section 3: Recommendations of the Provincial Advisory Committee on New Predictive Genetic Technologies}

\section{An Ongoing Provincial Genetics Advisory Committee}

1. Recommendations made by the Advisory Committee are broadly based and farreaching. The Committee therefore recommends that the need for further consultation and implementation be recognized through an ongoing process. With this in mind, it is recommended that Ontario establish a Provincial Genetics Advisory Committee to advise on genetic services in the Province of Ontario. The committee should provide advice to the Government of Ontario through the Deputy Minister of Health and Long-Term Care in the following areas:

- New developments in the genetic sciences,

- Evaluation of existing genetic services, and

- Recommendations on the timely provision of new genetic tests and services following formal evaluation of proposed genetic testing by the committee.

- Legal and ethical issues,

- Human and infrastructure resource requirements for genetic services,

- Educational needs for Ontarians, including professions involved in all aspects of the provision of genetic services,

- A process for the implementation of new genetic services that includes both public and private laboratories,

- Any other areas as requested by the provincial government.

The committee's membership should be reflective of the broad based expertise necessary to achieve its mandate including geneticists, genetic counsellors, health economists, legal/ethical experts, epidemiologists, laboratory scientists, mental health professionals, and community representatives, including members of health related voluntary organizations. Liaison positions should exist with other relevant committees, such as the Test Review Committee under the Quality Management Programs/Laboratory Services (QMPLS) of the Ministry of Health and Long-Term Care (MOHLTC).

\section{Approach to Introduction of New Genetic Tests and Services}

2. Ontario should ensure that new genetic services are evaluated on the basis of technical accuracy ('analytical validity'), clinical effectiveness (clinical validity), usefulness to tested individuals (clinical utility), adverse and additional effects, 
expansion potential and cost (social utility), ethical/legal implications and resource implications. This evaluation will require the participation of experts and should include the perspective of relevant stakeholders including patients, their families and the community.

3. The evaluation framework developed by the Advisory Committee should be the basis of the evaluation process for new services. This evaluation process should include all aspects of genetic services including legal, ethical, social, psychosocial, epidemiological, clinical and laboratory components.

4. Implementation of new tests should only be considered after a review of the expected downstream impacts, including psychological impacts on patients, and the balance between the costs of the introduction of the new genetic test against other strategies for the prevention of illness.

5. Whenever new tests are introduced which affect an identifiable community, that community should be involved from the earliest stages of planning. The promotion, uptake and diffusion of new genetic services should acknowledge the cultural diversities and needs of the people of Ontario.

6. Ontarians should be provided with equitable timely access to genetic services across Ontario. Furthermore, any Ontarian should have access to genetic services if they have concerns about their genetic risks.

7. Where new genetic services are introduced, clear guidelines and care maps where appropriate, should be developed and made available as to what is expected in the genetic management of the condition.

8. Where predictive testing will not alter the onset of disease [e.g. Huntington Disease], genetic testing should still be considered because other potential benefits may exist.

\section{Programmatic Genetic Services}

9. Genetic testing should be provided as part of an integrated, multidisciplinary service, incorporating genetic assessment and counselling, quality testing, psychosocial support and follow-up services, including surveillance, prevention and treatment, as appropriate.

10. Psychosocial and emotional support services, being fundamental to the genetic consultation process, should be integrated into genetics service provision and access to psychosocial support services should be available throughout the province. 


\section{Education And Information}

11. Ontario should undertake to develop and promote a genetics educational program for Ontarians, to meet public and professional needs through

- a multifaceted public education program;

- fostering appropriate education of health professionals at undergraduate, graduate, post graduate and continuing educational levels.

12. Providers and the public should receive timely information concerning the availability of new predictive genetic services, criteria recommended for application, and resources available to patients accessing services. This framework should include a variety of methods for disseminating genetic information to provide:

- an index of genetic services available in Ontario;

- information for each new genetic test to health providers, including provincial guidelines for referral to genetic services, eligibility for genetic testing, access to testing and counselling, risk assessment, prevention and surveillance strategies, an outline of financial, ethical, legal and psychosocial implications of the test, and information on further information sources for patients.

\section{Quality Management And Guidelines}

13. Each aspect of genetic services in Ontario requires quality management and guidelines that applies to:

- The pretest preparation (counselling, education materials, etc.);

- Analytical (laboratory tests and their interpretation);

- Post-analytical follow-up (interpretation and reporting to patients;

- Patient monitoring following testing.

14. Where an approved genetic test is not provided in the province, Ontario should ensure that samples for testing are sent only to accredited laboratories in other jurisdictions, with acceptable quality assurances programs.

\section{Human Resources For Genetic Services}

15. The human resources and health system impact that will result from increasing demand for genetic services must be addressed if the province is to respond to this pressure. This is especially important, given the probable rapid uptake of these new technologies and the long lead time required to train professional personnel. This should include strategies to:

- encourage retention and recruitment of personnel involved in the delivery of genetic services to genetics training programs;

- introduce or enhance accredited training programs for genetic services; 
- ensure that all personnel directly involved in genetic services work in a regulated health environment. The issue of regulation of professions involved in the delivery of genetic services who are currently not regulated should be examined following further consultation.

\section{Non-Discrimination}

16. The Legislature should consider amending the Human Rights Code to prevent discrimination on the basis of genetic traits. This could be done by explicitly including "genetic trait" as a prohibited ground of discrimination in Part 1, or, as the Ontario Law Reform Commission recommended in its 1996 Report, by amending the definition of "because of handicap" in section 10(1). If the Legislature adopts the latter course of action, the Human Rights Commission should issue an interpretive rule providing that genetic conditions, both present and future, fall within the ambit of its legislative protection.

17. The government should consider establishing measures that are proactive in avoiding discriminatory uses of genetic information. To this end, the committee recommends that the government establish an approval system for the use of genetic testing and genetic information in the contexts of insurance, employment and any other domains outside of health care where the use of genetic testing and genetic information could have negative or undesirable social consequences.

18. The government should consider implementing a moratorium that would prevent insurance companies and employers from using genetic information to determine eligibility for insurance or employment. This moratorium should remain in effect until proper policies and processes with respect to the use of genetic information in these contexts are implemented.

\section{Research Review}

19. The government should ensure that all genetic testing undertaken in the research context in Ontario will have thorough research ethics review by independent and accountable research ethics boards.

\section{Patents, Direct Marketing and Commercialization of Genetic Tests}

20. The committee recommends that the government of Ontario engage in discussions with the government of Canada regarding patents, direct to consumer marketing and other areas of federal jurisdiction related to the commercial use of genetic tests. 


\section{Informed Consent}

21. The Committee recommends that informed consent with regard to predictive genetic testing should be express and documented, notwithstanding section 11(4) of the Health Care Consent Act, 1996 which provides that consent may be expressed or implied. Express consent represents the culmination of an informed consent process in which an individual is provided information about the potential risks and benefits of, and alternatives to, the proposed genetic test. It confirms the voluntary nature of genetic testing and the right of the individual to withdraw his or her consent.

\section{Genetic Testing of Minors}

22. Newborns and children should not be tested for genetic conditions where there are no timely medical or psychosocial benefits, or where these benefits will not accrue until adulthood (as in the case of carrier status or adult-onset disease).

23. As a general rule, parental consent should be required for newborn genetic screening. The Provincial Advisory Committee, or another body accountable to the government, should investigate whether, and under what circumstances, newborn screening without express parental consent is permissible.

24. The practice of banking newborn screening data and samples should be reviewed with a view to ensuring that individual rights of privacy and confidentiality are protected and that informed consent is integral to this practice. This review should include the issue of the reuse or testing of banked newborn samples.

\section{Privacy and Confidentiality of Genetic Information}

25. Within the context of privacy legislation, the government should enact legislation to protect the privacy of genetic information. This legislation should particularly address the following issues:

- the privacy and control of information obtained from laboratory testing, as well as blood and tissue samples;

- the establishment of norms for the collection and storage of genetic information;

- the establishment of norms for determining who should have access to stored genetic information and genetic samples, including physicians and other health professionals;

- a tested individual's right to request that his or her DNA sample be destroyed;

- the banking of newborn screening data and samples; 
- standards of confidentiality regarding an individual's genetic information as relates to other family members;

- the creation and treatment of genetic records as distinct from medical records.

26. (a) Legislation should not impose a duty to disclose genetic information to high risk relatives.

(b) The issue of physician privilege to disclose genetic information to an individual's high-risk relatives against his or her wishes, should be reviewed. 


\title{
Section 4: Appendices
}

\section{Appendix A}

\author{
Provincial Advisory Committee on New Genetic \\ Predictive Technologies
}

\section{Terms of Reference}

\section{Purpose}

The Ministry of Health and Long-Term Care (MOHLTC) wishes to develop strategies and policies proactively in the area of predictive genetic testing in order for Ontario to keep pace with this rapidly evolving area of services for the improvement of health and the alleviation of human suffering.

The purpose of the committee is to develop principles/guidelines/broad criteria to guide operational decision making by MOHLTC in introducing new genetic predictive technologies in Ontario. The breadth of expertise required for the committee must include expertise across the broad array of clinical, technical, financial, psychosocial, ethical and legal concerns.

\section{Pac Terms of Reference}

To provide advice to MOHLTC regarding the future of predictive genetic testing, with specific reference to:

1. the extent to which predictive genetic testing will present an opportunity, and to which testing services will impact on the health care system and people of Ontario over the short term (two to three years) and the longer term (ten years);

2. a framework MOHLTC can use to reach future funding decisions relating to new predictive genetic tests and treatment modalities that might become available over the next five years;

3. criteria for choosing the sites for predictive genetic testing services, taking into account the existing programs which would complement and facilitate delivery of service, access for patients and persons at risk, availability of genetic counselling and patient care, and the volume of activity to support appropriate turn around times and skill development. Of special interest is the extent to which a centralized or decentralized program will provide maximum efficiencies for common and less-common testing and the economy of scale that might be achieved through high volumes; 
4. a framework for continuous evaluation of changing technology and research and how these will be incorporated into ongoing services;

5. a framework to be used to evaluate new genetic screening modalities once introduced

6. a framework for ensuring broad quality assurance issues are met;

7. broad issues regarding the collection and sharing of information;

8. ethical, legal and social implications including informed consent, privacy and confidentiality, and familial implications;

9. issues concerning genetic discrimination and stigmatization which could be faced by people or groups seeking employment, life insurance, adoption, immigration, or in any other endeavour;

10. how best to deal with education of providers, patients and the general population;

11. how best to deal with psychological factors which may occur in the tested population;

12. a framework for distinguishing between appropriate and inappropriate genetic testing;

13. a framework for distinguishing between what genetic screening testing should be publicly funded and what excluded.

- The Committee will be informed regarding any Federal-Provincial initiatives in these areas and will give consideration to incorporate the products of these initiatives as appropriate. It is also envisaged that the products of the provincial committee will inform the work of the Federal-Provincial initiative.

- The Committee will ensure that all recommendations for a framework are informed, to the extent possible, of approaches being taken in other jurisdictions, particularly those with a publicly funded health care system. 


\section{Sub-Committees}

A sub-committee structure will be used to assemble the proposed framework for the introduction of new genetic predictive technologies.

Although there will be overlap, the sub-committees should consider the

following areas in the development of their guidelines:

- criteria to assess the validity and utility of a new technology,

- guidelines for implementation,

- guidelines for ongoing monitoring and evaluation,

- human and capital resource requirements relating to the short term and the five year view,

- translation of research into service relating to the short term and the five year view,

- approaches taken by other jurisdictions, as appropriate,

- commercialization and the role of the private sector,

- data management.

\section{Clinical Sub-Committee}

To examine all issues of a clinical nature in regard to new predictive genetic technologies, including:

- Development of eligibility criteria for testing (taking into account validity and utility);

- Development of guidelines for offering testing to persons at risk;

- Development of guidelines for facilitating - mechanisms for referrals

- access to testing

- access to all related services

- management of persons changing from at-risk to affected status

- Development of guidelines for service standards and requirements;

- Development of recommendations regarding pre- and post-test counselling, and patient follow up;

- Regulatory requirements.

\section{Psychosocial Sub-Committee}

- Develop strategies for addressing the psychosocial implications of genetic screening as these relate to persons at risk and their family members and where necessary, for intervention;

- Develop recommendations for screening persons at risk requiring psychosocial counselling, including management of persons changing from at-risk to affected status. 


\section{Laboratory Sub-Committee}

To examine all issues regarding laboratory predictive genetic testing, including:

- appropriate technology;

- quality assurance;

- laboratory licensing;

- laboratory insurance;

- specimen repository and data management;

- development of laboratory expertise;

- necessary volumes per test;

- monitoring and making recommendations regarding new technological developments;

- criteria for selecting testing sites;

- appropriate turn around times;

- standardized reporting;

- transportation requirements for samples;

- regulatory requirements;

- patent issues;

- partnership issues, including commercialization and role of the private sector;

- communication and privacy issues.

\section{Legal and Ethical Sub-Committee}

Development of mechanisms to address the legal and ethical implications of genetic

predictive testing, including:

- consent;

- privacy;

- confidentiality of patient and family health information;

- discrimination;

- coercion;

- access;

- role of the private sector;

- patent issues;

- patient recall;

- multiple tests on the same sample for the same condition and for multiple conditions;

- management of persons changing from at-risk to affected status.

\section{Resource Assessment and Utilization Sub-Committee}

Incorporation of the issues below into the decision-making framework:

- human resources and capital planning;

- integration into current health services;

- mechanisms for ensuring appropriate utilization of new predictive technologies. 


\section{Education Sub-Committee}

- Develop recommendations for modalities and approaches to public, patient and provider education requirements, including adult education, literacy, translation;

- Review educational modalities currently available provincially, nationally and internationally.

\section{Evaluation Sub-Committee}

- Develop an evidence-based framework for evaluation of validity of new genetic predictive technologies;

- Develop criteria for ongoing evaluation of each new genetic predictive test implemented;

- Develop proposal for evaluation of benefits, risks, costs, and affordability for each new genetic test being considered for implementation;

- Develop proposal for evaluation of the framework under development by the Advisory Committee on New Genetic Predictive Technologies. 


\section{Appendix B}

Provincial Advisory Committee on New Predictive

Genetic Technologies

\section{Membership}

Dr. Judith Allanson, Genetics Program, Children's Hospital of Eastern Ontario

Sharon Balsys, Senior Advisor, Communications and Information Branch, Ministry of Health and Long-Term Care

Dr. Sean Blaine (Co-Chair, Education Sub-Committee), Assistant Professor, Department of Family and Community Medicine, University of Toronto, Research Scholar Family Health Care Research Unit

Dr. George Browman (Chair, Evaluation Sub-Committee), CEO, Hamilton Regional Cancer Centre

Dr. June Carroll, Co-Chair, Education Sub-Committee, Associate Professor, Sydney G Frankfort Chair in Family Medicine, Department of Family and Community Medicine, University of Toronto, Family Medicine Centre, Mount Sinai Hospital, Representative of the Ontario College of Family Physicians

Dr. David Cole, Depts. of Laboratory Medicine \& Pathobiology, Medicine, and Pediatrics (Genetics), University of Toronto, Director, Adult Genetics Services, University Health Network

Dr. Colin D'Cunha, Director and Chief Medical Officer of Health, Public Health Branch, Ministry of Health and Long-Term Care

Dr. Mary Jane Esplen (Chair, Psychosocial Sub-Committee), Head, Program of Psychosocial \& Psychotherapy Research in Cancer Clinician Scientist, Dept of Psychiatry, Mount Sinai Hospital

Dr. Alasdair Hunter (Co-Chair, Clinical Sub-Committee), Director, Genetics Program, Children's Hospital of Eastern Ontario

Phil Jackson, Director, Strategic Health Policies Branch, Ministry of Health and Long-Term Care

Dr. Birthe Jorgensen, Projects Manager, Medical Advisory Secretariat, Ministry of Health and Long-Term Care

Michael Kilpatrick, Senior Policy Analyst, Medical Advisory Secretariat, Ministry of Health and Long-Term Care

Trudo Lemmens, (Co-Chair, Legal and Ethical Issues, Sub-Committee), Assistant Professor, Faculty of Law, University of Toronto 
Dr. Les Levin, Senior Medical Advisor, Head, Medical Advisory Secretariat, Ministry of Health and Long-Term Care

Dr. Alex MacKenzie, Director of Research Institute, Children's Hospital of Eastern Ontario

Grace Maddox, Vice-President (volunteer), Ontario Division, Canadian Cancer Society

Dr. Roxanne Mykitiuk, (Co-Chair, Legal and Ethical Issues Sub-Committee) Associate Professor, Osgoode Hall Law School, York University

Leela Prasaud, Manager, Quality Management, Laboratories Branch, Ministry of Health and Long-Term Care

Dr. Kenneth P.H. Pritzker, Pathologist-in-Chief, Mount Sinai Hospital

Maureen Provencher, Program Consultant Operations, Hospital \& Priority Programs Unit, Ministry of Health and Long-Term Care

Francine Robert, Genetics Nurse, North Bay and District Health Unit

Dr. Kirsten Rottensten, Public Health Branch, Ministry of Health and Long-Term Care

Dr. Brian Sheridan, Vice President, Medical Affairs, Canada, MDS Laboratory Services, Representative of the Ontario Association of Medical Laboratories

Dr. Anne Summers (Chair, Advisory Committee on New Predictive Genetic Technologies), Genetics Program, North York General Hospital

Elaine M.W.Taylor, Chair, Huntington Society of Canada

Adam Topp, VP \& Chief Financial Officer, Sunnybrook and Women's Health Sciences Centre

Luke A. Vanneste, Senior Vice President, Bank of Nova Scotia

Dr. Lea Velsher (Co-Chair, Clinical Sub-Committee), Clinical Genetics, North York General Hospital

Charlotte Weiss, Legal Counsel, Ministry of Health and Long-Term Care

Dr. Philip Wyatt (Chair, Laboratory Sub-Committee), Genetics Program, North York General Hospital 
Sub-Committee Chairs and Members

\section{Education Sub-Committee}

Dr. Sean Blaine, Co-Chair, Assistant Professor, Department of Family and Community Medicine, University of Toronto, Research Scholar at Family Health Care Research Unit

Dr. June Carroll, Co-Chair, Associate Professor, Sydney G Frankfort Chair in Family Medicine, Department of Family and Community Medicine, University of Toronto, Family Medicine Centre, Mount Sinai Hospital, Representative of the Ontario College of Family Physicians

Sharon Balsys, Senior Advisor, Communications and Information Branch, Ministry of Health and Long-Term Care

Morag Bell, Genetic Counsellor, Credit Valley Hospital

Dr. Annette Burfoot, Associate Professor, Department of Sociology, Queen's University

Dr. Niall Byrne, Centre for Research in Education, Faculty of Medicine, University of Toronto

Dr. Mary Jane Esplen, Head, Program of Psychosocial \& Psychotherapy Research in Cancer Clinician Scientist, Dept of Psychiatry, Mount Sinai Hospital

Dr. Ian Johnson, Assistant Professor, Dept of Public Health Sciences, University of Toronto

Margaux Lachance, Genetic Nurse Consultant, Northeastern Regional Cancer Care Centre

Dr. Wendy Meschino, Genetics Program, North York General Hospital Grace Maddox, Vice-President (volunteer), Ontario Division, Canadian Cancer Society

Jennifer Poudrier, Research Assistant, Dept. of Sociology, Queen's University

\section{Evaluation Sub-Committee}

Dr. George Browman, Chair, CEO, Hamilton Regional Cancer Centre

Dr. Bharati Bhapat, Geneticist, Pathology and Laboratory Medicine, Mount Sinai Hospital

Dr. Andrea Eisen, Assistant Professor, McMaster University, Medical Oncologist, Hamilton Regional Cancer Centre 
Dr. Michael Evans, CCFP, Principal Investigator, Knowledge Translation Program, Research Scholar, Family Healthcare Research Unit, Staff Physician, Toronto Western Hospital, University Health Network; Asst. Professor, Dep't of Family \& Community Medicine, University Of Toronto

Dr. Sandra Farrell, Medical Director, Regional Genetics Program, The Credit Valley Hospital

Dr. Mita Giacomini, Associate Professor, Centre for Health Economics \& Policy Analysis, Dept. of Clinical Epidemiology and Biostatistics, McMaster University

Dr. Fiona Miller, Associate Professor, Department of Clinical Epidemiology and Biostatistics, Member, Centre for Health Economics and Policy Analysis, McMaster University

Dr. Kirsten Rottensten, Public Health Branch, Ministry of Health and Long-Term Care Elaine M. W. Taylor, Chair, Huntington Society of Canada

\section{Psychosocial Sub-Committee}

Dr. Mary Jane Esplen, Chair, Head, Psychosocial and Psychotherapy Research in Cancer Genetics, Assistant Professor \& NCIC Scientist, Department of Psychiatry, Faculty of Medicine, University of Toronto, Mount Sinai Hospital/ Samuel Lunenfeld Research Institute

Melyssa Aronson, Genetic Counsellor, Familial Gastrointestinal Cancer Registry, Mount Sinai Hospital

Dr. Mario Cappelli, Clinical Psychologist, Mental Health Program, Children's Hospital of Eastern Ontario, Clinical \& Assistant Professor of Psychology, Pediatrics, Graduate \& Postdoctoral Studies, University of Ottawa, Allied Health Clinical Scientist, Children's Hospital of Eastern Ontario Research Institute

Cathy Gilles, Genetic Counsellor, Genetic Counselling Program, Thunder Bay District Health Unit

Margaux Lachance, Genetic Nurse Consultant, Northeastern Regional Cancer Care Centre

Alexander Liede, Genetic Counsellor, Centre for Research in Women's Health, University of Toronto

Dr. Jon Hunter, Head, Psychosomatics Program, Dept. of Psychiatry, University of Toronto, Mount Sinai Hospital

Francine Robert, Genetics Nurse, North Bay and District Health Unit

Dr. Allen Swayze, Psychiatrist, Toronto

Nancy Webb, Director, Toronto Huntington Disease Resource Centre 


\section{Clinical Sub-Committee}

Dr. Alasdair Hunter, Co-Chair, (retired), Director, Genetics Program, Children's Hospital of Eastern Ontario

Dr. Lea Velsher, Co-Chair, Clinical Genetics, North York General Hospital

Richard Birthwhistle, Professor, Departments of Family Medicine and Community Health and Epidemiology, Queen's University

Dr. William Feldman, Professor Emeritus of Pediatrics, University of Toronto, Editor-in-chief, Annals, Royal College of Physicians and Surgeons of Canada.

Andrea Shugar, Genetic Counsellor, Canadian and American Board-Certified Genetic Counsellor

Dr. Gary Viner, Assistant Professor, Department of Family Medicine, University of Ottawa

Dr. Philip Wells, Canada Research Chair in Thromboembolic Diseases, Chief, Division of Hematology, Ottawa Hospital

\section{Legal \& Ethical Issues Sub-Committee}

Trudo Lemmens, Co-Chair, Assistant Professor, Faculty of Law, University of Toronto

Roxanne Mykitiuk, Co-Chair, Associate Professor, Osgoode Hall Law School, York University

Bita Amani, Graduate Fellow, Centre for Innovation Law and Policy, University of Toronto

Lisa Austin, Assistant Professor, Faculty of Law, University of Toronto Mireille Lacroix, Research Associate, Faculty of Law, University of Toronto

Charlotte Weiss, Legal Counsel, Ministry of Health and Long-Term Care

\section{Resource Assessment and Utilization Sub-Committee}

Adam Topp, Chair, Vice President \& Chief Financial Officer, Sunnybrook and Women's Health Sciences Centre 


\section{Laboratory Sub-Committee}

Dr. Philip Wyatt, Chair, Genetics Program, North York General Hospital

Dr. Sylvia Asa, Pathologist-in-Chief, University Health Network \& Toronto Medical Laboratories

Dr. Nancy Carson, Head, Molecular Genetics Diagnostic Laboratory, Children's Hospital of Eastern Ontario

Vince D'Mello, Deputy Registrar, The College of Medical Laboratory Technologists of Ontario

Dr. Joel Goodman, Vice President, Clinical Operations Gamma-Dynacare Medical Laboratories, Representative of the Ontario Association of Medical Laboratories

Joanne Miyazaki, Manager Business Development, Quality Management Program Laboratory Services

Leela Prasaud, Manager, Quality Management, Laboratories Branch, Ministry of Health and Long-Term Care

Dr. Kenneth Pritzker, Pathologist-in-Chief, Department of Pathology and Laboratory Medicine, Mount Sinai Hospital

Dr. Brian Sheridan, VP, Medical Affairs, Canada, MDS Laboratory Service Representative of the Ontario Association of Medical Laboratories

Dr. Sherryl Taylor, Co-Director, DNA Diagnostic Laboratory, Kingston General Hospital, Professor, Queen's University 


\section{Appendix C}

\section{Molecular Genetic Tests Offered In Ontario}

(Source: GeneTests-Gene Clinics: Human Genetics Information Resource, 2001)

\section{Clinical tests are available for:}

22q11 Deletion Syndrome

Achondroplasia

Alpha-1-Antitrypsin Deficiency

Alpha-Thalassemia

Angelman Syndrome

Apert Syndrome

Beckwith-Wiedemann Syndrome

Beta-Thalassemia

BRCAl Hereditary Breast/Ovarian Cancer

BRCA2 Hereditary Breast/Ovarian Cancer

CADASIL

Canavan Disease

Charcot-Marie-Tooth Neuropathy Type 1A

Charcot-Marie-Tooth Neuropathy Type X

Congenital Bilateral Absence of the Vas Deferens

Crouzon Syndrome

Cystic Fibrosis

Cystinosis

DFNA 3 (Connexin 26)

DFNB 1 (Connexin 26)

DRPLA

Duchenne/Becker Muscular Dystrophy

Fabry Disease

Facioscapulohumeral Muscular Dystrophy

Factor V Leiden Thrombophilia

Fragile X Syndrome

FRAXE Syndrome

Friedreich Ataxia

Gaucher Disease

Genotypic Gender Assignment

Hemoglobin C

Hemoglobin E

Hemoglobin S

Hereditary Hemochromatosis

Hereditary Neuropathy with Liability to Pressure Palsies
Hereditary Sensory Neuropathy Type I

Hexosaminidase A Deficiency

Huntington Disease

Hyperkalemic Periodic Paralysis

Hypochondroplasia

Ichthyosis, X-Linked

Jackson-Weiss Syndrome

Kallmann Syndrome, X-Linked

Leber Hereditary Optic Neuropathy

Marfan Syndrome

Medium Chain Acyl-Coenzyme A

Dehydrogenase Deficiency

Mental Retardation Syndromes, Undiagnosed

Miller-Dieker Syndrome

MTHFR Thermolabile Variant

Mucopolysaccharidosis Type II

Muenke Syndrome

Multiple Endocrine Neoplasia Type 1

Multiple Endocrine Neoplasia Type 2

Myotonic Dystrophy Neurofibromatosis 1

Oculopharyngeal Muscular Dystrophy

Parentage Testing

Pfeiffer Syndrome Type 1, 2, and 3

Polycystic Kidney Disease 1, Autosomal

Dominant

Polycystic Kidney Disease 2, Autosomal

Dominant

Prader-Willi Syndrome

Prothrombin G20210A Thrombophilia

Retinoblastoma

Rh D Genotyping

RNA Banking

Saethre-Chotzen Syndrome

Schimke Immunoosseous Dysplasia 
Sex-Determining Region Y

Simpson-Golabi-Behmel Syndrome

Smith-Magenis Syndrome

Spinal and Bulbar Muscular Atrophy

Spinal Muscular Atrophy

Spinocerebellar Ataxia Type 1

Spinocerebellar Ataxia Type 2

Spinocerebellar Ataxia Type 3

Spinocerebellar Ataxia Type 6

Spinocerebellar Ataxia Type 7

Spinocerebellar Ataxia Type 8

\section{Research tests are available for:}

Autism

Cleft Lip/Palate Syndrome

Dysplastic Nevus Syndrome

Ectodermal Dysplasia

Ectrodactyly

Episodic Ataxia Type 2

Familial Adenomatous Polyposis

Familial Hemiplegic Migraine

Familial Malignant Melanoma

Familial Vestibulopathy

FAMMM, Familial Atypical Multiple

Mole Melanoma Syndrome
Telomere Detection

Thanatophoric Dysplasia Type I

Thanatophoric Dysplasia Type II

Uniparental Disomy Testing, General

Williams Syndrome

$\mathrm{X}$ Inactivation Studies

Y Chromosome Deletion

Y Chromosome Detection/Molecular

Genetics

Zygosity Testing

Febrile Convulsions

Hereditary Non-Polyposis Colon Cancer

Hirschsprung Disease, HSCR

MTHFR Deficiency

Osteoporosis

Progressive Myoclonus Epilepsy, Lafora Type

Russell-Silver Syndrome

Severe Speech Delay

Wiskott-Aldrich Syndrome

\section{Ontario Ministry of Health and Long-Term Care}

\section{Approved Laboratories That Provide Predictive Genetic Testing}

1. Children's Hospital of Eastern Ontario, DNA Diagnostic Laboratory, Ottawa

2. Hospital for Sick Children Molecular Genetics Laboratory, Toronto

3. London Health Sciences Centre, Molecular Diagnostic Laboratory, London

4. Kingston General Hospital, DNA Diagnostic Laboratory, Kingston

5. McMaster University Medical Centre, Ontario Provincial Hemoglobinopathy, Hamilton

6. Mount Sinai Hospital, Toronto

7. North York General Hospital, Molecular Genetics Laboratory, Toronto

8. The Credit Valley Hospital, Genetics Laboratory, Ontario

In addition to these laboratories, numerous research laboratories throughout the province of Ontario provide genetic testing on a research basis. 


\section{Appendix D}

\section{Glossary of Terms for Genetic Disorders and Genetic Testing}

\section{Autosomal dominant disorders}

Disorders where inheritance of a mutation from one parent only (or arising anew during egg or sperm formation) can be sufficient for the person to be affected. Dominant disorders include familial hypercholesterolaemia, Huntington Disease, adult polycystic kidney disease and neurofibromatosis.

\section{Autosomal recessive disorders}

Disorders, where for a person to be affected, a mutation has to be inherited from both biological parents. Such parents are usually unaffected carriers because they only have a single copy of the affected gene. Common recessive disorders include cystic fibrosis, sickle cell disease and thalassemia.

\section{Carrier}

For a recessive disorder, where two copies of the mutation must be present for the clinical condition to be manifested, the individual who carries only one copy of the mutation (heterozygote) is described as being a carrier. Usually, these individuals are unaffected by the clinical condition, but in some cases, subtle differences might be detectable. For example, a carrier of sickle cell disease is well, but a small percentage of their red blood cells have a sickle shape under selected laboratory conditions.

\section{Compound Heterozygote - (see also heterozygote)}

Both copies of the gene are mutated, but they are different mutations. For example, there might be a base-pair alteration at one location (e.g. codon 10) in one copy and a deletion at another location (e.g. codon 12) in the other copy of the gene. Most persons with recessive disorders are compound heterozygotes.

\section{Diagnostic genetic test}

Diagnostic testing is performed on individuals with clinical signs of a potential disease or condition. The purpose of the testing is to make a diagnosis of whether or not the person currently has a specific disorder. For example, a person with muscle weakness and cramps will be diagnosed as having a clinical sign called myotonia. DNA testing could then be initiated to determine what type of myotonia they have. This gives a specific diagnosis or alternatively, can rule out other specific diagnoses. 
Expressivity (or variable expressivity)

Expressivity is the degree to which an affected person manifests the disorder. There might be such subtle expression that the person is unaware they have the disorder. There can be significant variation within and between families. For example, for the BRCAl and 2 genes, a woman might have bilateral breast cancer, but no ovarian cancer, while her sister might develop only ovarian cancer. In this case, the disorder is expressing itself variably in different women, even in the same family.

\section{Gene}

The fundamental hereditary unit; a sequence of chromosomal DNA that is required for the production of a functional product, usually a protein.

\section{Genetic disorders or diseases}

Conditions that are due to alterations in the genetic endowment of an individual. They may be the direct consequence of defects in single genes; or in whole chromosomes, parts of which may be lost, duplicated or misplaced; or due to the interaction of multiple genes and external factors.

\section{Genetic Screening}

Genetic screening may be defined as any kind of test performed for the systematic early detection or exclusion of a genetic disease, the predisposition or resistance to such a disease, or to determine whether a person carries a gene variant that may produce disease in offspring. Screening may be concerned with the general population or with specific sub-populations defined on some basis other than their health.

Distinctions should be made between reproductive screening (prenatal screening to find affected pregnancies, and carrier screening to find persons who may pass on disease to offspring), or screening individuals for genetic risks to their own health (screening for predisposition to disease, for presymptomatic disease, for those affected with disease)

Screening can be population-based (i.e. newborns, pregnant women, individuals of a certain age) or selective, where a specified subset of a population is targeted (i.e. individuals from populations known to be at increased risk; for example, those of Mediterranean heritage are at increased risk of thalassemia)

\section{Genetic test}

All laboratory procedures on a specimen(s) to detect the presence or absence of, or change in, a particular gene or chromosome, or a change in a gene product, in relation to a genetic disorder when the results describe heritable information that can be linked directly to an individual or circumscribed population. 


\section{Genome:}

All the genetic material containing the entire genetic information in the chromosomes of a particular organism (in humans, about three thousand million base pairs per single chromosome set)

\section{Genomics}

The field of genetics concerned with studies of the genome.

\section{Heterogeneity}

Heterogeneous diseases have the same clinical expression, but multiple genetic causes. For example, at least two different mutations can produce the clinical condition of adult-onset polycystic kidney disease. Thus, polycystic kidney disease is genetically heterogenous.

\section{Heterozygote (Heterozygous)}

There are two copies of most genes (some are present in even more copies). If one is mutated, the person is heterozygous for that mutation, meaning they have one normal copy and one altered (mutated) copy (see also carrier).

\section{Homozygote (Homozygous)}

There are two copies of most genes (some are present in even more copies). If both copies of the gene are similar, either normal or mutated, the person is homozygous (either homozygous normal or homozygous for the mutation).

\section{Multifactorial disorders}

Disorders whose genetic components work with other, often environmental, factors in determining a disease outcome.

\section{Mutation}

The change in a gene or chromosomes that causes a disorder or the inherited susceptibility to a disorder.

\section{Orphan Disease}

An orphan disease is rare. SACGT defines a rare disease or condition as having a prevalence of less than one in 2,000 individuals, or an incidence of less than one in 10,000 individuals. 


\section{Penetrance}

For some disorders, only a percentage of persons with the mutation will manifest the disorder. The penetrance is the proportion of individuals with the mutation who manifest the disorder. In a disorder with $80 \%$ penetrance, $80 \%$ of persons with the mutation will have some manifestation of the disorder, while $20 \%$ will show no signs of the disorder, even on careful clinical examination. The disorder could be described as being not fully penetrant, since not every person with the mutation gets the disorder.

\section{Predictive genetic test}

Predictive testing is performed on individuals with no clinical signs of the potential disease or condition for which they are being tested. The test is done to determine if the person has the mutation for the disorder, and therefore, indicate if the person is likely to develop the disorder in the future.

Depending on the disorder, some predictive tests provide information about an increased risk, but do not provide a definitive prognosis. For example, BRCAl/2 mutations for hereditary breast and/or ovarian cancer: the presence of the mutation indicates increased risk, but the individual with a mutation might never develop breast or ovarian cancer, even at an elderly age.

Other kinds of predictive tests will give virtually certain knowledge of the future onset of a disorder (sometimes called presymptomatic tests). For example, if a test for the mutation leading to Huntington disease shows that the person has the mutation, the person will manifest the disease, assuming they live long enough.

\section{Protein}

A molecule composed of one or more chains of amino acids in a specific order: the order is determined by the sequence of bases in the gene coding for the protein. Proteins are involved in all aspects of the body's structure and function. 


\section{Appendix E}

Sub-Committee Reports and Other Documents

Produced for the Committee

Draft Report of the Legal and Ethical Issues Sub-Committee, Ontario Provincial

Advisory Committee on New Predictive Genetic Technologies, November 29, 2001

Committee members: Lemmens T, Mykitiuk R, Lacroix M, Austin L, Amani B

Final Report of the Evaluation Sub-Committee, Evaluation Framework for Assessing Predictive Genetic Tests, Ontario Provincial Advisory Committee on

New Predictive Genetic Technologies, November 1, 2001

Committee members: Bhapat B, Browman GP, Eisen A, Evans M, Farrell S,

Giacomini M, Miller F, Rottensten K, Taylor E

Background Papers - Evaluation Subcommittee:

- Giacomini M, Miller F, Browman G, Confronting 'Grey Zones' in Human Technology Assessment: A Three-Dimensional Model for Evaluating Genetic Testing Services for Public Insurance Coverage in Canada, November 1, 2001

- Browman G, Eisen A, Farrell S, Assessing Analytic and Clinical Validity of Genetic Predictive Technologies and Systematic Review Methods

- Eisen A, Farrell S, Process of Template Development

- Giacomini M, Miller F, O'Brien B, But What Will They Really Cost? Economic Considerations for the Public Funding of Emerging Genetic Tests

- Miller F, Giacomini M, Evaluating Predictive Genetic Technologies: The Ontario Case in Perspective

- Miller F, Giacomini M, Defining the Characteristics of Predictive Genetic Tests: A Framework for Evaluation Decision-Making

Final Report of the Laboratory Sub-Committee, Ontario Provincial Advisory Committee on New Predictive Genetic Technologies, November 2001

Committee members: Asa S, Carson N, D’Mello V, Goodman J, Miyazaki J, Prasaud L, Pritzker K, Sheridan B, Taylor S, Wyatt P

Final Report of the Clinical Sub-Committee, Ontario Provincial Advisory Committee on New Predictive Genetic Technologies, November 30, 2001 Committee members: Birtwhistle RV, Feldman W, Hunter A, Shugar A, Velsher L, Viner G, Wells P 
Final Report of the Psychosocial Sub-Committee, Ontario Provincial Advisory Committee on New Predictive Genetic Technologies, November 12, 2001Committee members: Esplen MJ, Aronson M, Cappelli M, Hunter J, Lachance M, Liede A, Robert F, Swayze A, Webb N

Final Report of the Education Sub-Committee, Ontario Provincial Advisory Committee on New Predictive Genetic Technologies, November 27, 2001

Committee members: Blaine S, Carroll J, Balsys S, Bell M, Burfoot A, Byrne N, Esplen MJ, Johnson I, Lachance M, Meschino W, Maddox G, Poudrier J 


\section{Appendix F}

The Toolkit - The Evaluation Template

Submitted by the Sub-Committee on Evaluation

Provincial Advisory Committee on New Predictive Genetic Technologies

\section{Contents}

Part 1 About the Evaluation Tool Kit

Part 2 Flowchart for using the Evaluation Template

Part 3 Evaluation Template

Part 4 The Summary Evaluation Template

Part 5 Application for Service Evaluation

Part 6 A Glossary of Terms

\section{Part 1. About the Evaluation Tool Kit}

The Evaluation Sub-Committee has developed a Tool Kit to assist the Advisory Committee and the Expert Panels in their decision processes. The tool kit has five components:

\section{(Part 2.) Flowchart for using the Evaluation Template}

This chart schematizes, in graphic form, the steps to be taken in the evaluation of a proposed predictive genetic service

\section{(Part 3.) The Evaluation Template}

The Evaluation Template is an 11 page form which lists questions to be answered, and decisions to be taken, in the evaluation of specific predictive genetic services. The template has five sections, each of which outlines a specific criterion for evaluation (intended purpose, effectiveness, additional effects, economic considerations and expected demand \& expansion potential). Most of these sections have sub-categories of questions to be answered. Completion of the template requires a review of available evidence, and committee deliberation. Both the Advisory Committee and the Expert Panel will contribute to the completion of the Template.

\section{(Part 4.) The Summary Evaluation Template}

The Summary Evaluation Template is a one page form for the presentation of summary information about each of the five main criteria assessed in the evaluation of a predictive genetic service. This summary form can be completed by the Advisory Committee once the full Evaluation Template is finished. It can be used by decision-makers to quickly review the main findings of the Advisory Committee. 


\section{(Part 5.) Application for Service Evaluation}

This is a sample application form that lists the issues to be addressed by the individual or group advocating for the public funding of a new predictive genetic service. Completion of this form constitutes step one in the process for decision making.

\section{(Part 6.) A Glossary of Terms}

The Glossary of Terms identifies a series of terms that are particular to the evaluation template and of more generic relevance to genetic disorders and genetic testing. This glossary should be of assistance to members of the Advisory Committee and the Expert Panel, to ensure that there is common understanding of the main terms and concepts being used in the evaluation.

These tools are for guidance only. In many cases, the evaluation will require techniques that are more sophisticated than the tools supplied. We rely on Expert Panels to use appropriate methodologies. We assume that with experience these tools will evolve over time and become increasingly useful. 
Part 2. Flowchart for Using the Evaluation Template

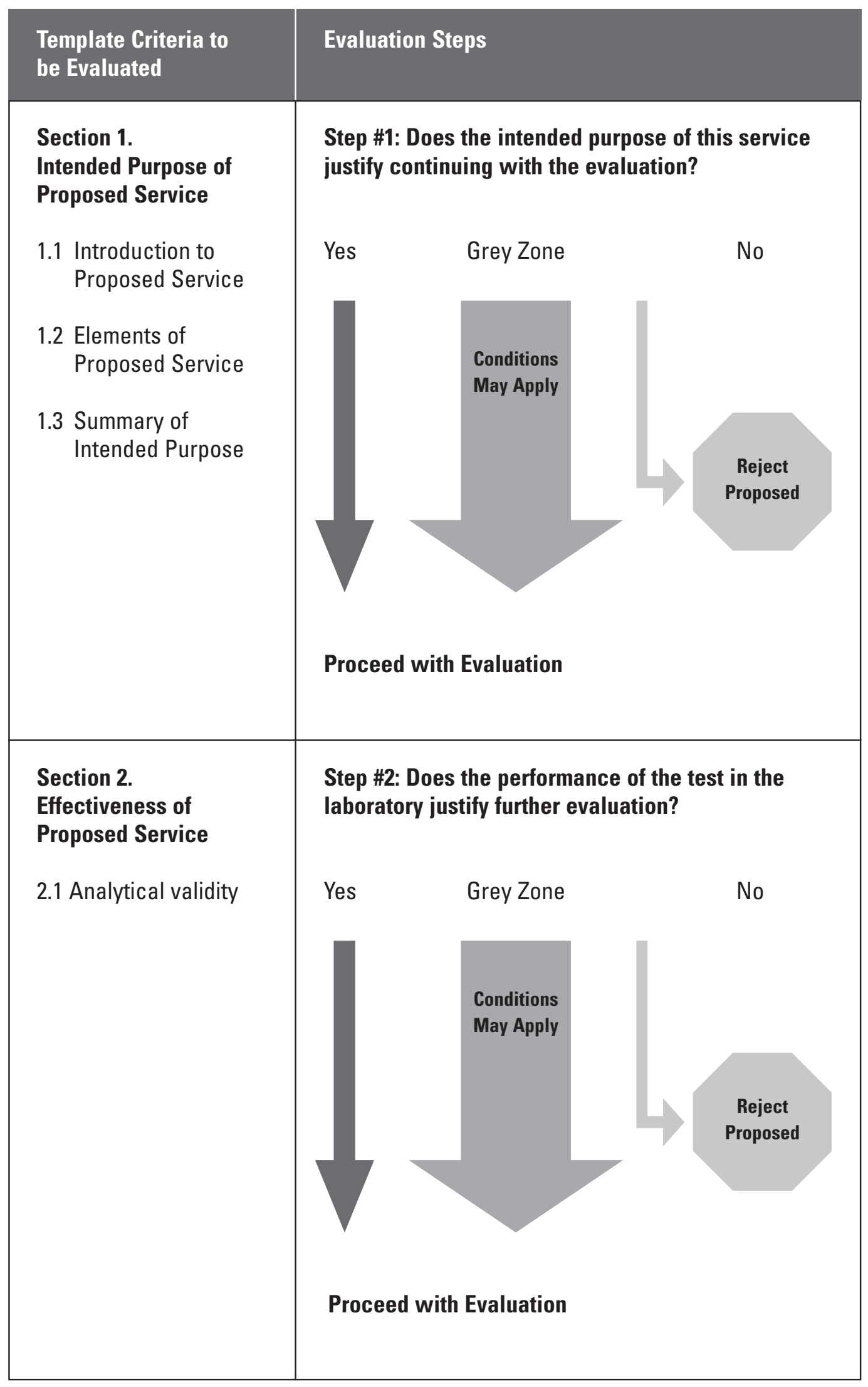


Template Criteria to

Evaluation Steps

be Evaluated

\section{Section 2.}

Effectiveness of

Proposed Service (cont'd)

2.2 Clinical Validity

Proceed with Evaluation

Section 2.

Effectiveness of

Proposed Service (cont'd)

2.3 Availability \& Effectiveness of Alternatives

2.4 Expected outcomes of Service Use
Yes

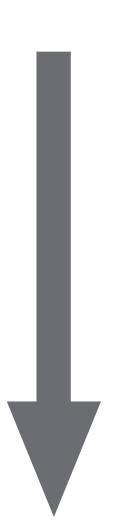

Grey Zone

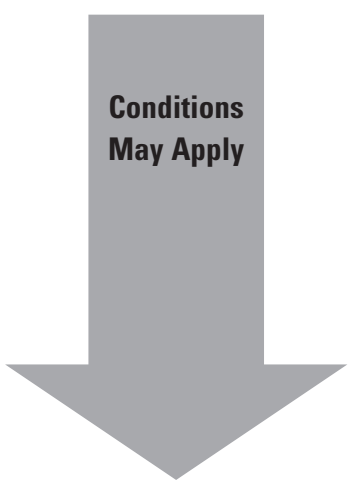

No

Reject

Proposed
Step \#3: Does the clinical performance of the test justify further evaluation?

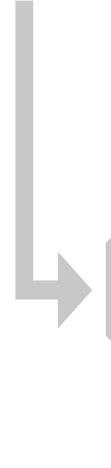

Proceed with

Step \#4: Considering the alternatives to the proposed service (section 2.3) and the expected outcomes of service use (section 2.4) does the information justify proceeding with the evaluation?

Yes

Grey Zone

No
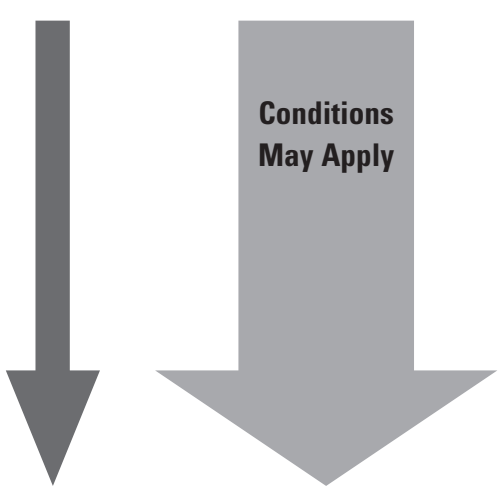

Reject

Proposed

Proceed with Evaluation 
Template Criteria to

be Evaluated

\section{Section 3.}

Additional Effects of Proposed Service

\section{Evaluation Steps}

Step \#5: Are the known and potential additional effects of the proposed service acceptable?

Yes

Grey Zone No
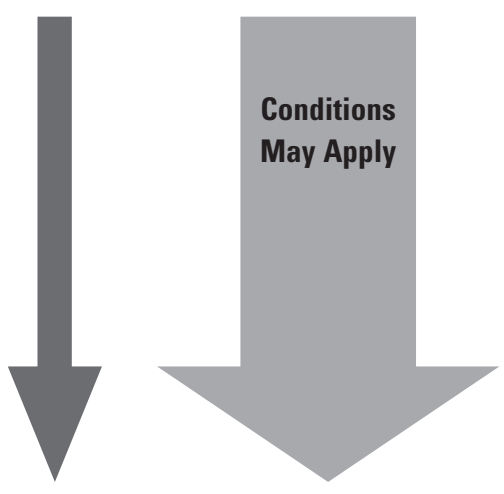

Reject

Proposed

Proceed with Evaluation

\section{Section 4}

Economic

Considerations for

Proposed Service

4.1 Costs of proposed service

4.2 Expected demand 4.3 Expansion potential
Step \#6: Are the known and potential costs of providing the proposed service acceptable?

Yes

Grey Zone

No
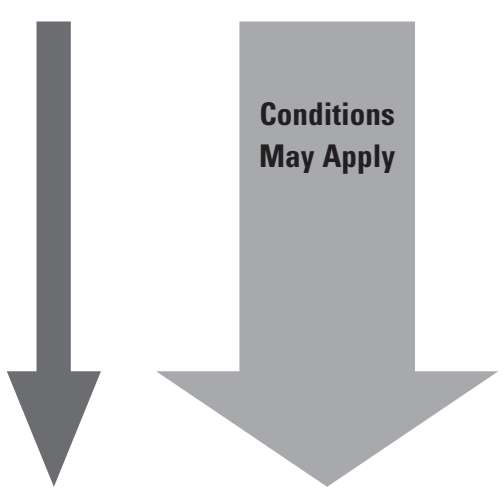

Reject

Proposed

Proceed with Evaluation 
Part 3. Evaluation Template

\section{Section 1. Intended Purpose of Proposed Service:}

\subsection{Introduction to Proposed Test/Service}

Description of the evaluation task

\subsection{Elements of Proposed Service}

\section{2a. Clinical condition.}

Specify the clinical condition for which the service is intended, including the prevalence or incidence of the condition (and variation across populations), its clinical manifestations and natural history, to the extent known. Describe the genetic basis of the clinical condition, including mode of inheritance, penetrance and expressivity (see glossary).

\section{2b. Test technology (ies).}

Provide a description of the proposed test. Describe the specific laboratory measurement(s) of the test, e.g. specific mutation, metabolite, enzyme activity. The description should be written in a language that would be understandable to non-laboratorians. 


\section{$1.2 c$ Target population.}

Specify the target population(s) for which the service is intended, e.g. members of high-risk families, ethnic populations, clinically-defined high risk groups, etc. Specify who will be eligible for testing, i.e. the criteria for test eligibility.

\subsection{Summary of Intended Purpose}

Summarize the intended purpose of the service.

The intended purpose of the service consists of a clear presentation of what it is supposed to do and why it would make an important contribution to health from the individual, familial or population perspective. If a test has multiple potential purposes, each should be described separately.

\section{Step \#1. Evaluation of Intended Purpose of Service;}

Considering the above information, does the intended purpose of this service justify continuing with the evaluation?

$\square$ No Recommend rejection of proposed service

Yes Continue with evaluation

$\square$ "Grey Zone" Continue with evaluation; identify relevant

(Uncertain) concerns and propose ways to resolve them: 
Section 2. Effectiveness of Proposed Service:

\subsection{Analytic Validity (Test Performance)}

\section{1a. Analytical validity}

Specify the analytical validity of the proposed test technology. Analytical validity is defined as the extent to which a test measures or detects the analyte it is intended to measure or detect. An analyte is defined as the substance measured by a laboratory test, e.g. DNA mutation, allele, chromosome, metabolites or enzyme activity. Analytical validity is expressed by sensitivity (the probability that a test will detect an analyte when it is present in the sample), specificity (the probability that a test will be negative when an analyte is absent from a sample) and accuracy (the proportion of correct test results) under defined conditions.

\section{$2.1 b$ Qualifying statements}

Outline potential concerns about the analytical validity of the proposed service, or the quality of the available evidence about analytical validity. Outline any concerns about the reliability of the test under normal (as distinct from experimental) conditions.

\section{Step \#2. Evaluation of Analytical Validity of Proposed Service;}

Considering the above information (from 2.1a and 2.1b), does the performance of the test in the laboratory justify further evaluation?

$\square$ No

Yes

$\square$ "Grey Zone" (Uncertain)
Recommend rejection of proposed service

Continue with evaluation

Continue with evaluation; identify relevant concerns and propose ways to resolve them: 


\subsection{Test Performance (Clinical validity)}

A predictive test makes claims about its performance in predicting the occurrence of a future clinical state for an individual; in some cases it makes claims about the expected severity of that state and or the time, or age, of expected onset. Information from predictive tests for inherited conditions may also inform predictions about future clinical states for family members of the tested person.

For predictive tests relating to the measurement of gene mutations or their products, the methods for assessing clinical validity will depend on the penetrance of the mutation. For fully penetrant mutations, the presence or absence of the mutation provides complete information about the probability of the future clinical condition, and the validity of the test can be assessed using the diagnostic test evaluation paradigm. Analytical test performance and clinical test performance are closely related, though lab practices may reduce the reliability of test results.

For partially penetrant mutations, the absence of the mutation (a negative test) may be informative in ruling out an increased risk of a particular condition. But, the presence of a mutation (a positive test) confers only a probability for the development of the clinical condition. This is usually expressed in terms of 'risk'. The absolute risk of developing the condition may be expressed as a simple probability, or percentage for an individual and this may be age-related (e.g., given the presence of mutation $\mathrm{X}$, the risk of developing condition $\mathrm{X}_{1}$ is $40 \%$ by the age of 40 years). The risk can also be expressed relative to the underlying risk in the population. For example, a mutation may confer a relative risk of 3.5, meaning that the risk of developing the condition is 3.5 times that of the underlying population from which the individual was selected or sampled.

The test's performance is assessed according to sensitivity, specificity, accuracy and predictive values and relies, to a greater or lesser degree, on the kind of clinical population studied. The clinical validity of the test performance relates to the adequacy of the data, the confidence with which claims about the test's predictive power can be made (including claims about predictive power for age at onset or severity, where made), and the validity of the results in both the test populations, and other (non-test) populations.

\section{$2.2 a$ Test performance (clinical)}

Specify the expected performance of the test under clinical conditions, and the information it is expected to provide about future clinical conditions in tested individuals. 
Describe the best available evidence from which validity can be assessed, and outline potential concerns about the claims for clinical validity of the proposed service.

\section{Step \#3. Evaluation of Clinical Validity of Proposed Service:}

Considering the above information (from 2.2a and 2.2b), does the clinical performance of the test justify further evaluation?

$\square$ No Recommend rejection of proposed service

Yes Continue with evaluation

$\square$ "Grey Zone" More Information Required

(Uncertain) If clinical validity is not completely established, specify ways in which additional data could be gathered that might help confirm the clinical validity, e.g. pilot testing in selected groups

A pilot or a full study may be justified to obtain the necessary information

$\square$ "Grey Zone" Orphan Disease

(Uncertain) In the case of orphan diseases where clinical validity is suggested but not completely established, specify how the proposed service should be used in clinical practice

Standardized protocols and circumstances for clinical practice could be developed by other sub-committees 


\subsection{Availability and Effectiveness of Alternatives to Proposed Service}

\section{3a. Alternatives to proposed testing service}

Discuss the availability and effectiveness of other a) laboratory methods or b) ways to estimate risk or genetic status for the same or similar predictive purposes.

\section{3b. Alternative sources of risk information}

What additional clinically useful information is being provided that makes the proposed service test more useful than the alternatives?

Is the proposed service intended to a) complement or b) replace one or more of these other methods? Please explain.

\subsection{Expected Outcomes of Service Use}

\section{4a. Medical interventions}

Discuss the extent to which knowledge of genetic risk status can alter the approach to the overall management of the clinical condition (i.e. what other factors, such as environment, lifestyle, or other medical conditions, may influence the development or prognosis of this condition, irrespective of test results).

Discuss the availability and effectiveness of clinical interventions to reduce the problems associated with the condition, e.g. clinical treatments, surveillance protocols.

Also, identify potential negative clinical outcomes for tested person arising from use of the service, e.g., the use of potentially dangerous treatment or surveillance options, the risk of false positive or negative results and the consequences of inconclusive test results. 


\section{$2.4 b$ Non-medical interventions}

Discuss the availability and significance of non-medical interventions to aid tested persons or family members, including the usefulness of the information to diagnosed persons for personal and family planning, uncertainty reduction, etc.

Also, identify potential negative outcomes for tested persons arising from use of the service, e.g. reduced insurability, increased fatalism, residual uncertainty from inconclusive results, etc.

\section{Step \#4. Evaluation of Alternatives to Proposed Service and Outcomes} of Proposed Service:

Considering the alternatives to the proposed service (section 2.3) and the expected outcomes of service use (section 2.4), does the information justify proceeding with the evaluation?

No

Recommend rejection of proposed service

Yes Continue with evaluation

$\square$ "Grey Zone" Continue with evaluation; identify relevant

(Uncertain) concerns and propose ways to resolve them: 


\section{Section 3. Additional Effects of Proposed Service}

\subsection{Additional Effects}

- Identify the additional effects of the proposed service, both known and potential. Additional effects are those effects that extend beyond expected or intended outcomes for the tested individual to individuals other than the person tested, including the family and the community.

Examples of additional effects include:

- discovery of non-paternity

- detracting from a family member's right not to know their diagnosis

- learning the risk status of a minor,

- gender effects

- potential for discrimination

\section{Step \#5. Evaluation of Additional Effects of Proposed Service}

Considering the above information (from section 3.1), are the known and potential additional effects of the proposed service acceptable?

No Recommend rejection of proposed service

Yes Continue with evaluation

$\square$ "Grey Zone" Limitations on Clinical Practice

(Uncertain) Specify limitations on clinical practice

Standardized protocols and circumstances for clinical practice could be developed by other sub-committees

More information required

Specify ways in which additional data could be gathered that might help in the evaluation of the additional effects of the proposed service

A pilot or a full study may be justified to obtain the necessary information 


\section{Section 4. Economic Considerations}

\subsection{Costs of Proposed Service}

Discuss the available data on the direct costs of the proposed service. These considerations may include:

- the laboratory testing algorithm

- the personnel providing all components of the service

- the equipment and overhead expenses

\subsection{Expected Demand for Proposed Service}

What is the anticipated demand for the proposed service in the target population? The expected demand reflects the quantity of services that would be provided if the service were covered.

Discuss the factors that are likely to affect the demand for the proposed service. Provide some indication of the confidence the committee has in these estimates.

Provide an estimate of the expected demand for the proposed service
High
Low
$\square$ Moderate
$\square$ Uncertain

\subsection{Expansion Potential for Proposed Service}

\section{3a Expansion potential}

What is the potential for expansion of the proposed service? Expansion potential is the likelihood that the genetic testing service, once covered, may become redefined in the course of clinical practice or product marketing to include broader populations, clinical contexts or indications. This will be determined not only by the prevalence of associate diseases, but also by popular beliefs about the relevance of information about risk status, and the availability of product marketing. 
Discuss the factors that are likely to affect the expansion potential of the proposed service. Provide some indication of the confidence the committee has in these estimates.

Provide an estimate of the expansion potential of the proposed service.

High

Low

Moderate

Uncertain

\section{Step \#6. Consideration of The Economic Impact of The Proposed Service:}

A formal economic evaluation is not required. Please refer to background document 7.3.

Considering the above information (from section 4), are the known and potential costs (immediate costs and demands) of providing the service affordable?

$\square$ No Recommend rejection of proposed service

Yes $\quad$ Proceed with evaluation

$\square$ "Grey Zone" Limitations

(Uncertain) Specify limitations on clinical practice or identify a time line for re-evaluation

Periodic re-evaluation processes, research protocols and clinical protocols could be developed 
Part 4. Evaluation Template: Summary

1. Intended Purpose of Service

- Intended Purpose of the Proposed Service (from Section 1):

- Recommendations (from 1.3, Step \#1)

\section{Effectiveness of Proposed Service}

- Recommendations (from Section 2, Steps \#2 through \#4)

\section{Additional Effects of Proposed Service}

- Recommendations (from Section 3, Step \#5)

\section{Economic Considerations}

- Recommendations (from section 4, Step \#6) 
Part 5: Application for Service Evaluation

\section{Applicant Information}

Contact Name:

Organization:

Address:

Phone:

Fax:

Date:

\section{Application Form}

\section{Clinical Condition.}

Specify the clinical condition for which the service is intended, including the prevalence or incidence of the condition (and variation across populations), its clinical manifestations and natural history, to the extent known. Describe the genetic basis of the clinical condition, including mode of inheritance, penetrance and expressivity (see glossary).

\section{Test Technology (ies).}

Provide a description of the proposed test. Describe the specific laboratory measurements(s) of the test, e.g. specific mutation, metabolite, enzyme activity. The description should be written in a language that would be understandable to nonlaboratorians.

\section{Target Population.}

Specify the target population(s) for which the service is intended, e.g. members of high-risk families, ethnic populations, clinically-defined high-risk groups, etc. Specify who will be eligible for testing, i.e., the criteria for test eligibility. 


\section{Expected Demand for Proposed Service}

What is the anticipated demand for the proposed service in the target population? The expected demand reflects the quantity of services that would be provided if the service were covered.

\section{Alternatives to Proposed Service}

Discuss the availability and effectiveness of other a) laboratory methods or b) ways to estimate risk or genetic status for the same or similar predictive purposes. What additional clinically useful information is being provided that makes the proposed service test more useful than the alternatives?

Is the proposed service intended to a) complement or b) replace one or more of these other methods?

\section{Effectiveness of Proposed Service:}

a) Analytic validity

Analytical validity is defined as the extent to which a test measures or detects the analyte it is intended to measure or detect. An analyte is defined as the substance measured by a laboratory test, e.g. DNA mutation, allele, chromosome, metabolites or enzyme activity. Analytical validity is expressed by sensitivity (the probability that a test will detect an analyte when it is present in the sample), specificity (the probability that a test will be negative when an analyte is absent from a sample) and accuracy (the proportion of correct test results) under defined conditions.

Specify the analytical validity of the proposed test technology. Outline potential concerns about the analytical validity of the proposed service, or the quality of the available evidence about analytical validity. Outline any concerns about the reliability of the test under normal (as distinct from experimental) conditions 
A predictive test makes claims about its performance in predicting the occurrence of a future clinical state for an individual; in some cases it makes claims about the expected severity of that state and or the time, or age, of expected onset. Information from predictive tests for inherited conditions may also inform predictions about future clinical states for family members of the tested person.

For predictive tests relating to the measurement of gene mutations or their products, the methods for assessing clinical validity will depend on the penetrance of the mutation. For fully penetrant mutations, the presence or absence of the mutation provides complete information about the probability of the future clinical condition, and the validity of the test can be assessed using the diagnostic test evaluation paradigm. Analytical test performance and clinical test performance are closely related, though lab practices may reduce the reliability of test results.

For partially penetrant mutations, the absence of the mutation (a negative test) may be informative in ruling out an increased risk of a particular condition. But, the presence of a mutation (a positive test) confers only a probability for the development of the clinical condition. This is usually expressed in terms of risk. The absolute risk of developing the condition may be expressed as a simple probability, or percentage for an individual and this may be age-related (e.g., given the presence of mutation $\mathrm{X}$, the risk of developing condition $X_{1}$ is $40 \%$ by the age of 40 years). The risk can also be expressed relative to the underlying risk in the population. For example, a mutation may confer a relative risk of 3.5, meaning that the risk of developing the condition is 3.5 times that of the underlying population from which the individual was selected or sampled.

The test's performance is assessed according to sensitivity, specificity, accuracy and predictive values and relies, to a greater or lesser degree, on the kind of clinical population studied. The clinical validity of the test performance relates to the adequacy of the data, the confidence with which claims about the test's predictive power can be made (including claims about predictive power for age at onset or severity, where made), and the validity of the results in both the test populations, and other (non-test) populations.

Specify the expected performance of the test under clinical conditions, and the information it is expected to provide about future clinical conditions in tested individuals. 


\section{Summary}

Summarize the intended purpose of the service.

The intended purpose of the service consists of a clear presentation of what it is supposed to do and why it would make an important contribution to health from the individual, familial or population perspective. If a test has multiple potential purposes, each should be described separately. 


\section{Part 6. Glossary of Terms}

\section{Glossary of Terms for the Evaluation Template}

\section{Additional effects}

Additional effects are those effects that extend beyond expected or intended outcomes for the tested individual, to individuals other than the tested individual. These effects include effects on family, and community, e.g. discovery of non-paternity, detracting from a family member's right not to know their diagnosis, learning the risk status of a minor, gender effects, potential for increased discrimination, etc.

\section{**Analytical validity}

Analytical validity is defined as the extent to which a test measures or detects the analyte it is intended to measure or detect. An analyte is defined as the substance measured by a laboratory test, e.g. DNA mutation, allele, chromosome, metabolites or enzyme activity. Analytical validity is expressed by sensitivity (the probability that a test will detect an analyte when it is present in the sample), specificity (the probability that a test will be negative when an analyte is absent from a sample) and accuracy (the proportion of correct test results) under defined conditions.

\section{${ }^{* *}$ Clinical validity}

Clinical validity is defined as the accuracy with which a laboratory measurement predicts the presence or absence of a clinical condition.

A predictive test makes claims about its performance in predicting the occurrence of a future clinical state for an individual; in some cases it makes claims about the expected severity of that state and or the time, or age, of expected onset. Information from predictive tests for inherited conditions may also inform predictions about future clinical states for family members of the tested person.

For predictive tests relating to the measurement of gene mutations or their products, the methods for assessing clinical validity will depend on the penetrance of the mutation. For fully penetrant mutations, the presence or absence of the mutation provides complete information about the probability of the future clinical condition, and the validity of the test can be assessed using the diagnostic test evaluation paradigm. In this case, the test's performance is assessed according to sensitivity, specificity, accuracy and predictive values. 
For partially penetrant mutations, the absence of the mutation (a negative test) may be informative in ruling out an increased risk of a particular condition. But, the presence of a mutation (a positive test) confers only a probability for the development of the clinical condition. This is usually expressed in terms of risk. The absolute risk of developing the condition may be expressed as a simple probability, or percentage for an individual and this may be age-related (e.g., given the presence of mutation $\mathrm{X}$, the risk of developing condition $\mathrm{X}_{1}$ is $40 \%$ by the age of 40 years).

The risk can also be expressed relative to the underlying risk in the population. For example, a mutation may confer a relative risk of 3.5, meaning that the risk of developing the condition is 3.5 times that of the underlying population from which the individual was selected or sampled.

\section{Service}

The unit of analysis for the evaluation framework is the genetic test service, which we define as the package of: test technology + target population + clinical condition. The intended purpose of the service consists of a clear argument regarding what it is supposed to do and why it would make an important contribution to the health of the population. The purpose must apply to the fully defined service. 